\title{
Unemployment and Income Distribution: Some Extensions of Shaikh's Analysis ${ }^{\dagger}$
}

\section{Walter Paternesi Meloni* and Antonella Stirati***}

\author{
Working Paper No. 137
}

September $21^{\text {st }}, 2020$

\begin{abstract}
After the 1980s, advanced capitalist economies witnessed a significant decline of the labor share in income. Along with the conventional view, which ascribed this decline to technological factors and international trade, another line of enquiry has endorsed a 'Political Economy' approach to identifying several drivers of the labor share erosion. Among the latter, the role of persistent labor market slack has remained relatively unexplored. We try to fill this gap moving from a recent contribution by Anwar Shaikh, who elaborated on the relation between unemployment and changes in income distribution and in the US economy. We study this relationship by adopting a long-term approach, using two alternative measures of labor market slack (namely, the unemployment rate and the unemployment intensity, an index that incorporates the duration of unemployment). We first extend Shaikh's method of analysis to eight mature countries, and subsequently we approach the relationship between changes in labor market slack and the (adjusted) wage share in the private sector of the economy from 1960 to 2017 with other econometric techniques. Our findings confirm the
\end{abstract}

\footnotetext{
$\dagger$ The present work is part of a broader research project entitled "Interpretations of the decoupling between real wages and productivity growth at the aggregate level and analysis of low-wage incidence by sector of activity and geographical areas." The project benefited from financial support by the Institute for New Economic Thinking (INET). For comments and suggestion, thanks are due to Fabrizio Antenucci, Matteo Deleidi, Riccardo Pariboni, Luigi Salvati and Davide Romaniello. We also thank Anwar Shaikh, Thomas Ferguson and two anonymous readers for valuable comments on a previous draft of the manuscript. The usual disclaimer applies.
}

* Post-doctoral Research Fellow, Department of Economics, Roma Tre University

** Full Professor, Department of Economics, Roma Tre University 
existence of a negative relationship between labor market slack and the wage share, and we find no tendency to return to a 'normal' unemployment rate associated with a stable wage share.

https://doi.org/10.36687/inetwp137

Keywords: wage share, income distribution, unemployment, labor market slack, unemployment duration, bargaining power.

JEL Classifications: E11, E25, J64. 


\section{Introduction and background}

As widely acknowledged and discussed, wage income shares in GDP have been falling in all advanced countries since the mid-1970s/early 1980s - an element of novelty with respect to the constancy postulated by one of the Kaldor's stylized facts, and a worrying phenomenon, among other things, for its connection with increasing income inequality and polarization of wealth as well as for the negative consequences on consumption and aggregate demand (Stockhammer, 2013; Cynamon and Fazzari, 2016; Hein and Prante, 2018; Pariboni et al., 2020). Many analyses and interpretations have been advanced, which can be very broadly and with a certain degree of simplification divided into two main groups.

The first comprises a variety of analyses that are embedded in neoclassical theory of distribution, and hence must consider the substitutability between production factors. This would suggest a relative stability over time of income shares, since any reduction in the return to a factor of production would cause a greater 'intensity' of its use, that is, in the case of labor, higher labor to capital and labor to GDP ratios (Bentolila and Saint-Paul, 2003). Hence, in order to explain the observed large changes in income shares, the various contributions that belong to this broad group tend to emphasize biased (i.e. unskilled-labor saving) ${ }^{1}$ technical progress (Hutchinson and Persyn, 2012; Hogrefe and Kappler, 2013; Bassanini and Manfredi, 2014; IMF, 2017) and/or the major increase in world-wide (unskilled) labor supply resulting from the expansion of international trade and the large 'newcomers' - such as China and India - that have been integrating into global markets (Acemoglu, 1998; 2003; Guscina, 2006). ${ }^{2}$ It should be emphasized that both channels (technical change and international trade) according to this approach would not affect unemployment, which would always tend to be at its equilibrium level, but would negatively affect the equilibrium wage, particularly for unskilled workers in mature industrial economies.

The other broad group of interpretations of the changes in income shares can be identified as not subscribing to traditional neoclassical substitutability between production factors, and hence embracing a 'conflict' and/or institutional theory of income distribution. Such a theoretical framework can more freely account for the changes in income distribution as caused by institutional and economic changes that have adversely affected labor bargaining positions, since in this framework, unlike in the neoclassical one, a fall in wages would not necessarily lead to a change in techniques or consumption patterns such as to bring about a greater intensity in the use of labor vis-

\footnotetext{
${ }^{1}$ Hicks (1964) defined 'labour saving technical progress' such that it would cause a fall of the equilibrium wage-profit ratio.

${ }^{2}$ There are also other related factors, which this body of literature has considered among the drivers of the decline in the labor share. Among them: industry concentration and the consequent rising market power (Barkai, 2019); the emergence of the innovative 'superstar firms' (Autor et al., 2017; OECD, 2018); the transition toward a more capital-intensive economy focused on intellectual property (Koh et al., 2016); the falling relative price of investment goods and technological progress (Karabarbounis and Neiman, 2013; IMF, 2017); the process of automation (Acemoglu and Restrepo, 2018; Martinez, 2018).
} 
$\grave{a}$-vis other 'production factors.' In other words, according to these explanations, there are no offsetting effects on income shares deriving from elasticity of substitution, while the functional distribution is quite responsive to the evolution of the bargaining position of labor. The latter, in turn, may be affected by a number of social, economic and institutional factors: rather than reflecting technological factors, the functional distribution of income can be seen as 'the most immediate indicator of the balance of forces between labour and capital' (Franzini and Pianta, 2015, p. 71).

The analysis in the present paper is meant to be a contribution to the second broad group of interpretations. These have generally adopted, both analytically and in empirical investigations, a political economy approach, focusing on the role of labor market (de)regulation and institutional changes along a variety of dimensions, such as: i) the process of structural change intended as a shift toward the low-pay and low-productivity segment of the service sector (Stockhammer, 2017; Storm, 2017; Beqiraj et al., 2019; Pariboni and Tridico, 2019a); ii) the retrenchment of welfare states and trade unions (Kristal, 2010; Bengtsson, 2014; Stockhammer, 2017; Tridico and Paternesi Meloni, 2018; Hein et al., 2020); iii) increasing labor market flexibility and the weakening of workerprotective labor laws (Brancaccio et al., 2018; Deakin et al., 2014); iv) the increasing process of globalization, which fostered trade openness (Rodrik, 1997; Onaran, 2011; Stockhammer, 2017) and financial flows related to offshoring practices (Elsby et al., 2013) and/or to portfolio investments (Jayadev, 2007); and v) the effects of increasing financialization, a phenomenon that can be observed from different perspectives (Stockhammer, 2009; Hein, 2015; Dünhaupt, 2017; Özdemir, 2019; Pariboni and Tridico, 2019b; Pariboni et al., 2020), including the influence of the returns on financial assets on the profit rate (Pivetti, 1991; Hein, 2014). Although those factors may have been important, it is somewhat surprising that the role of persistent unemployment and more generally of labor market slack has remained relatively unexplored in this body of literature. ${ }^{3}$ Yet in the analyses of the classical economists and Marx, which can be regarded as the historical and analytical roots of the conflict theory of income distribution, labor market conditions were regarded as very relevant factors in affecting wages, along with, of course, other institutional, historical and political elements.

By focusing on labor market slack uniquely, our enquiry could also contribute to clarifying whether unemployment could be one channel through which some of the factors highlighted by the literature act upon income distribution. For example, according to the literature on financialization and corporate governance, one of the reasons why the latter would have adversely affected the wage share is the reduced incentive to enhance long-term growth through real investment (van Treeck,

\footnotetext{
${ }^{3}$ Only Kristal (2010) and Storm and Naastepad (2012, chapter 6) straightforwardly include the unemployment rate among the determinants of declining wage share or real wage growth. Other contributions, such as Dünhaupt (2017), Stockhammer (2017) and Pariboni and Tridico (2019b), consider the possible effect of the unemployment on income distribution only after having investigated on other predominant factors (technological factors, financialization, globalization, structural change and so forth). Moreover, most of them focus on the short run, while in this work we aim at identifying long-run relationships.
} 
2009; Tori and Onaran, 2017), with firms more oriented to short-term strategies and 'downsize and distribute' behavior (Lazonick and O'Sullivan, 2000; OECD, 2012; Lazonick, 2014; van Treeck, 2015; Blecker, 2016; Palley, 2016; Hein, 2017). On the aggregate level, this may involve higher job insecurity, an increase in bad jobs compared to relatively good ones, as well as higher unemployment, which thus would be one of the channels through which those changes might have affected distribution. Similarly, international capital mobility may not only have a threat effect of potential off-shoring (Onaran, 2011; Stockhammer, 2017), but it may also have involved actual deindustrialization and thus higher unemployment. Finally, a variety of contributions have regarded interest rates as directly affecting the normal profit rate or the mark-up charged by firms (Pivetti, 1991; and for a different formulation Hein, 2014; 2015), and hence income distribution. ${ }^{4}$ But it is an open question whether this can be regarded as a mechanical transmission, that is, one that would always take place, or one that also depends on 'wage resistance' and workers' bargaining strength, which influence nominal and real wage dynamics (Stirati, 2001; Paternesi Meloni and Stirati, 2018). In this respect, if labor market conditions are found to have a significant role, the implication would be in favor of the latter rather than the former view.

Against this background, the main focus of this paper is to explore the role of labor market slack in affecting the adjusted wage share in the private sector of the economy. While the pro-cyclical behavior of real wages has been well documented in empirical analyses (Stirati, 2016), our purpose is to enquire whether persistent changes in unemployment are found to have lasting consequences on income distribution. To do so, we take as a source of inspiration the recent work by Shaikh (2016, chapter 14), who finds that an index of unemployment intensity constructed combining the unemployment rate with a measure of unemployment duration performs well in explaining the changes in the wage share in the United States over the post-war period. In our paper, we extend Shaikh's analysis in two main directions. On the one hand, we apply a similar empirical investigation to other large mature economies besides the US, namely, Canada, France, Germany, Italy, Japan, Spain, Sweden and the United Kingdom. On the other hand, we extend the box of tools by using different econometric techniques capable of detecting the long-term relation between changes in the unemployment rate - or an index of 'unemployment intensity' - and income distribution to the same set of countries. At the same time, however, we assess Shaikh's claim that there is a 'normal' unemployment rate (or unemployment intensity index) acting as a long-term attractor for the economic system.

\footnotetext{
${ }^{4}$ Note that in a multisector economy, the increase in the mark-up in an industry would affect all input-output relative prices and costs, as well as the cost of a given wage basket, with consequences for the profit rate and income distribution that cannot be established a priori (see Steedman, 1992; Shaikh, 2016, pp. 2218-21).
} 
The rest of the paper goes as follows. In Section 2, we present some alternative simple formalizations of the relationship between unemployment and income distribution. In Section 3, we discuss Shaikh's notion of 'classical' normal unemployment. In Section 4, we provide some descriptive analyses investigating the stationarity of the unemployment rate and the unemployment intensity index; in addition, we replicate for a number of countries the empirical analysis carried out by Shaikh for the United States concerning the relationships between the rate of change of the wage share in the private sector of the economy and two metrics of labor market slack, namely, the unemployment rate and the index of unemployment intensity. Section 5 is then devoted to econometric analyses, with a view to assessing the long-run relationship between income distribution and labor market slack with three different methods. Section 6 summarizes and concludes.

\section{The 'classical wage curve'}

Recently, Anwar Shaikh (2016) has devoted a rather detailed analysis and empirical work to what he calls the 'classical wage curve.' It is quite natural, then, to take this as a starting point for constructive extensions and critical reflections. One very interesting contribution is his finding, for the United States, of an inverse relationship between changes in the wage share and an unemployment index reflecting unemployment level and duration (more details in Section 4). This result is very close to the findings of Paternesi Meloni and Stirati (2018), where a similar long-term negative relationship between real wage growth - once controlling for the pace of labor productivity - and the unemployment rate emerges for a panel of OECD mature countries. However, unlike the work of Shaikh, the work by Paternesi Meloni and Stirati (2018) rejects the notion of an 'equilibrium' unemployment rate (or any other index of labor market slack) as an attractor for the economic system. While we shall elaborate on these theoretical aspects and provide an empirical analysis in greater detail below (see Sections 3 and 4, respectively), we now discuss the general picture.

Following the classical tradition, given the limit set by output per worker and the necessarily positive rate of profit in an economy featuring private ownership of the means of production, the real wage will be comprised between a maximum level, corresponding to a minimum rate of profit, and a minimum level, corresponding to some historically determined consumption floor, that is, the 'subsistence wage' of the classical tradition (Stirati, 1992). Between these two limits, there lay a set of abstractly feasible income distributions: which will prevail will depend on the relative bargaining strength of the parties. In turn, such bargaining strength may be affected by several circumstances, among which two broad sets used to be regarded by the classical economists as the most important: on the one hand, the institutional setting, particularly concerning labor market and wage regulations and the degree of organization of workers and employers, as well as their political representation; on 
the other, labor market conditions (that is, labor market slack or tightness). In contemporary economic literature, labor market conditions and their impact on wage dynamics are usually described using the unemployment rate. There are reasons, however, to regard unemployment as a useful but incomplete indicator of labor market conditions: in this section, for simplicity, we refer to 'unemployment' as a description of labor market conditions, but it should be understood that it could be substituted by other variables or sets of variables describing them (for instance, as in our empirical analysis, an index of unemployment intensity). ${ }^{5}$ Thus, following Shaikh, we can write the following equation (1):

$\frac{W}{Q}=B$

where $W$ is the real wage rate, and $Q$ is output per worker (in real terms). Overlooking now the various problems arising from its measurement (they will be discussed in Section 4 ), $B$ represents the wage share. In turn, given other institutional circumstances, changes in $B$ are regarded as a function of the 'unemployment gap,' as in equation (2):

$\frac{\Delta B}{B}=f\left(U^{*}-U_{t}\right)$

where $\frac{\Delta B}{B}$ is the percent change of the wage share, $U^{*}$ is the rate of unemployment at which such change is zero, and $U_{t}$ is the current actual unemployment rate. In turn, equations (1) and (2) imply, as in equation (3), that:

$\dot{W}=f\left(U^{*}-U_{t}\right)+\dot{Q}$

where $\dot{W}$ and $\dot{Q}$ are, respectively, the rate of growth of real (product) wages and productivity. Hence, if $U^{*}$ prevails (that is, if $U_{t}=U^{*}$ ), real wages will grow at the same rate as productivity, and no change will take place in income shares.

The above formulation entails a continuously falling wage share until $U^{*}$ is attained. However, if $U^{*}$ is simply the particular unemployment rate at which there are no changes in the income shares, but is not an attractor for the economy, and $U_{t}$ can actually remain lower or higher than $U^{*}$ for very long time spans, then the implication of a continuous increase or fall in the wage share may appear rather strong, albeit perhaps not too far from what has been observed in advanced economies in recent

\footnotetext{
${ }^{5}$ For instance, the variability of the unemployment rate can be limited since a persistent lack of employment opportunities may induce adjustments on the supply side, while sustained labor demand can stimulate participation and reduce underemployment. Enlarged indicators, like the index of unemployment intensity proposed by Shaikh or other multidimensional measures, can be used to represent the labor market slack.
} 
decades. On the other hand, several empirical contributions to the analysis of income shares take the wage share level as the dependent variable. Considering the wage share level as the dependent variable and the unemployment rate as one of its determinants involves, other things given, what is reported in equation (4):

$B \equiv \frac{W}{Q}=f(U)$

This implies that a persistent change in the unemployment rate (say, from 3\% to 5\%) would entail a once for all change in the wage share - that is, the wage share would fall over some time span but would eventually stabilize at a new lower level. This could also be expressed, as in equation (5), by:

$W=B(U) * Q$

where $W$ is the real wage rate, $Q$ is real output per worker, and $B$ indicates the relationship between real wage and productivity levels, in turn a function of the unemployment rate. In this perspective, a constant level of the unemployment rate would entail a given value of $B$, hence (other things constant) no changes in the wage share, and real wages growing at the same rate as productivity (that is, $\dot{W}=$ $\dot{Q})$. Such a one-to-one connection between real wages and productivity might also appear rather too strong, at least outside a neoclassical theoretical framework. Although some close relationship between the two has empirical support, recent works have found that its coefficient is lower than one, suggesting a decoupling between the growth rates of productivity and wages. (Stansbury and Summers, 2018; Paternesi Meloni and Stirati, 2018).

Finally, one might treat more loosely real wage dynamics as a function of both unemployment and productivity growth (other things given), without a priori assumptions about the value of the parameters, as in equation (6):

$\dot{W}=\alpha \dot{Q}+\beta U$

This would imply that real wage dynamics depends on both productivity growth and unemployment, and that in general the coefficient on productivity may be different from one. However, in this way, the coefficient on productivity growth is treated as independent from the unemployment rate, which in turn is unlikely.

Thus, there seem to be, at least in principle, no fully satisfactory ways of providing simple formal representations of the connection between unemployment rate (or, more general, labor market 
slack) and income distribution. Nevertheless, empirical analyses can be of some help in clarifying the features of the relationship. In Sections 4 and 5, we explore the empirical relation between the wage share and the unemployment rate (or another index of labor market slack) in the medium to long run - that is, averaging across the cycle. This is a necessary qualification for two reasons. The first is that we are interested in exploring the underlying persistent factors affecting 'normal' income distribution and not its short run fluctuations. In addition to this, we want to clear our analysis from short-run disturbing factors. In particular, it is well known that productivity varies in a pro-cyclical manner, owing to labor hoarding and short-term changes in the intensity of its use (Okun, 1962; Basu, 1996); accordingly, this causes changes of the wage share in the opposite direction in the early phases of expansions and contractions, in a way that obviously has no connection with lasting changes in income distribution.

As previously mentioned, our research relates with Shaikh's empirical exploration of the relationship between labor market conditions and changes in the wage share. Thus, before turning to the empirical part of the paper, we briefly discuss in the next section Shaikh's argument on the existence of normal rate of unemployment or unemployment intensity acting as a long-term attractor (Shaikh, 2016, chapter 14).

\section{The classical 'equilibrium' unemployment: an acceptable notion?}

Shaikh's analysis is constructed around the idea that there is a (turbulent) long-run tendency of the economy to return to the normal unemployment rate - more precisely, an index of unemployment intensity - associated with a stable wage share (see equation 1, above). Such normal unemployment hence functions as an attractor through the relationship between the reserve army of labor (proxied by the unemployment intensity), the normal profit of enterprise and private business investment. The inspiration is classical and Marxian, and the 'equilibrium' normal unemployment rate is very different from a monetarist or a New-Keynesian equilibrium unemployment, since it is involuntary and is not determined by imperfections or obstacles to competition. ${ }^{6}$ This normal unemployment is that required to keep the wage share and the corresponding normal profit rate at the levels that ensure that the actual growth of the economy matches (on average) the 'Harrodian' natural rate (the sum of labor force growth and productivity growth). In turn, the latter condition is required to keep unemployment constant. The normal unemployment rate can change over time owing to institutional changes, which cause shifts of the 'classical wage curve,' that is, the Phillips-like relation between unemployment and changes in the wage share. In particular, it shifts downwards as a consequence of reduced labor

\footnotetext{
${ }^{6}$ See, on this, Shaikh (2016, chapter 12, section 3).
} 
protection, since a reduced labor strength requires lower 'disciplining' unemployment in order to preserve profitability. ${ }^{7}$

Analytically, at the core of the above view that there is a 'normal' unemployment (intensity), which represents an attractor for the system, is the notion that aggregate private investment is driven by the expected profits of enterprise, defined as the difference between the normal profit rate and the normal interest rate. Hence, the accumulation process is regarded as fundamentally profit-driven, though aggregate 'autonomous' demand can also play a role.

Without entering here into the many facets and complexities of the proposed analysis of accumulation, a fair, albeit simplified, account is that with respect of accumulation, the fundamental features of the closed, no finance, no government sector economy are Ricardian, in the sense that all income is spent directly (by households) or is saved by firms, as retained profits, only in order to finance investment. Hence, aggregate demand adjusts to aggregate supply (Say's law holds), and the profit-driven accumulation can be sustained. When richer and more realistic features are introduced - such as exports, government spending and bank credit - this opens the ground for the role of aggregate demand, and changes in the level of one of those have persistent level effects on output, capital (via induced investment), employment, productivity, and labor supply. Persistent changes in the pace of growth of those autonomous demand components can also have persistent effects on the actual rate of growth of the economy, and this in turn may drive changes in the natural growth rate as well, through its positive effects on productivity and labor force. However, attempts to persistently 'pump' economic growth by means of injections of autonomous demand require, according to Shaikh, increasing doses of the latter in order to counterbalance the negative impact on accumulation caused by decreasing unemployment and the consequent increase in the wage share. Eventually, accumulation will have to slow down to restore the reserve army (normal unemployment) and profitability.

This overall picture deserves to be examined in depth and is likely to be controversial within a broadly defined post-Keynesian approach, where in recent years the view of demand-led growth has prevailed, albeit in diverse analytical frameworks (for a survey, see Cesaratto, 2015; Lavoie, 2016). The representation appears also somewhat in contrast with increasing empirical evidence that output growth is consistently a major determinant of business investments, while mixed results and relatively

\footnotetext{
${ }^{7}$ The existence of some 'equilibrium' or 'normal' unemployment rate representing an attractor for the economic system is traceable not only in mainstream models, but also in models of Marxist, neo-Kaleckian or post-Keynesian orientation (Stockhammer, 2008), where generally this particular unemployment rate is that one consistent with stable (conflict) inflation. In these contexts too, the normal unemployment rate can change over time owing to institutional changes, and in particular become lower as a consequence of reduced labor protection, since a reduced labor strength requires lower unemployment in order to preserve price stability.
} 
small impacts, if any, are reported concerning profitability and the cost variables. ${ }^{8}$ Addressing the general question of accumulation is outside the scope of the present paper, which will be focused on the relationship between labor market slack and the wage share. However, exploring the evidence concerning this relationship will also provide some insights regarding the long-term tendencies of unemployment rate and unemployment intensity index.

\section{Unemployment and income distribution: some descriptive evidence}

We take as a starting point for our empirical exploration Shaikh's analysis, in which the author shows the influence of labor market slack - measured by an index of unemployment intensity - on the rate of change of the wage share in the United States. The author constructs an index of unemployment intensity for the United States, which we have reproduced (with a minor modification concerning the duration of unemployment) in order to verify whether the relationship also holds in other countries. The unemployment intensity is constructed by multiplying the unemployment rate for an index representing the average duration of unemployment, with the idea that unemployment becomes more intense (i.e. it has a higher impact on changes in the wage share) when its duration increases. Thus, we have computed the unemployment intensity, as in the work of Shaikh (2016, p. 662), by multiplying the unemployment rate (UN_rate) for an index of unemployment duration (indur) obtained by dividing the actual duration of unemployment (expressed in months) for the countryspecific minimum duration, as in equation (7):

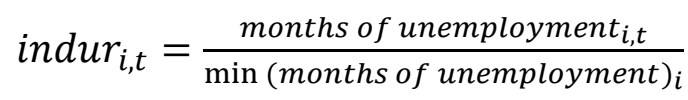

In this way, the index of unemployment duration indicates how many times the duration of unemployment is longer than the minimum duration in each country. ${ }^{9}$ Such minimum duration

\footnotetext{
${ }^{8}$ An increasing body of empirical literature on the determinants of aggregate investment finds large accelerator effects together with a low sensitivity of business investment to profitability and interest rate changes. Khotari et al. (2014), Schoder (2014), Girardi and Pariboni (2020) and Girardi et al. (2020) assessed the positive role of aggregate demand, and particularly its autonomous components, in shaping the process of capital formation. Moreover, several works belonging to the wage/profitled literature that estimates an investment function found poor or not significant profitability effects and larger GDP effects (Naastepad and Storm, 2006; Hein and Vogel, 2008; Obst et al., 2017). Finally, the insensitivity of investment to interest rates has been documented by Sharp and Suarez (2014), while Deleidi (2018) finds no significant relationship between loans granted to enterprises and the corresponding interest rates.

${ }^{9}$ We refer to the average duration of unemployment of unemployed persons from 0 to 18 months. See Appendix A for descriptive statistics and Appendix B for further detail on data and sources. We differ from Shaikh in normalizing for a single yearly minimum value (for each country), while Shaikh normalizes the index with respect to 'some base year chosen to represent the normal duration' (p. 662). In building our index, we opted for normalizing with the minimum duration in each country. This is partly to keep as close as possible to Shaikh's procedure, since he chooses his 'base years' featuring very low unemployment rate and duration. Although minimum is not 'normal', it is nevertheless 'feasible'. The alternative of normalizing for each country with its average unemployment duration would have decreased the absolute variance of the index within and between countries, but at the cost of losing information about the possible role of persistently high duration of unemployment (and hence high average duration) in some countries.
} 
generally occurs in a different year $(t)$ in each country $(i) .{ }^{10}$ Therefore, our index of unemployment intensity is computed as in the following equation (8):

$U N_{-}$int $_{i, t}=U N_{-}$rate $_{i, t} *$ indur $_{i, t}$

\subsection{Are unemployment and wage shares stationary?}

As a step toward empirically assessing the notion of a 'normal' unemployment rate, we verify if series of unemployment rate and unemployment intensity are stationary. If stationarity was not confirmed, this would cast some doubts on the above notion, although other possibilities would remain open, such as institutional changes leading to changes in the 'normal' unemployment rate or convergence taking place more slowly than can be captured by our data.

We check the stationarity of the private sector adjusted wage share (PAWS), the unemployment rate (UN_rate) and the unemployment intensity $\left(U N_{-}\right.$int $)$for the United States and for other eight selected mature countries, namely Canada, France, Germany, Italy, Japan, Spain, Sweden and the United Kingdom. ${ }^{11}$ Before turning to the statistics, some remarks on the calculation of the PAWS are needed. Following Stockhammer (2013), we correct the adjusted wage share (AWS) by subtracting the wage share in the government sector. ${ }^{12}$ The latter is equal to the share in GDP of government consumption $(C G)$, as value added in the public sector coincides with labor incomes. Since the wage share for the total economy $(A W S)$ is the sum of the adjusted wage share in the private sector and the wage share in the public sector $(G W S)$, weighted by their respective sizes, we have the following equation (9):

$$
A W S=(1-C G) * P A W S+C G * G W S
$$

As the wage share in the government sector is equal to one - that is, GWS $=1$ in equation (9) - the private sector adjusted wage share is computed as in equation (10):

$$
P A W S=\frac{A W S-C G}{1-C G}
$$

\footnotetext{
${ }^{10}$ Specifically, the minimum duration of unemployment is detected in the following years: Canada, 1976; France, 1975; Germany, 1991; Italy, 2008; Japan, 1981; Spain, 2008; Sweden, 1971; United Kingdom, 2004; United States, 1969.

${ }^{11}$ The selection of countries is dictated by data availability concerning the duration of unemployment for a sufficiently long time-span. We refer to West Germany before 1991. See Appendix A for details.

${ }^{12}$ Adjusted wage share means adjusted for self-employment: the procedure imputes wage payments for the self-employed to avoid counting all their income as profit income (see Krueger, 1999; Gollin, 2002). This adjustment is common in the literature (see ILO, 2019), and we directly use adjusted data (see Appendix A).
} 
We exclude the public sector, where, by definition, there are no profits, in order to avoid distortions related to changes in its weight. ${ }^{13}$

Series concerning the unemployment rate, the unemployment intensity and the private sector adjusted wage share are depicted for the case of the United States in Figure 1, and in Figure 2 for the remaining countries. Both figures can be read as follows. The upper-left quadrant plots the abovementioned series: it should be noted that the series of $U N_{-}$int are shorter than those of $U N_{-} r a t e$ due to poorer availability of data on unemployment duration. Second, in the upper-right quadrant, we represent the relationship between the rate of change of the trend component of the PAWS (on the vertical axis) and the trend component of the $U N_{-}$int (on the horizontal axis); for the same period of analysis, which is different depending on the country, the lower-right quadrant depicts the relationship between the rate of change of the trend component of the PAWS and the trend component of the $U N \_r a t e$. And finally, the same analysis presented in the lower-right quadrant is reproduced in the lower-left quadrant with respect to the whole period under scrutiny (1960-2017). ${ }^{14}$ Importantly, we follow Shaikh's methodology and apply the Hodrick-Prescott (HP) filter to the series in order to preserve only the long-term trend: in this way, we refer to the trend component of each variable in order to avoid depicting cyclical dynamics, as 'the point is to distinguish between structure and fluctuations' (Shaikh, 2016, p. 666). ${ }^{15}$

\footnotetext{
${ }^{13}$ For the sake of comparability, it is worth noting that this adjustment represents a difference with respect to the original w ork by Shaikh (2016, chapter 14), which focuses on the wage share as a whole.

${ }^{14}$ Note that some discrepancies between values reported in the two lower quadrants may depend on the filtering procedure, which will be discussed right away.

${ }^{15}$ Recently, the HP filter (Hodrick and Prescott, 1997) has been criticized by Hamilton (2018), as this technique would identify spurious cycles and suffer from an end-of-sample bias. Particularly, the latter would pollute the computation of the trend component of the series in its last point in time, which would engender troubles for current policymaking (Mohr, 2006). Nevertheless, since we are interested in depicting long-term trends over a large time-span, and not in analyzing the relation between the trend and the cyclical component, these issues do not represent an inescapable pitfall for the sake of our purposes. Therefore, we replicate the Shaikh's exploration with the smoothing parameter standardly used for yearly data $(\lambda$ equal to 100$)$. While the filtering procedure for both the unemployment rate and the unemployment intensity is quite intuitive, concerning income distribution, the HP filter has been applied to the private sector adjusted wage share, and then we calculate the growth rate on filtered values.
} 


\section{Figure 1. Private sector adjusted wage share, unemployment rate and unemployment intensity in the United States}

\section{UNITES STATES}
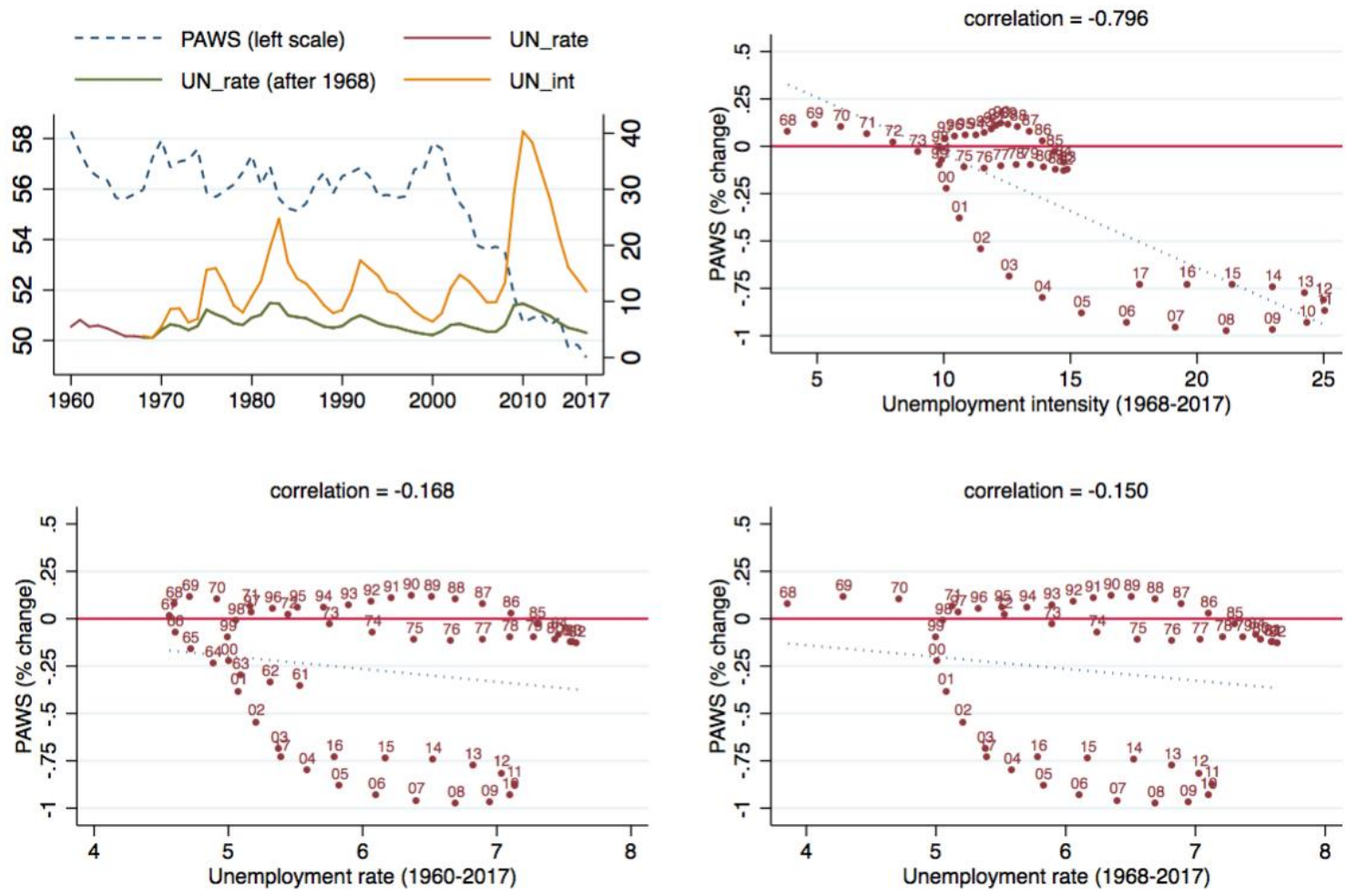

Caption: PAWS is the adjusted wage share in the private sector of the economy; UN_rate is the unemployment rate; UN_int is the index of unemployment intensity. Subfigures in the upper-right, the lower-right and the lower-left quadrants are based on trend values calculated by means of the HP filter $(\lambda=100)$.

At visual inspection, the general downward trend in labor share, as well as the upward trend experienced by unemployment intensity in recent decades, confirm our reservations concerning the stationarity of series, while the stationarity of the US unemployment rate seems to represent an exception (below, we will see an upward trend for other countries). We then found it appropriate to continue with empirical investigation on unemployment and labor share trends by applying econometric tests to verify both stationarity and trend-stationarity. Specifically, we performed an Augmented Dickey-Fuller test (ADF), the results of which are summarized in Appendix C.

We first make use of the standard stationarity test, which implies only a constant term, and then we control if series are trend-stationary by also considering a deterministic trend. Our empirics refer to the longer timespan available (i.e. from the 1960s) for the PAWS and the UN_rate, while starting later when referred to $U N_{-}$int (the data on the duration of unemployment are available only from the 1980s for the majority of countries). While a tendency to decline is well recognized and clearly emerges at visual inspection for what concerns the wage share - and therefore it is quite unsurprising to prove its non-stationarity - this preliminary test leads us to consider also both measures of labor 
market slack as non-stationary variables in all countries except the United States at the 95\% level (Table C1). ${ }^{16}$ Putting it differently, this test confirms that neither the unemployment rate nor the unemployment intensity presents a constant average overtime. ${ }^{17}$ Furthermore, we wish to answer an additional question: namely, whether the range of variation of each variable is constant over time around a linear trend that approximates its evolution. For this reason, we test trend-stationarity: the answer is a clear 'no,' with both the unemployment measures presenting significant variations around their time-trend, while - concerning the private sector adjusted wage share - trend-stationarity is confirmed at the $95 \%$ level only for Canada and Spain (Table C2). ${ }^{18}$ Thus, the evidence casts doubts on the existence of a sort of 'equilibrium' unemployment rate or unemployment intensity to which the economy would tend to return and settle, as in models assuming a 'vertical Phillips curve' in the long run, and also as suggested, on completely different analytical grounds, by Shaikh. Effectively, the US represents an exception as far as the unemployment rate is concerned, since the confidence level of $5 \%$ is respected for the stationarity of the unemployment rate. The index of unemployment intensity is not stationary in the United States with a 95\% confidence interval if the entire 1968-2017 period is considered, but it is if the period is cut before the 2008 crisis. However, Shaikh (2014), who looks at a longer time span, between 1948 and 2011, finds that in the in the United States, unemployment intensity 'rises to ten times its original value' (p. 663). ${ }^{19}$

\subsection{The Phillips-type dynamic of the wage share: a graphical representation}

We begin with the United States as a starting point to investigate the relationship between labor market slack and income distribution. Although we refer to a different time span, the private sector adjusted wage share (instead of the total economy) and a slightly different normalization for the unemployment intensity index, our results are essentially in line with Shaikh's concerning the Phillips-type relation between unemployment intensity and the rate of change of the wage share. As shown in Figure 1 (upper-right quadrant), in the case of the US, the unemployment intensity index correlates strongly with the changes in the private sector adjusted wage share, with what appears to

\footnotetext{
${ }^{16}$ The results are confirmed when confining the analysis to the 1960-2007 period. Therefore, non-stationarity cannot be attributable uniquely to the global financial crisis of 2008-09 and the subsequent period of economic stagnation.

${ }^{17} \mathrm{We}$ have further verified the robustness of our results to additional tests with almost equal findings for all series. An interesting difference holds for the United States, whose unemployment rate is stationary at the $10 \%$ confidence level with the Philipps Perron test (by considering 3 lags, as indicated Newey-West procedure), while the ADF test respects the 5\% level (by considering 2 lags, minimizing the Akaike criterion).

${ }^{18}$ Importantly, this element will lead us to make use of differentiated variables in our econometrics (Section 5): rejecting also trend-stationarity implies that series taken in levels are likely to contain a unit root, and then a simple detrending procedure, as suggested by Shaikh, will be not sufficient to avoid unbiased estimates. As can be seen in Appendix C (Table C3), all variabl es are I(1) at the $95 \%$ confidence level (some exceptions concern the unemployment intensity, which, however, is I(1) for all countries at the $90 \%$ confidence level).

${ }^{19}$ This statement is consistent with the values of the unemployment intensity reported in figure 14.11 of his book, which stand at about 3.5 in 1948 (the first available year) and at about 35 in 2011 (the latest).
} 
be a downward shift in the relationship since the 2000s and two loops that are consistent with the reasonable consideration that - given the unemployment intensity - the direction of change also matters, so the dynamic of the wage share is moderately higher (or less negative) when the intensity of unemployment is decreasing. The unemployment rate appears to correlate much less, particularly between the 1970s and 1990s (Figure 1, lower-right quadrant).

Extension of the empirical descriptive analysis to other mature economies shows that there is some diversity of patterns across countries. We replicate the empirical exercise presented for the United States on unemployment rate and intensity for the remaining eight countries under scrutiny. Findings are reported in Figure 2.

Before we discuss such patterns, however, it must be emphasized that there is a common, quite striking feature: for by far the greatest number of the years considered, the changes in the PAWS are below the zero line, so what we see most of the time is a varying intensity in the pace of decline in the wage share, and only very seldom an increase. This, of course, must be a source of some caution in the interpretation of the correlation with measures of unemployment. It is likely that in periods characterized by long-standing high unemployment and declining wage share, the changes of the latter may end up being dominated by relatively 'exogenous' changes in the rate of growth of productivity or prices. This is the case because there are limitations to the degree to which nominal wages can fall, owing to the fact that a large section of the workforce even nowadays is contractualized and that there are social norms about decent wages in nominal and real terms. Real wages, too, can only fall very gradually, owing to contractual provisions about price indexation, social norms as well as established minimum living standards (Yellen, 2017) - in classical terms, the existence of a 'subsistence' floor. Thus, when the rate of growth of nominal or real wages is close to zero for large sections of the labor force, a weakening of labor market conditions can hardly cause a decline in wages. 
Figure 2. Private sector adjusted wage share, unemployment rate and unemployment intensity in other major countries

CANADA
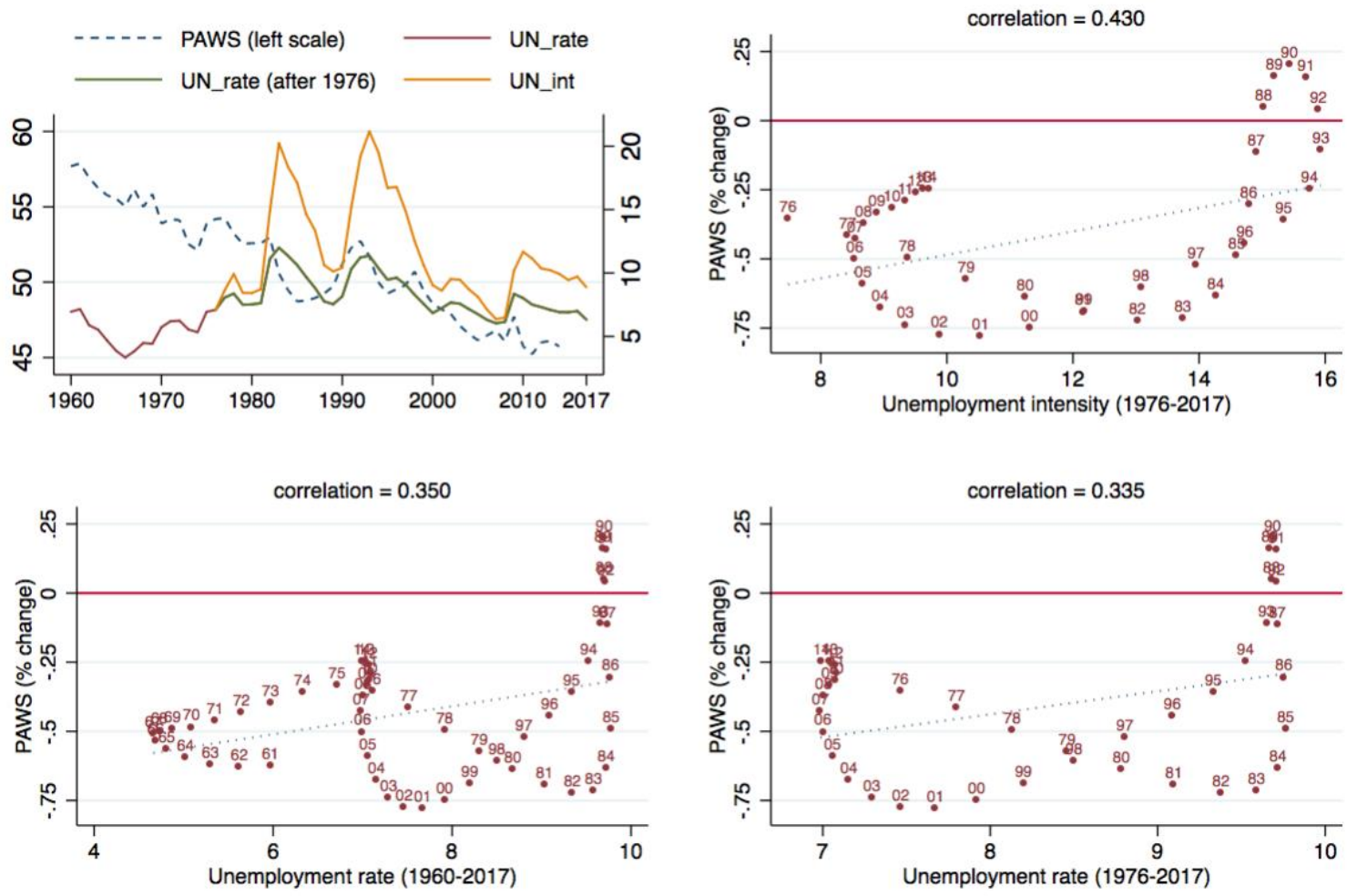

\section{FRANCE}
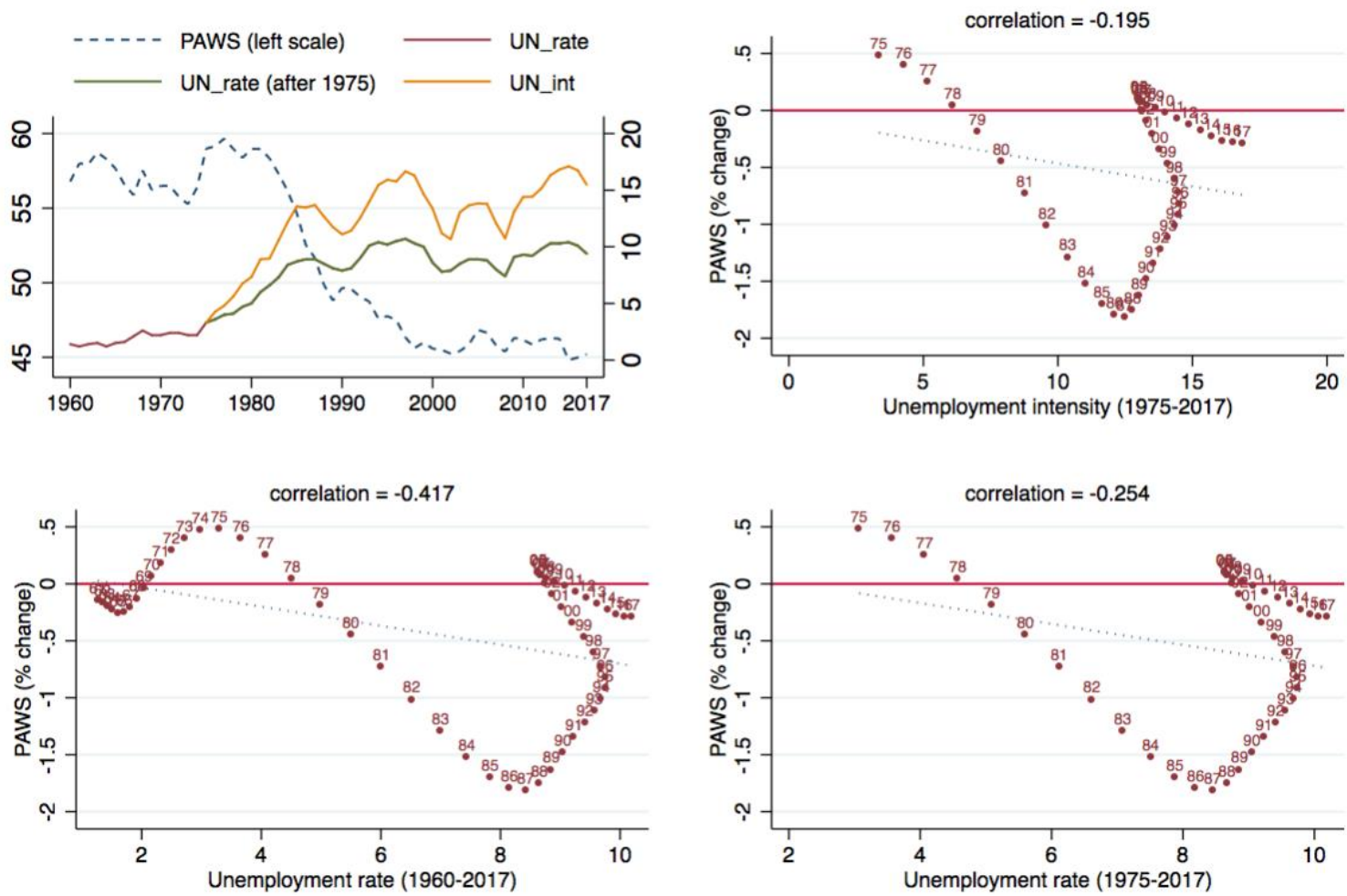


\section{GERMANY}
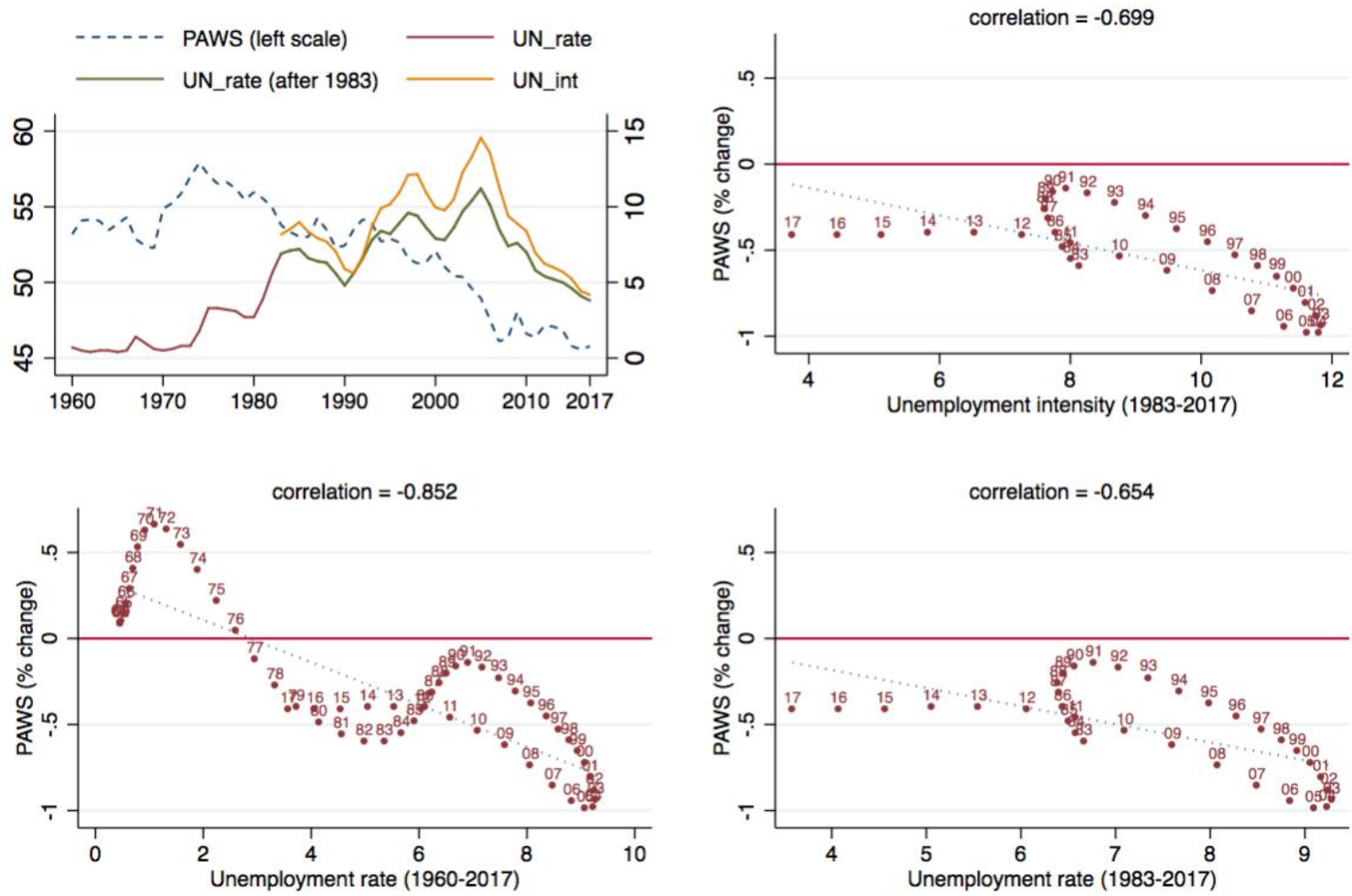

ITALY
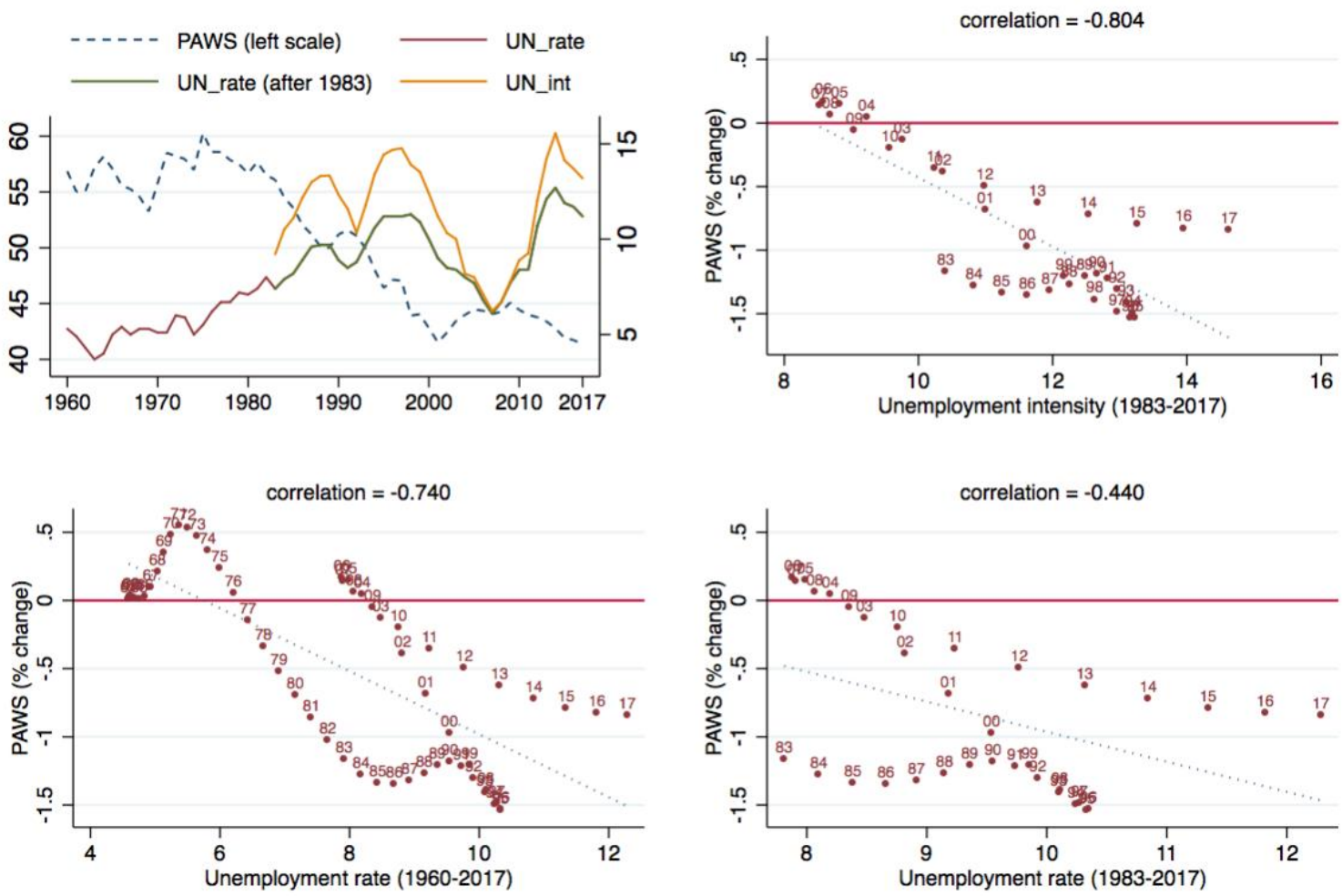
JAPAN
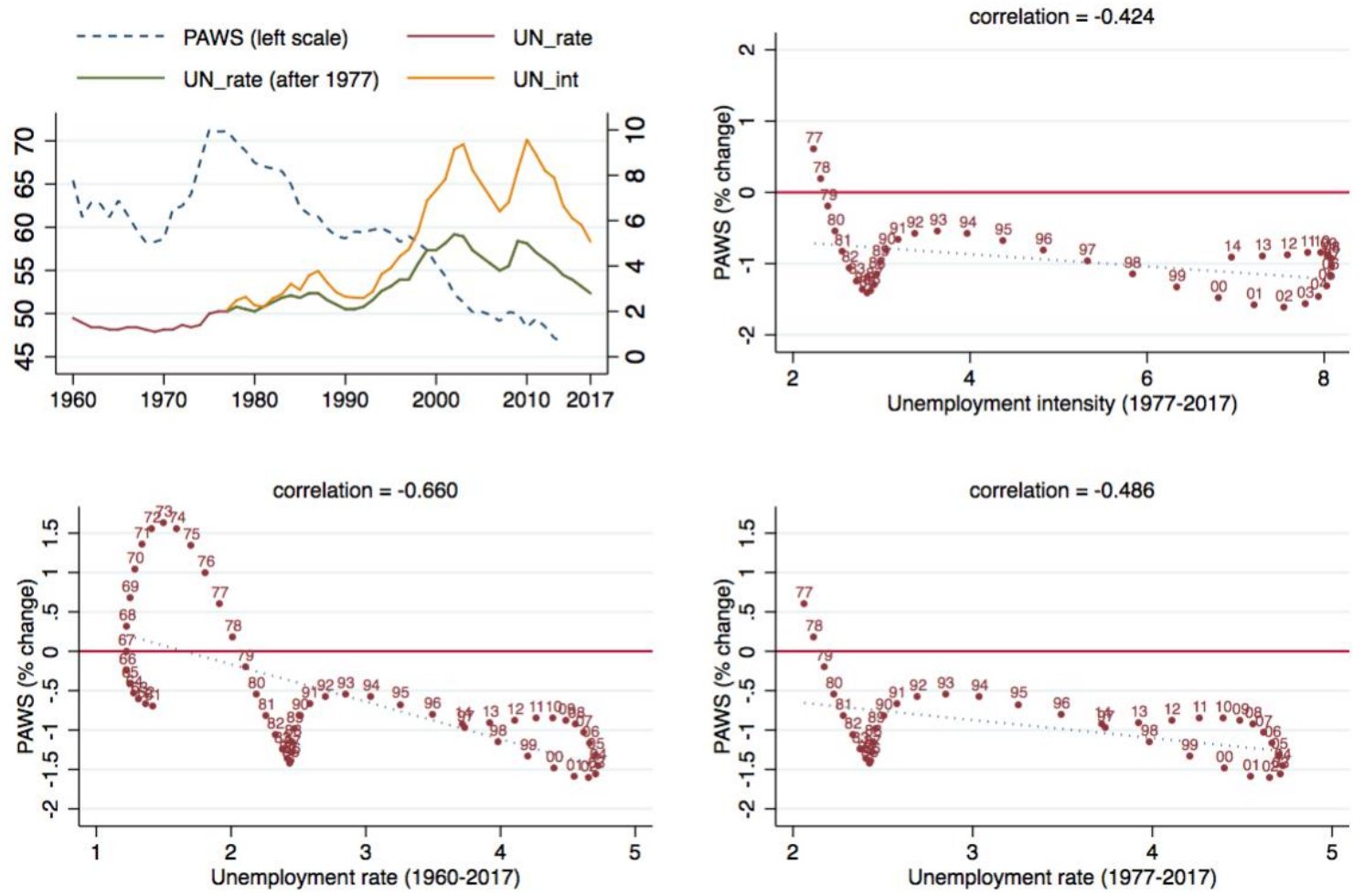

\section{SPAIN}
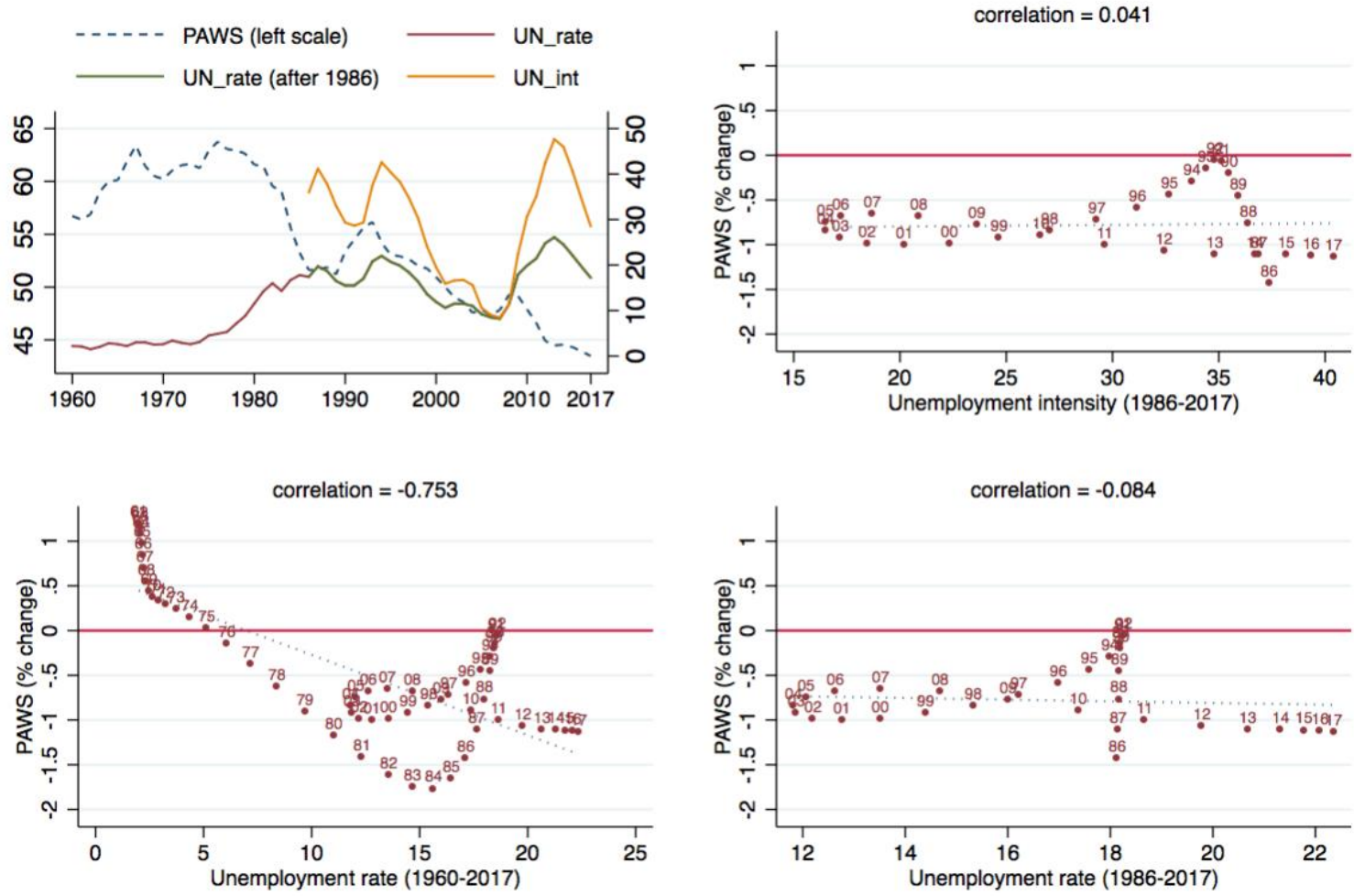


\section{SWEDEN}
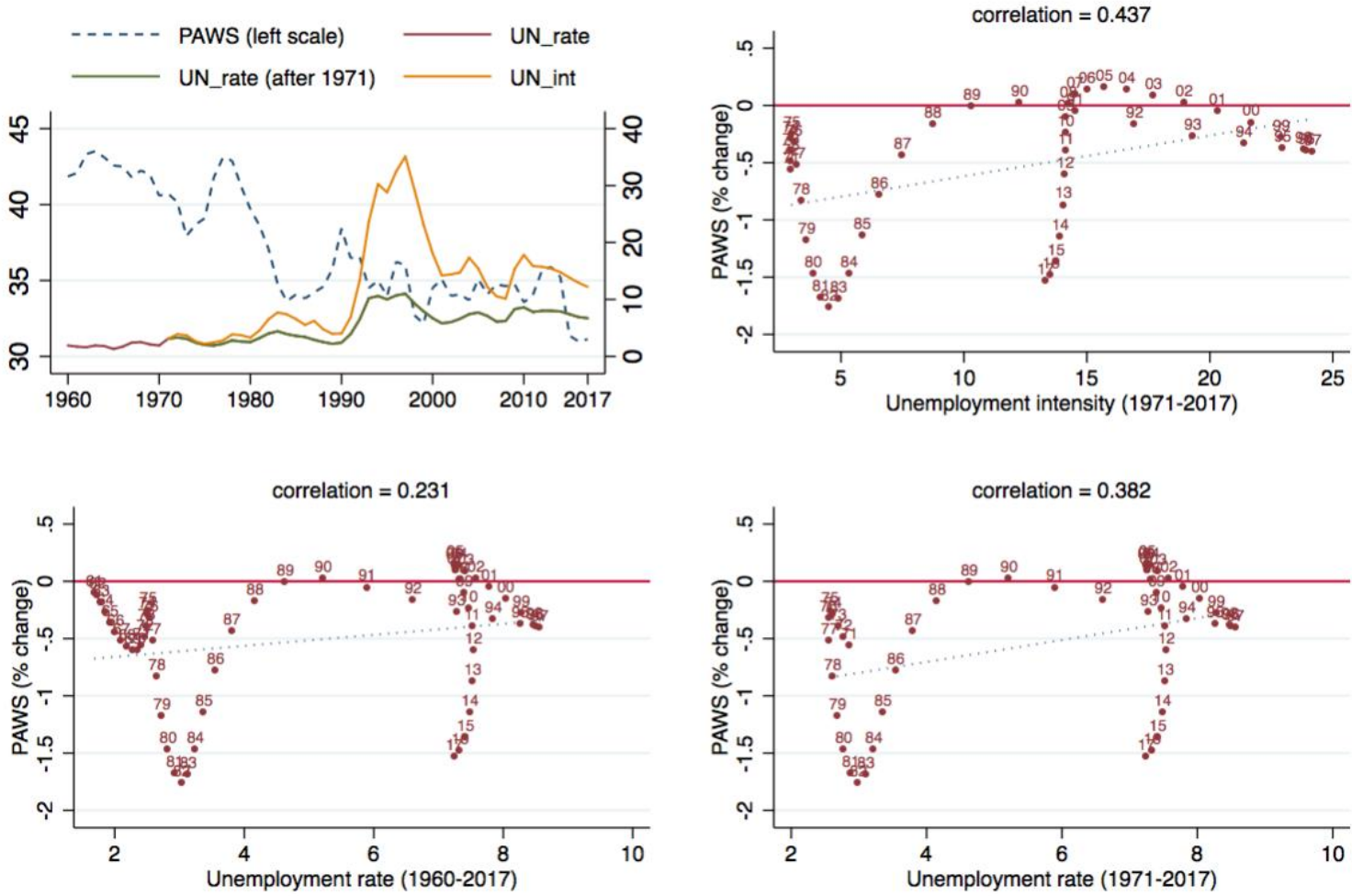

UNITED KINGDOM
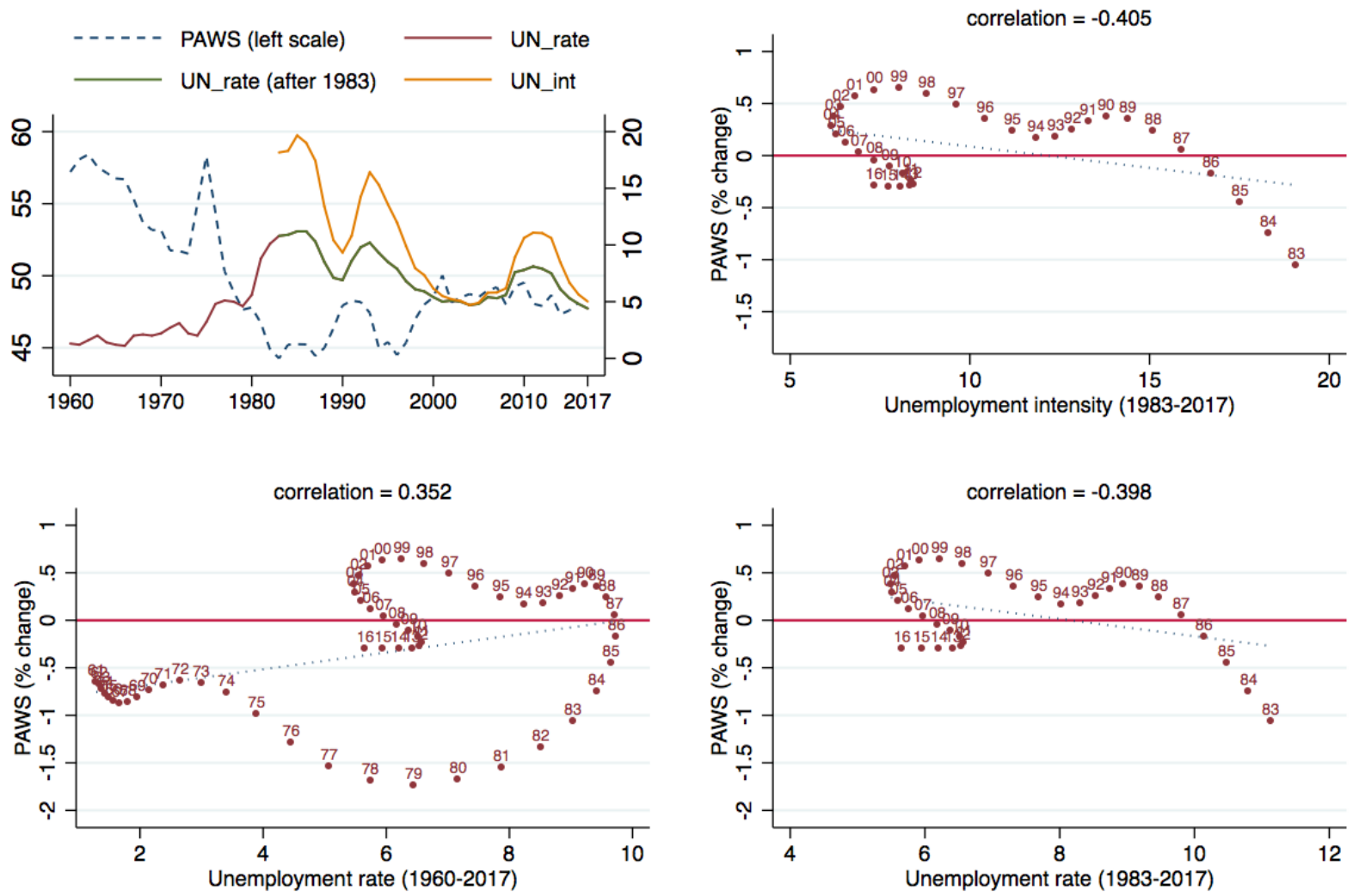

Caption: see Figure 1. 
Moving now to the evidence concerning other countries besides the US, there are other two countries in which there is a strong Phillips-type correlation between the unemployment index and the rate of change of the wage share in the private sector of the economy: Italy and Germany. In the former, like in the US, unemployment intensity performs remarkably better in 'explaining' the rate of change of the wage share in comparison with the unemployment rate for the same period; while in the latter, both measures of unemployment present high negative correlation with changes in income distribution. In addition, there are other two countries, Japan and France, where the negative correlation holds, too, but is more moderate - particularly in France in the 1975-2017 period, while it is stronger for a longer time span beginning in the 1960s, and particularly marked in the decade between the mid-1970s and mid-1980s. In both France and Japan there are no remarkable differences between correlations with unemployment rate or unemployment intensity. Then there are two other countries in which the Phillips-type relation only holds in some periods: the United Kingdom and Spain. In the former there is a negative, moderate but clearly visible correlation in the period beginning in the 1980s both with the unemployment rate and unemployment intensity. Over a longer time span we observe an upward shift of the curve in the mid-1980s. Although this may appear somewhat surprising from the point of view of UK political and union history, the shift might be connected to the inversion in the direction of change, with the progressive decline of unemployment rate and unemployment intensity since then. In Spain, where the correlation with the unemployment rate is very high over the longer time span beginning in the 1960s (particularly between 1960 and 1990), the relation becomes flat after the mid-1980s: both unemployment rate and unemployment intensity have remained extremely high since then, and the wage share falls at an almost constant pace, regardless of the size of unemployment. No Phillips-type relation can be detected in Canada and Sweden.

Some very broad considerations can be drawn from the above. The first is that the Phillips-type relation between an index of labor market slack and the rate of change in the wage share, though by no means an iron-clad law, is visible in most countries at least in some phases of their recent history. This is the case even though, as noted above, most of the movement is in the negative part of the diagrams. It may also be observed that although in two cases only the index of unemployment intensity has a significantly higher correlation with the wage share dynamics, it never happens to be less correlated with it than the standard unemployment measure. Interestingly, this runs counter to the logic of some hysteresis models that explain the low sensitivity of wages and prices to high unemployment rates with the scarce competitive pressure from the long-term unemployed (Ball, 1999; Llaudes, 2005; Rusticelli, 2014): looking at income distribution, it seems that longer average duration of unemployment, if anything, increases the impact of the unemployment rate. 
Finally, the evidence suggests a further problem with the notion of a 'normal' unemployment rate or unemployment intensity. The definition of the latter would have implied, if anything, a downward shift in the 'curve' owing to reduced worker protection and bargaining power in recent decades, implying lower 'normal' unemployment; by contrast, both unemployment and unemployment intensity have generally been higher (on average) in the most recent phase, even before the 2008 crisis, than they were in the 1970 or early 1980s. What we often observe is a flattening of the relationship (in the negative quadrant) for very high unemployment rates, consistent with the notion that wage reductions (as opposed to slower growth) hardly obtain, and with results concerning the (long period) downward sloping Phillips curve in nominal wages as well as in real wages (Paternesi Meloni and Stirati, 2018).

\section{Econometric analysis}

The previous section has been predominantly focused on descriptive analyses aimed at exploring the correlation between the level of unemployment (rate or intensity) and the rate of change of the wage share. In this way, we have highlighted the existence of an inverse relationship between unemployment and the dynamics of the wage share in several countries and periods. In this section, we want to continue exploring the 'structural' (as opposed to short-run) links between unemployment and income distribution by means of other econometric techniques. This may also help clarify the 'form' of the relationship, as discussed in Section 2, above. Since our variables are not stationary, and their levels are generally not co-integrated, we study the relationship between their prime differences, which are stationary; that is, we explore the relation:

$\triangle P A W S=\eta * \Delta U N$

where $\triangle P A W S$ is the change in the wage share, $\triangle U N$ represents the variation of a selected metric of unemployment, and $\eta$ captures the sign and the magnitude of the relationship. 
Table 1. Correlation between variables

\begin{tabular}{lcccc}
\hline$\triangle P A W S$ & $\Delta U N_{-}$rate & $\Delta U N_{\_}$rate & $\Delta U N_{-1}$ int & $\Delta U N_{-}$int \\
\hline Canada & $0.342^{* *}$ & $-0.274^{* *}$ & 0.083 & $-0.461^{* * *}$ \\
& $(54)$ & $(53)$ & $(38)$ & $(37)$ \\
France & 0.190 & -0.161 & 0.047 & -0.159 \\
& $(57)$ & $(56)$ & $(42)$ & $(41)$ \\
Germany & 0.021 & $-0.405^{* * *}$ & -0.083 & $-0.472^{* * *}$ \\
& $(57)$ & $(56)$ & $(34)$ & $(33)$ \\
Italy & -0.148 & $-0.359^{* * *}$ & -0.215 & $-0.318^{*}$ \\
& $(57)$ & $(56)$ & $(34)$ & $(33)$ \\
Japan & 0.133 & -0.177 & -0.101 & -0.221 \\
& $(54)$ & $(53)$ & $(37)$ & $(36)$ \\
Spain & -0.056 & $-0.232^{*}$ & -0.148 & $-0.355^{* *}$ \\
& $(57)$ & $(56)$ & $(31)$ & $(30)$ \\
Sweden & -0.066 & $-0.284^{* *}$ & -0.046 & $-0.275^{*}$ \\
& $(57)$ & $(56)$ & $(43)$ & $(42)$ \\
United Kingdom & -0.168 & $-0.505^{* * *}$ & -0.102 & $-0.518^{* * *}$ \\
& $(56)$ & $(55)$ & $(33)$ & $(32)$ \\
United States & $-0.244^{*}$ & $-0.381^{* * *}$ & $-0.386^{* * *}$ & $-0.265^{*}$ \\
& $(57)$ & $(56)$ & $(49)$ & $(48)$ \\
\hline \multirow{2}{*}{ All panels } & -0.030 & $-0.277^{* * *}$ & $-0.119^{* *}$ & $-0.275^{* *}$ \\
\hline
\end{tabular}

The table reports the Pairwise correlation between changes in the private sector adjusted wage share and changes in the two measures of labor market slack (unemployment rate and unemployment intensity). Significance is expressed as *if $<$ $0.1, * *$ if $<0.05$, and $* * *$ if $<0.01$. Number of observations in parenthesis.

Quite tentatively, some descriptive evidence further motivates our inquiry: by simply estimating a correlation between variables (Table 1), for the majority of countries we find evidence of a negative and significantly different from zero correlation between $\triangle P A W S$ and lagged $\triangle U N$ (rate and intensity, with the coefficient of the latter slightly higher than the former). Current $\Delta U N$ has a smaller coefficient in absolute terms and ambiguous sign: this is most likely due to the well-known short term pro-cyclical behavior of productivity (labor hoarding).

This explorative evidence, which essentially confirms the existence of a negative correlation between increasing labor market slack and the wage share in the private sector, leads us to move toward an econometric analysis that will be based on three different methodologies, each of which presents some desirable features and properties concerning the objectives mentioned above.

\subsection{Time series analysis}

As a first attempt to empirically estimate the size and the significance of the relationship expressed in equation (11), we estimate an autoregressive distributed lag model (ARDL) that depicts the relationship between the yearly changes in the private sector adjusted wage share and the changes in the unemployment rate (or, alternatively, in the unemployment intensity). Two main reasons justify the use of an ARDL model as an initial empirical strategy. First, the correlations presented in Table 1 suggest to us that we ought to consider also the lagged values of $\Delta U N_{-} r a t e$ or $\Delta U N_{-} i n t$, since their 
correlation with $\triangle P A W S$ is often more significant and greater in size than that of current values. Second, this method presents a desirable property for the sake of our purposes, since, once the model is estimated, it allows us to operate a re-parameterization in order to obtain a long-run coefficient between the two variables. ${ }^{20}$

We start by using the unemployment rate and estimate a short-term dynamic equation in first difference, since, different from their levels, ${ }^{21}$ the ADF test indicates that $\triangle P A W S$ and $\triangle U N \_r a t e$ are stationary for all countries at least at the 95\% confidence level (see Appendix C, Table C3). Therefore, we select the optimal lag structure of the ARDL by means of the Schwarz Bayesian information criteria. As the selected optimal lag structure of the ARDL model is $(1,1)$, for each of our nine countries under scrutiny, we estimate the following equation (12):

$$
\Delta P A W S_{t}=c+\gamma \Delta P A W S_{t-1}+\beta_{1} \Delta U N_{-} \text {rate }_{t}+\beta_{2} \Delta U N_{-} r a t e_{t-1}+\varepsilon_{t}
$$

where $\triangle P A W S$ represents the change of the private sector adjusted wage share, $\triangle U N_{-} r a t e$ is the change of unemployment rate, $c$ is the constant term, and $\varepsilon$ represents the error term. By following Pesaran and Shin (1998), we therefore calculate the long-run relationship between $\triangle P A W S$ and $\Delta U N_{-}$rate introduced in equation (11) based on the following expression (13):

$\eta=\frac{\beta_{1}+\beta_{2}}{1-\gamma}$

Estimations results can be seen in Table 2. Let us start by focusing on the long-run coefficients, which are negative for all countries (except Canada), and statistically significant at the $95 \%$ confidence interval for Germany, Italy, the United Kingdom and the United States. For Spain and Sweden, the significance is lower (90\%), while the relation is not significant for France and Japan. ${ }^{22}$ Concerning the magnitude of the relationship, when strongly significant the coefficients range from -0.3 and -0.8 . Estimated coefficients are higher for Italy and the United Kingdom, while moderately lower for the

\footnotetext{
${ }^{20}$ Technically, this procedure is grounded on the use of ARDL models for the analysis of long-run relations and yields consistent estimates of the long-run coefficients that are asymptotically normal, irrespective of whether the underlying regressors are stationary (Pesaran and Shin, 1998). Although in a different context, this methodology has been recently used by Basu and Foley (2013), Millemaci and Ofria (2014) and Deleidi et al. (2019).

${ }^{21}$ Being our variables of interest generally $\mathrm{I}(1)$, we also tested if they are cointegrated. Evidence indicates that $P A W S$ and $U N \_$rate are not cointegrated for the majority of countries, as we detect a Johansen-type cointegration only for France (at the 90\% level) and the United Kingdom (at the 95\% level). Accordingly, we opted for the use of alternative method to assess the existence and the magnitude of a long-run relationship.

${ }^{22}$ The significance of the long-term coefficients has been computed by using the ARDL approach, while short-term coefficients (and their standard errors) are calculated by means of 2SLS estimations: this allows us to overcome the simultaneity problem, namely, the possibility that estimates are influenced by the feedback of the dependent variable on the independent.
} 
remaining countries (for instance, in the United States an increase of the $U N_{-}$rate of one percentage point is, on average, associated with a 0.3 percentage point decrease in the $P A W S$ ).

While the long-term relationship is negative in all countries except Canada, the short-term coefficients present different results: in particular, the coefficient on the current variation of the unemployment rate is generally positive (statistically significant only in Canada and France), while its lagged change is commonly negative, larger in size and more significant. This indicates a delay in the effect of increasing labor market slack on the deterioration of the wage share, together with its already mentioned counter-cyclical behavior owing to the short-term, pro-cyclical fluctuations in productivity. $^{23}$

Table 2. ARDL regressions

ARDL $(1 ; 1)$ regressions with unemployment rate. Dependent variable: $\triangle P A W S$. Sample: 19602017.

\begin{tabular}{|c|c|c|c|c|c|c|c|c|c|}
\hline & Canada & France & Germany & Italy & Japan & Spain & Sweden & $\begin{array}{c}\text { United } \\
\text { Kingdom }\end{array}$ & $\begin{array}{l}\text { United } \\
\text { States }\end{array}$ \\
\hline \multicolumn{10}{|l|}{ Short run } \\
\hline$\Delta U N_{-}$rate & $\begin{array}{c}0.472 * * * \\
(0.129)\end{array}$ & $\begin{array}{c}0.494 * * \\
(0.208)\end{array}$ & $\begin{array}{l}0.343^{*} \\
(0.186)\end{array}$ & $\begin{array}{l}-0.057 \\
(0.262)\end{array}$ & $\begin{array}{c}0.517 \\
(0.694)\end{array}$ & $\begin{array}{l}-0.004 \\
(0.092)\end{array}$ & $\begin{array}{c}0.136 \\
(0.229)\end{array}$ & $\begin{array}{c}0.132 \\
(0.225)\end{array}$ & $\begin{array}{l}-0.094 \\
(0.099)\end{array}$ \\
\hline$\Delta U N_{-}$rate $e_{-1}$ & $\begin{array}{c}-0.427 * * * \\
(0.132)\end{array}$ & $\begin{array}{c}-0.538^{* *} \\
(0.216)\end{array}$ & $\begin{array}{c}-0.659^{* * *} \\
(0.175)\end{array}$ & $\begin{array}{c}-0.607 * * \\
(0.264)\end{array}$ & $\begin{array}{l}-1.192^{*} \\
(0.671)\end{array}$ & $\begin{array}{l}-0.127 \\
(0.093)\end{array}$ & $\begin{array}{c}-0.481 * * \\
(0.228)\end{array}$ & $\begin{array}{c}-0.815^{* * *} \\
(0.226)\end{array}$ & $\begin{array}{c}-0.241^{* *} \\
(0.098)\end{array}$ \\
\hline$\triangle P A W S_{-1}$ & $\begin{array}{c}0.010 \\
(0.131)\end{array}$ & $\begin{array}{c}0.291 \\
(0.124)\end{array}$ & $\begin{array}{c}0.018 \\
(0.132)\end{array}$ & $\begin{array}{c}0.052 \\
(0.131)\end{array}$ & $\begin{array}{l}0.247^{*} \\
(0.131)\end{array}$ & $\begin{array}{c}0.410^{* *} \\
(0.125)\end{array}$ & $\begin{array}{c}0.087 \\
(0.133)\end{array}$ & $\begin{array}{c}0.153 \\
(0.124)\end{array}$ & $\begin{array}{c}0.001 \\
(0.139)\end{array}$ \\
\hline$c$ & $\begin{array}{c}-0.223 * * \\
(0.113)\end{array}$ & $\begin{array}{l}-0.155 \\
(0.115)\end{array}$ & $\begin{array}{l}-0.126 \\
(0.102)\end{array}$ & $\begin{array}{c}-0.153 \\
(0.157)\end{array}$ & $\begin{array}{l}-0.158 \\
(0.190)\end{array}$ & $\begin{array}{c}-0.095 \\
(0.142)\end{array}$ & $\begin{array}{l}-0.147 \\
(0.177)\end{array}$ & $\begin{array}{c}-0.103 \\
(0.163)\end{array}$ & $\begin{array}{c}-0.142 \\
(0.091)\end{array}$ \\
\hline $\begin{array}{l}\text { Long run } \\
\eta\end{array}$ & $\begin{array}{c}0.045 \\
(0.159)\end{array}$ & $\begin{array}{l}-0.061 \\
(0.344)\end{array}$ & $\begin{array}{c}-0.322 * * \\
(0.179)\end{array}$ & $\begin{array}{c}-0.701 * * \\
(0.304)\end{array}$ & $\begin{array}{c}-0.896 \\
(1.070)\end{array}$ & $\begin{array}{c}-0.224^{*} \\
(0.126)\end{array}$ & $\begin{array}{c}-0.377^{*} \\
(0.253)\end{array}$ & $\begin{array}{c}-0.807 * * * \\
(0.274)\end{array}$ & $\begin{array}{c}-0.336^{* * *} \\
(0.120)\end{array}$ \\
\hline Adjusted $\mathrm{R}^{2}$ & 0.236 & 0.150 & 0.185 & 0.132 & 0.129 & 0.175 & 0.097 & 0.247 & 0.165 \\
\hline $\begin{array}{l}\text { F statistics } \\
(\text { Prob }>\text { F) }\end{array}$ & $\begin{array}{c}6.36 \\
(0.001)\end{array}$ & $\begin{array}{c}4.24 \\
(0.009)\end{array}$ & $\begin{array}{c}5.16 \\
(0.003)\end{array}$ & $\begin{array}{c}2.64 \\
(0.059)\end{array}$ & $\begin{array}{c}2.42 \\
(0.077)\end{array}$ & $\begin{array}{c}4.89 \\
(0.005)\end{array}$ & $\begin{array}{c}1.86 \\
(0.148)\end{array}$ & $\begin{array}{c}6.92 \\
(0.001)\end{array}$ & $\begin{array}{c}3.38 \\
(0.025)\end{array}$ \\
\hline Obs. & 53 & 56 & 56 & 56 & 53 & 56 & 56 & 55 & 55 \\
\hline
\end{tabular}

$\overline{\triangle P A W S}=$ adjusted wage share in the private sector of the economy (first difference); $\triangle U N_{-} r a t e=$ unemployment rate (first difference); $\eta=$ long-run coefficient as $\left(\Delta U N_{-}\right.$rate $\left.+\Delta U N_{-} r a t e_{-1}\right) /\left(1-\Delta P A W S_{-1}\right)$.

Robust standard error in parentheses; *,**, and *** denote levels $0.1,0.05$, and 0.01 of significance.

\subsection{Panel exploration}

The empirical test proposed in Section 5.1 seems to confirm some of the evidence arising from the descriptive analysis presented in Section 4, that is, a connection between increasing unemployment

\footnotetext{
${ }^{23}$ Generally, the labor income share shows a counter-cyclical pattern since output initially decreases (or increases) at a faster pace than employment, so that labor productivity is highly pro-cyclical (the so-called Okun effect). This has been reported as a stylized fact (Romer, 2006) and empirically documented (IMF, 2012; ILO, 2019).
} 
and decreasing wage share, which, albeit with some exceptions, seems to hold for most countries. Nevertheless, as the statistical significance of the time-series analysis can be negatively affected by the low number of observations, we also find it appropriate to replicate the same exploration by using panel data techniques. Since longitudinal analyses imply the possibility to make use of a greater sample size, we can extend the exploration to the index of unemployment intensity, for which we have shorter time series and a lower number of observations (see Appendix A).

Let us start with the analysis grounded on the unemployment rate for the larger time span available (1960-2017). We present three alternative estimations, since, in addition to the standard dynamic fixed-effects (DFE) estimator, we make use of a pooled mean group (PMG) estimator (Pesaran et al., 1999) and of a mean group (MG) estimator (Pesaran and Smith, 1995). We apply this to the model represented by equation (14):

$$
\Delta P A W S_{i, t}=c_{i}+\beta_{1 i} \Delta U N_{t}+\beta_{2 i} \Delta U N_{t-1}+\gamma_{i} \Delta P A W S_{t-1}+\alpha_{i}\left(P A W S_{i, t-1}-\theta_{i} U N_{i, t}\right)+\varepsilon_{i, t}
$$

where $\Delta U N$ refers to $\Delta U N_{-}$rate and in which the long-run relationship between the variables in level is captured by the coefficient $\theta$ within a co-integrating equation. ${ }^{24}$ Some remarks on the estimators used are needed. The less complex estimator is the DFE, which assumes homogeneity in every dimension except in the constant term (and thus considering country heterogeneity only in $c_{i}$ ). ${ }^{25}$ As stated by Blackburne and Franck (2007), PMG and MG estimators have to be considered 'two important new techniques to estimate nonstationary dynamic panels in which the parameters are heterogeneous across groups' (p. 198). On the one hand, the MG estimator relies on estimating different time-series regressions and then averaging the coefficients (both in the short and the long run), so that it allows for heterogeneity in every dimension. On the other hand, the PMG estimator relies on a combination of pooling and averaging of coefficients: specifically, it considers the case of heterogeneity in the fixed effects and the short-term dynamics, but a homogeneous long-term relationship (that is, imposing $\theta_{i}=\theta$ for all countries). ${ }^{26}$ To put it simply, the PMG imposes homogeneity restrictions on long-run coefficients across countries while maintaining heterogeneity

\footnotetext{
${ }^{24}$ Remarkably, in time series analysis (Section 5.1), the error correction term has not been considered since cointegration does not hold for all countries (see footnote 21). When considering the sample as a panel, which is I(1) according to Table C3 in Appendix C, we do not find a highly statistically significant Pedroni-type panel cointegration. This is the reason why instead of making use of PDOLS or FMOLS estimators, which require strong cointegration, we use the approach proposed by Pesaran et al. (1999), which can be implemented both in the case where the regressors are stationary and where they follow unit root processes.

${ }^{25}$ DFE estimators are biased when applied to dynamic models, but the size of the bias tends to zero as the time dimension grows (Nickell, 1981). Moreover, this estimator is inconsistent if there is heterogeneity among countries. Pesaran and Smith (1995) proved the MG estimator to be consistent regardless of homogeneity or heterogeneity.

${ }^{26}$ Hence, the PMG calculates the short-term coefficients as averages across countries. Notably, Pesaran et al. (1999) have developed a maximum likelihood method to estimate the parameters, concluding that this estimator is inconsistent in case of homogeneity, but it is efficient if the long-term coefficient is homogeneous.
} 
for short-run dynamics. On the contrary, the MG does not require a restriction, and hence it allows all coefficients to vary as well as to be heterogeneous in the short and long run; nevertheless, the MG does not account for cross-country dependence which can arise from spatial or spillover effects, or could be due to unobserved common factors (Baltagi and Pesaran, 2007).

The results of our exploration are reported in Table 3.1, which reports the estimated coefficients for both the short and the long run, with the latter referring to the relationship between variables taken in levels, as indicated in equation (14), while the short-term coefficients can be interpreted as in Section 5.1. The long-term negative relationship between the private sector adjusted wage share and the unemployment rate is statistically significant in all estimations, with coefficients ranging from -0.68 (DFE model) and -1.31 (MG model). While concerning the short-term effects, we find that the relationship between the lagged variation of the unemployment rate is always significant and ranging from -0.25 (DFE) and -0.36 (PMG). Arguably, the PMG estimations may produce more persuasive results than the MG due to fact that cross-sectional dependence is taken into account. Therefore, in commenting on these results we find appropriate to refer to the PMG estimator, according to which a long-term coefficient of -1.044 is estimated: this means that a higher level of the unemployment rate of one percentage point is, on average, associated with a lower level of the private sector adjusted wage share of approximately 1 percentage points.

\section{Table 3. Panel explorations}

Table 3.1. Panel ARDL $(1 ; 1)$ regression with unemployment rate. Dependent variable: $\triangle P A W S$. Timespan: 1960-2017.

\begin{tabular}{|c|c|c|c|}
\hline & Pooled mean group (PMG) & Mean group (MG) & $\begin{array}{c}\text { Dynamic fixed effect } \\
\text { (DFE) }\end{array}$ \\
\hline \multicolumn{4}{|l|}{ Long run } \\
\hline UN_rate & $\begin{array}{c}-1.044 * * * \\
(0.147)\end{array}$ & $\begin{array}{c}-1.307 * * * \\
(0.322)\end{array}$ & $\begin{array}{c}-0.688 * * * \\
(0.288)\end{array}$ \\
\hline$\alpha$ & $\begin{array}{c}-0.077 * * * \\
(0.028) \\
\end{array}$ & $\begin{array}{c}-0.086 * * * \\
(0.028)\end{array}$ & $\begin{array}{c}-0.046^{* * *} \\
(0.011)\end{array}$ \\
\hline \multicolumn{4}{|l|}{ Short run } \\
\hline$\Delta U N_{-}$rate & $\begin{array}{c}0.262 * * * \\
(0.083)\end{array}$ & $\begin{array}{c}0.281 * * * \\
(0.091)\end{array}$ & $\begin{array}{l}0.118^{* *} \\
(0.049)\end{array}$ \\
\hline$\Delta U N_{-} r a t e_{-1}$ & $\begin{array}{c}-0.364 * * * \\
(0.099)\end{array}$ & $\begin{array}{c}-0.332 * * * \\
(0.080)\end{array}$ & $\begin{array}{c}-0.247 * * * \\
(0.052)\end{array}$ \\
\hline$\triangle P A W S_{-1}$ & $\begin{array}{l}0.921 * * * \\
(0.038)\end{array}$ & $\begin{array}{l}0.909 * * * \\
(0.044)\end{array}$ & $\begin{array}{l}1.013 * * * \\
(0.077)\end{array}$ \\
\hline$c$ & $\begin{array}{c}4.202 * * * \\
(1.505) \\
\end{array}$ & $\begin{array}{c}4.768 * * * \\
(1.479) \\
\end{array}$ & $\begin{array}{c}2.606^{* * * *} \\
(0.667) \\
\end{array}$ \\
\hline Obs. & 470 & 470 & 470 \\
\hline
\end{tabular}


As anticipated, the greater size of the sample nested in the panel analysis allow us to extend our exploration to the index of unemployment intensity. However, two gimmicks must be introduced for the sake of comparability between the two explorations that we now introduce (namely, the one based on unemployment rate and the one based on the unemployment intensity). First, as the data on unemployment duration are available only for a shorter timespan (namely, from the 1980s for most of the countries under scrutiny), we confine the analysis based on the unemployment rates to a shorter period (i.e. the same time window for which series on unemployment intensity are computable). Second, as by definition the range of variation of the unemployment intensity is different from that of the unemployment rate (as explained at the beginning of Section 4), we normalize the series for the sake of comparing the magnitude and the significance of the regression coefficients. to this purpose, we use the traditional normalization by standard deviation. ${ }^{27}$ Subsequently, we estimate the same model represented in equation (14) by considering $\Delta U N$ as $\Delta U N_{-}$rate or $\Delta U N_{-}$int, alternatively.

Table 3.2. Panel ARDL (1;1) regression with unemployment rate or unemployment intensity. Dependent variable: $\triangle P A W S$. Different timespans.

\begin{tabular}{|c|c|c|c|c|c|c|}
\hline & \multicolumn{2}{|c|}{ Pooled mean group (PMG) } & \multicolumn{2}{|c|}{ Mean group (MG) } & \multicolumn{2}{|c|}{ Dynamic fixed effect (DFE) } \\
\hline & UN_rate & $U N_{-}$int & UN_rate & $U N_{-}$int & UN_rate & $U N_{-}$int \\
\hline \multicolumn{7}{|l|}{ Long-run } \\
\hline$U N$ & $\begin{array}{c}-0.795 * * * \\
(0.080)\end{array}$ & $\begin{array}{l}-0.882 * \\
(0.078)\end{array}$ & $\begin{array}{l}-0.135 \\
(0.277)\end{array}$ & $\begin{array}{l}-1.039 \\
(0.742)\end{array}$ & $\begin{array}{c}-0.735 * * \\
(0.365)\end{array}$ & $\begin{array}{c}-0.763 * * \\
(0.336)\end{array}$ \\
\hline$\alpha$ & $\begin{array}{c}-0.079 * * * \\
(0.027) \\
\end{array}$ & $\begin{array}{c}-0.066^{* * *} \\
(0.020)\end{array}$ & $\begin{array}{l}-0.145^{*} \\
(0.076) \\
\end{array}$ & $\begin{array}{c}-0.147^{*} \\
(0.076) \\
\end{array}$ & $\begin{array}{c}-0.044 * * \\
(0.017) \\
\end{array}$ & $\begin{array}{c}-0.048^{* *} \\
(0.018) \\
\end{array}$ \\
\hline \multicolumn{7}{|l|}{ Short-run } \\
\hline$\Delta U N$ & $\begin{array}{c}0.137 * * * \\
(0.042)\end{array}$ & $\begin{array}{c}0.108^{* *} \\
(0.053)\end{array}$ & $\begin{array}{c}0.154 * * * \\
(0.047)\end{array}$ & $\begin{array}{l}0.128^{*} \\
(0.063)\end{array}$ & $\begin{array}{c}0.087 * * \\
(0.032)\end{array}$ & $\begin{array}{c}0.040 \\
(0.038)\end{array}$ \\
\hline$\Delta U N_{-1}$ & $\begin{array}{c}-0.147 * * * \\
(0.047)\end{array}$ & $\begin{array}{c}-0.176^{* *} \\
(0.072)\end{array}$ & $\begin{array}{c}-0.114^{*} \\
(0.058)\end{array}$ & $\begin{array}{c}-0.126^{*} \\
(0.065)\end{array}$ & $\begin{array}{c}-0.169 * * * \\
(0.034)\end{array}$ & $\begin{array}{c}-0.152 * * * \\
(0.042)\end{array}$ \\
\hline$\triangle P A W S_{-1}$ & $\begin{array}{c}0.071 \\
(0.049)\end{array}$ & $\begin{array}{c}0.048 \\
(0.053)\end{array}$ & $\begin{array}{c}0.079 \\
(0.055)\end{array}$ & $\begin{array}{c}0.063 \\
(0.056)\end{array}$ & $\begin{array}{c}0.084 \\
(0.053)\end{array}$ & $\begin{array}{c}0.075 \\
(0.054)\end{array}$ \\
\hline$c$ & $\begin{array}{c}0.892 * * \\
(0.370) \\
\end{array}$ & $\begin{array}{c}0.763 * * * \\
(0.225) \\
\end{array}$ & $\begin{array}{l}1.649^{*} \\
(0.987)\end{array}$ & $\begin{array}{l}1.700^{*} \\
(0.933)\end{array}$ & $\begin{array}{c}0.621 * * \\
(0.248) \\
\end{array}$ & $\begin{array}{c}0.640^{* *} \\
(0.249) \\
\end{array}$ \\
\hline Obs. & 331 & 331 & 331 & 331 & 331 & 331 \\
\hline
\end{tabular}

$U N=$ long-run coefficient (between variables in levels); $\triangle P A W S=$ adjusted wage share in the private sector of the economy (first difference); $\Delta U N=$ unemployment rate or unemployment intensity (first difference).

Standard error in parentheses; *, **, and *** denote levels $0.1,0.05$, and 0.01 of significance.

The results of this juxtaposition can be seen in Table 3.2. The long-term relationship between the PAWS and both the indicators of labor market slack is negative and statistically significant with the

\footnotetext{
${ }^{27}$ Technically, we divide all the series (private sector adjusted wage share, unemployment rate and unemployment intensity) by their standard deviations, and then we calculate first differences.
} 
PMG and the DFE estimators, and the coefficients are almost in line between the two approaches. While concerning the short-term effects, we find that the relationship between the lagged change of unemployment (both its rate and its intensity) and the change of PAWS is always significant. Concerning the comparison between the two measures of labor market slack, a caveat should be taken into consideration: having normalized the series, these estimations do not allow us to provide an economic interpretation of the size of the coefficients in absolute terms, while they are useful in order to assess whether the unemployment intensity produces a stronger depressing effect on the private sector adjusted wage share when compared to the unemployment rate. In this regard, estimates do not turn out to perform, on average, very differently, with only marginally higher coefficients associated with the unemployment intensity with respect to the unemployment rate (with the only exception being the DFE analysis in the short run).

As an additional attempt to test the robustness of our analysis, we replicate the panel ARDL regression on two different sub-periods identified by using 1980 as a watershed. The intuition behind this choice is solid and, as we will see, consistent with evidence. While we are interested in looking for long-run patterns, it can be argued that the overall timespan (1960-2017) consists of two distinct periods: the first one which involves the 1960s and the 1970s, when the policy orientation was still full-employment, and the period after 1980 during which the macroeconomic orientation has switched towards inflation control. Accordingly, we verify if pooling (time-series) data from the two distinct policy-regimes may (or may not) produce different results in terms of the connection between unemployment and income distribution. To do so, we look for structural breaks. Some problems may arise when dealing with breaks in a context of panel data. To mitigate them, we follow a two-steps strategy. At first, we verify the presence of country-specific breakdowns in series (see Appendix D, Table D1): most of the countries present breaks at the beginning of the 1980s, in particular when the unemployment rate is concerned. As a second step, for each country we verify whether 1980 can be considered a year-specific break (Table D2): this hypothesis turned out to be verified for all countries except the US. Accordingly, we use 1980 as a breakpoint, and we replicate the analysis provided in Table 3.1 with respect to sub-periods. The results of this robustness check are reported in Table D3. The negative association between labor market slack and the wage share is confirmed for both subperiods, although the MG estimations are not statistically significant in either subperiod (this may be a result of the lower number of observations). Results are somewhat inconclusive concerning a different intensity of the effects of unemployment on the wage share in the two subperiods. ${ }^{28}$ However, in this case as well we find it appropriate to rely on the PMG estimator, which should be

\footnotetext{
${ }^{28}$ This might be interpreted in the light of our comment in Section 4.2 concerning the fact that most of the time we observe declines in the wage share, and since the scope for wage decline is limited, changes in the wage share tend to be dominated by the rate of change in productivity.
} 
considered superior to the DFE as well, since the latter may particularly suffer from the short timespan (see footnote 25). Accordingly, empirical evidence suggests a higher coefficient in the first subperiod (about -0.9) than in the second one (-0.6).

With respect to the soundness of the models, it is worth mentioning that the PMG estimator generally offers an increase in the efficiency estimates as compared to the MG estimator under the long-run homogeneity (Pesaran et al., 1999). To test this assumption of long-run slope homogeneity, we perform a Hausman (1978) test - the results of which are reported in Appendix E - to verify whether there is a significant difference between PMG and MG or PMG and DFE estimators. Concerning the results from Table 3.1, the test indicates that the only discrepancy that is significant at the 95\% level stems from the comparison between DFE and PMG estimations, further suggesting the presence of a heterogeneous relation between unemployment and income distribution among countries (as shown in the statistical exercise provided in Section 4) and indicating the PMG estimations as the most appropriate. In addition, as the test does not reject the null hypothesis of slope homogeneity between MG and PMG models, the latter is recommended since it is more consistent and efficient then the former (Pesaran et al., 1999). Turning to the evidence provided in Table 3.2, the Hausman test indicates that the difference in coefficients is not systematic, with the only exception being the comparison between MG and PMG models with respect to the analysis based on the unemployment rate. However, even in this case, the PMG estimates must be considered as more appropriate due to their aforementioned underlying features.

\subsection{Impulse responses}

As an additional way to identify whether the effect of greater labor market slack on income distribution may go beyond the short run, and particularly to identify how it may behave at different time horizons after an initial shock (something that is not possible by means of the empirical methods used so far), we find it of interest to propose an additional empirical exercise to investigate the dynamic behavior of the private sector adjusted wage share $(\triangle P A W S)$ and the changes in unemployment rate $\left(\Delta U N_{-}\right.$rate $)$or in unemployment intensity $\left(\Delta U N_{-} i n t\right)$. To do so, in this section, we make use of an SVAR methodology. Two main reasons justify this further exploration.

On the one hand, we are not so far able to exclude that the previous analyses are unbiased from endogeneity and/or reverse causality issues. While we have already elaborated on the possible causes justifying the relationship moving from unemployment to income distribution, it can be argued that the opposite relation may also hold. For instance, changes in income distribution can produce changes in aggregate demand and consequently affect the labor market. 
On the other hand, we are interested in assessing the dynamic behavior of both the PAWS and the unemployment after an initial shock in the labor market occurs. We are also interested in assessing if changes in the unemployment rate and its intensity tend to persist over the short run, that is, whether they exhibit 'hysteresis' and, in connection with this, whether a persistent change in unemployment is associated with a persistent change of the wage share or if it eventually tends to stabilize.

The econometric methodology we shall use in this empirical exercise offers two main advantages with respect to those used in the previous explorations. SVAR models allow us to estimate the existing dynamic causal relationship among considered variables by ensuring the removal of any endogeneity problems (Kilian and Lütkepohl, 2017). Moreover, as the two variables interplay within the model, SVAR methods allow us to investigate the dynamic behavior of both variables under scrutiny, so that we will be able to verify: i) the persistency of the effects of changes in unemployment on the private sector adjusted wage share; and ii) the behavior of the unemployment rate after its initial shock.

After this conceptual premise, some technical remarks on the methodology used for this exploration are needed. After having checked stationarity for all variables taken in first differences (Appendix C, Table C3), we choose one period as the optimal lag by minimizing the Schwarz information criterion. Having verified that our variables are stationary and the selected lag is one, we estimate a reduced-form $\operatorname{VAR}(1)$, as in equation (15):

$x_{t}=c+\sum_{i=1}^{p} A_{i} x_{t-p}+e_{t}$

where $x_{t}$ is the $k x 1$ vector of the two variables, $c$ is the constant term, $A_{i}$ is the $k x k$ matrix of reducedform coefficients, and $e_{t}$ is a $k x 1$ vector composed by the error terms. Second, we impose an identification strategy to the reduced-form $\operatorname{VAR}(1)$ to obtain a structural model. In detail, an SVAR(1) can be represented as in equation (16):

$B_{0} x_{t}=c+\sum_{i=1}^{p} B_{i} x_{t-p}+w_{t}$

where $B_{0}$ represents the matrix of contemporaneous relationships between the $k$ variables in $x_{t}, B_{i}$ is the $k x k$ matrix of autoregressive slope coefficients, and $w_{t}$ is the vector of serially uncorrelated structural shocks. ${ }^{29}$ Furthermore, we set a recursive model based on a Cholesky decomposition that can be summarized in the system of equation (17):

\footnotetext{
${ }^{29}$ As in Kilian and Lütkepohl (2017), $w_{t}=B_{0}^{-1} e_{t}$. Moreover, following Lütkepohl (2005), the covariance matrix of structural errors is normalized as $\mathbb{E}\left(w_{t} w_{t}^{\prime}\right)=\sum_{w}=I_{K}$.
} 
$B_{0} x_{t}=\left[\begin{array}{cc}n a & 0 \\ n a & n a\end{array}\right]\left[\begin{array}{c}\Delta U N_{-} \text {rate } \\ \Delta P A W S\end{array}\right]$

where $n a$ indicates an unrestricted parameter, and a 0 represents a zero restriction. Once restrictions are imposed and the estimation of the $B_{0}$ matrix is implemented by means of the maximum likelihood method, an accumulated impulse response function (IRF) is estimated, and standard errors will be estimated through the asymptotic distribution. In the remaining empirics, we shall report IRFs with two-standard error bound with respect to a 10-years horizon. ${ }^{30}$

With this exploration, we are interested in assessing the dynamic effect of changes in the unemployment rate $\left(\Delta U N_{-} r\right.$ rate $)$ - or alternatively in the unemployment intensity $\left(\Delta U N_{-} i n t\right)-$ on changes that may occur both in the private sector adjusted wage share $(\triangle P A W S)$ and in the unemployment itself. By following the identification sets in the system represented in equation (17), which is based on the theoretical discussion provided in Section 2, we assume that the (increase of) unemployment rate, or alternatively (the increase of) the unemployment intensity, is supposed to (negatively) affect the wage share in the contemporaneous relationship. However, since both variables are treated as endogenous (and hence they are allowed to interplay), our model will also allow us to verify if changes in income distribution, as well as the initial shock in unemployment (rate or intensity), may affect the unemployment (rate or intensity) itself. ${ }^{31}$

In what follows, for each of the nine countries under investigation, we report the cumulative IRF of changes in both the PAWS and the $U N \_r a t e$ to structural shocks in the change of the $U N \_r a t e$. Moreover, we shall report the same IRF by using the $U N_{-} i n t$ instead of the $U N_{-}$rate with respect to the United States. We also apply panel-SVAR techniques (Pedroni, 2013) to a panel including all nine economies under scrutiny in order to verify an average relationship among countries by using both the unemployment rate and the unemployment intensity. ${ }^{32}$

Figure 3.1 reports the IRF with respect to the analysis conducted on the basis of unemployment rate for the largest timespan (i.e. from 1960 to 2016). The estimated dynamic pattern is quite common among countries: we generally find a moderate, and in same case positive, ${ }^{33}$ initial impact of an unemployment rate innovation on the $P A W S$, which becomes negative the year after the initial $U N \_r a t e$ shock in all countries except two cases, namely France, where it turns to negative at four years after the shock, and Canada, where the coefficients remain positive: in both cases, however, the

\footnotetext{
${ }^{30}$ This means that our IRFs are reported with a 95\% confidence interval (see Sims and Zha, 1999).

${ }^{31}$ It is worth specifying that this will occur only after the initial shock that moves from changes in unemployment to changes in income distribution.

${ }^{32}$ Specifically, we make use of a combination of idiosyncratic and common shocks (in jargon, composite shocks). Notably, this strategy allows us to take into account both shocks that only affect the single units composing the panel, and shocks that simultaneously involve all countries included in the panel (Pedroni, 2013).

${ }^{33}$ This pattern, however, appears in line with the countercyclical behavior in the wage share, discussed above.
} 
responses are small and not statistically significant. In four out of nine countries, namely Germany, Italy, the United Kingdom and the United States, and when the whole panel is considered, the negative effect is statistically significant at the $95 \%$ confidence interval. We also find a negative response of PAWS to unemployment rate shocks in Spain, Sweden and Japan, but this is less significant in the first two countries (68\% confidence level) and not statistically significant for Japan. When significant, such a depressing impact on the private sector adjusted wage share stabilizes - starting, on average, from three to four years after the original unemployment shock, with no sign of reversion in a 10year horizon. Concerning the effects on the unemployment rate itself, for all countries, a pattern of persistence ('hysteresis') is confirmed after the initial change in the UN_rate. 


\section{Figure 3. IRFs from SVAR analysis}

Figure 3.1. Cumulated response of the private sector adjusted wage share to unemployment rate shocks (timespan: 1960-2017)

\section{Canada}
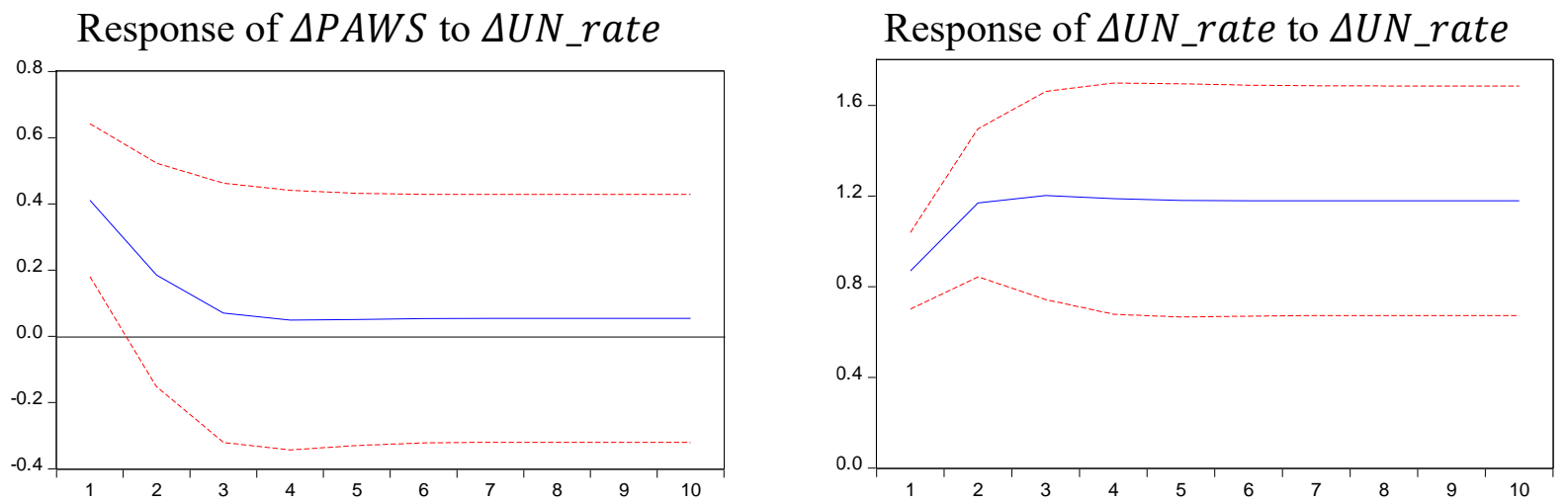

France
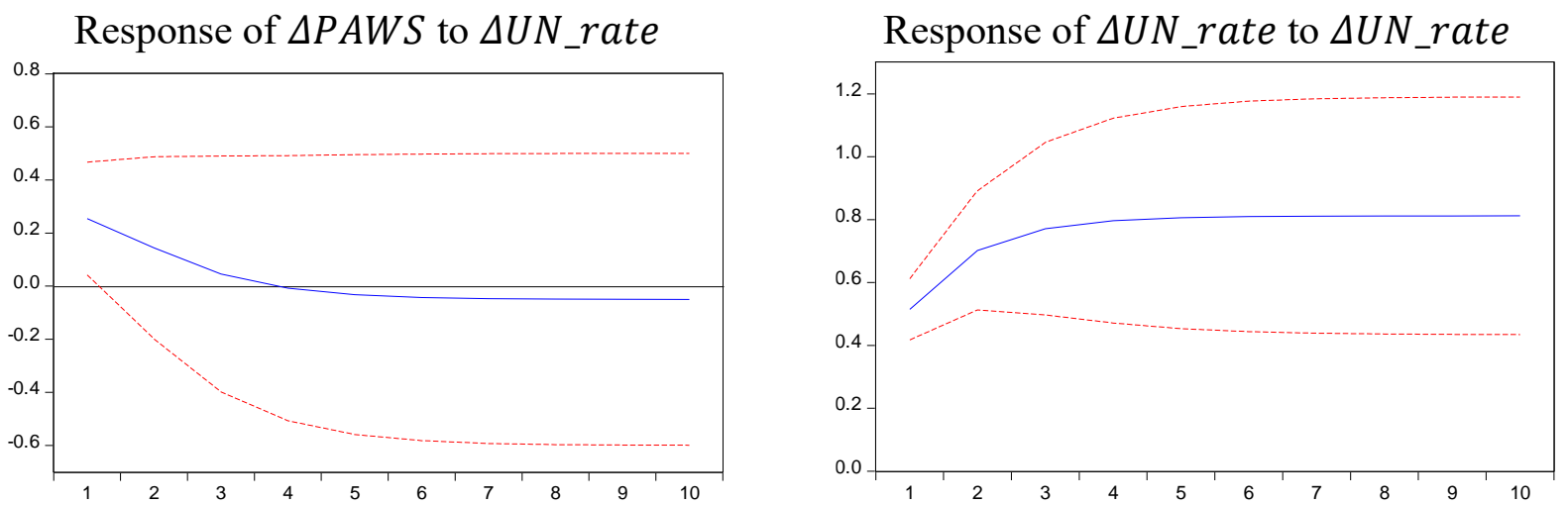

Germany
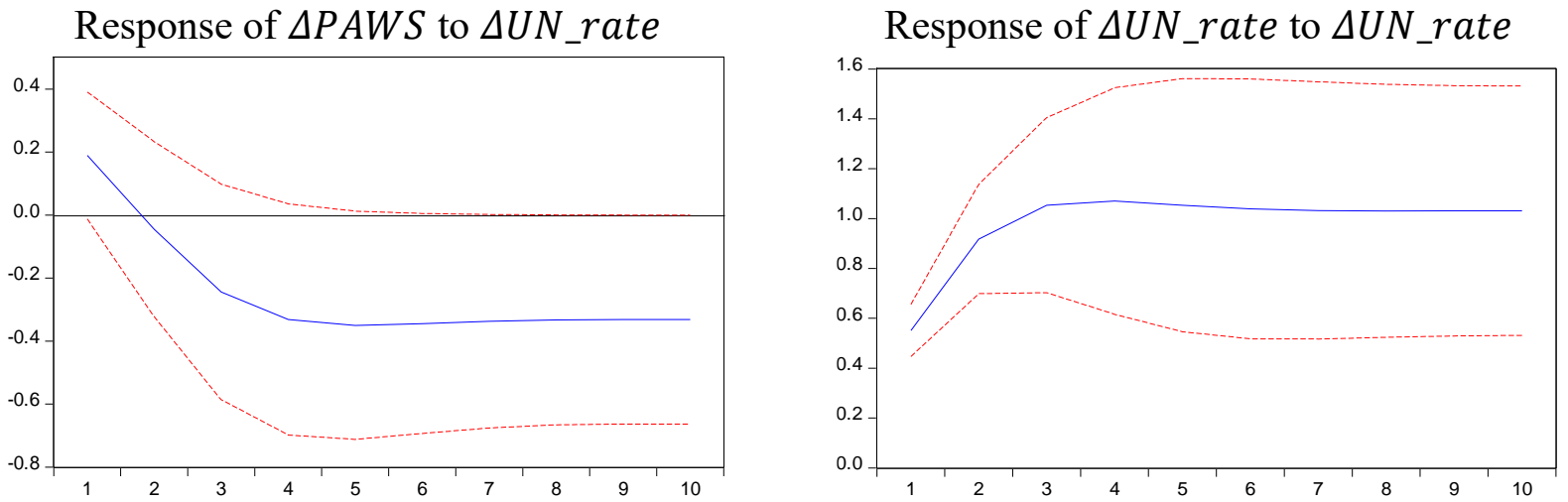
Italy
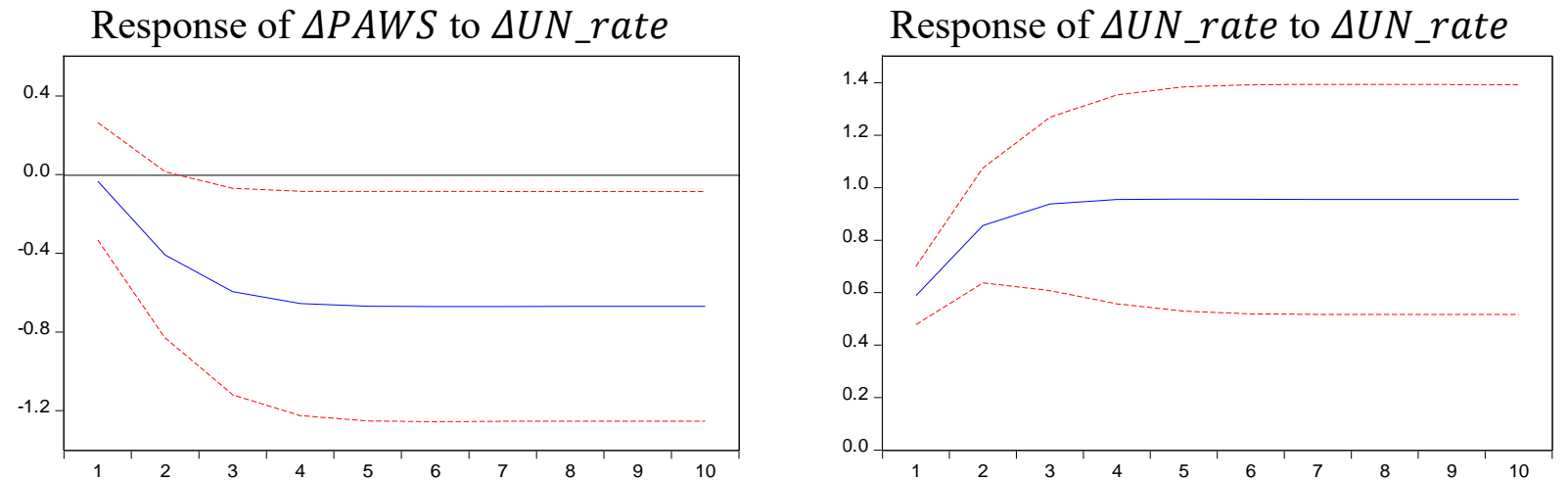

Japan

Response of $\triangle P A W S$ to $\triangle U N \_r a t e$
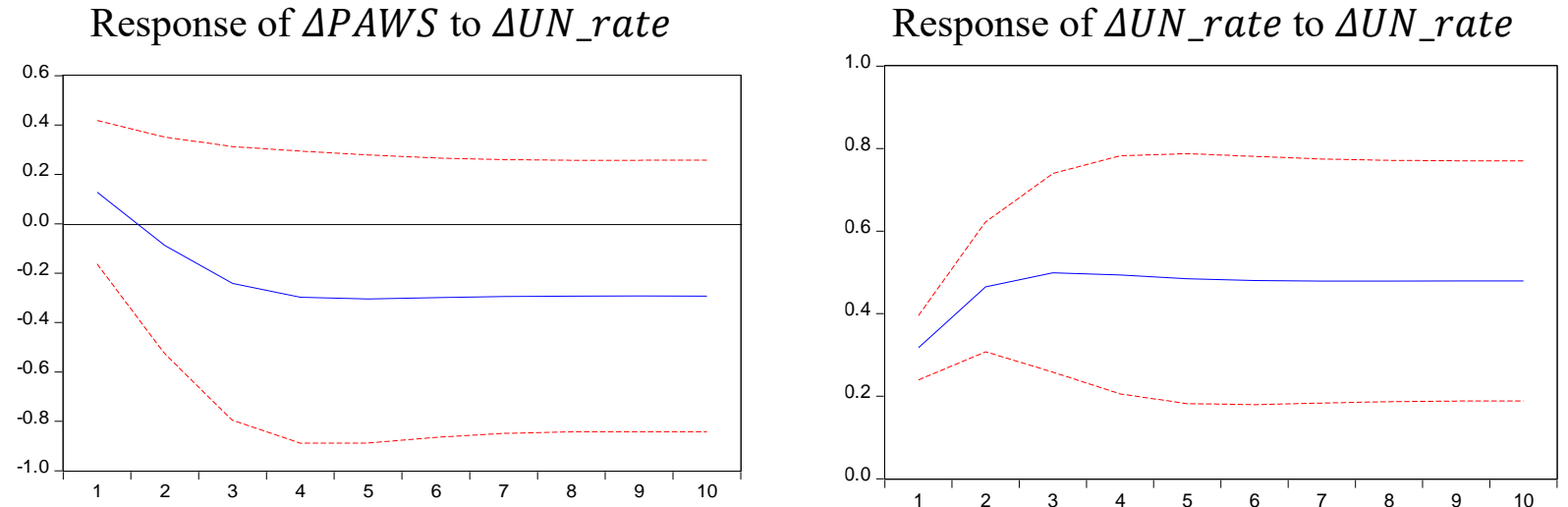

Spain

Response of $\triangle P A W S$ to $\triangle U N \_r a t e$

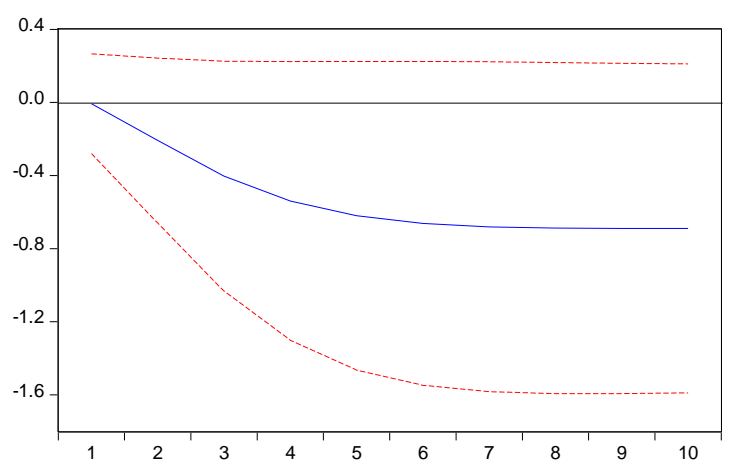

Response of $\Delta U N \_r a t e$ to $\Delta U N \_r a t e$

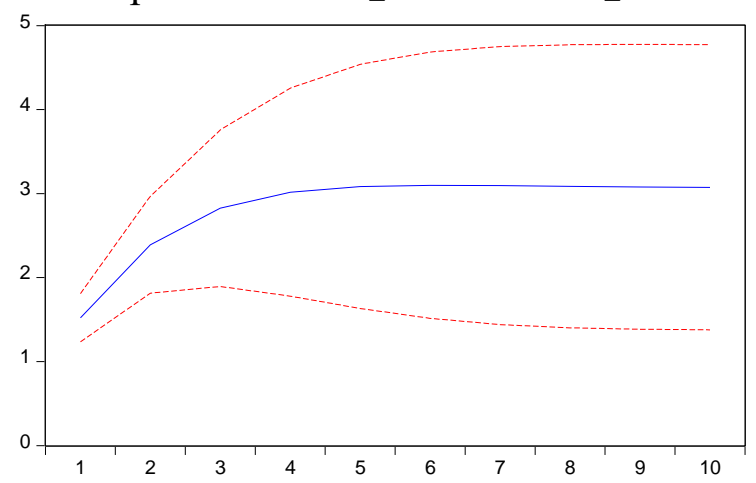

Sweden

Response of $\triangle P A W S$ to $\triangle U N \_r a t e$

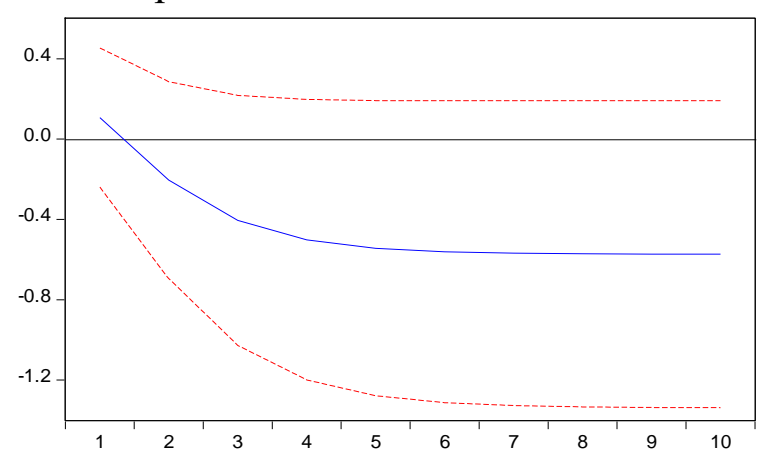

Response of $\Delta U N_{-} r a t e$ to $\Delta U N \_r a t e$

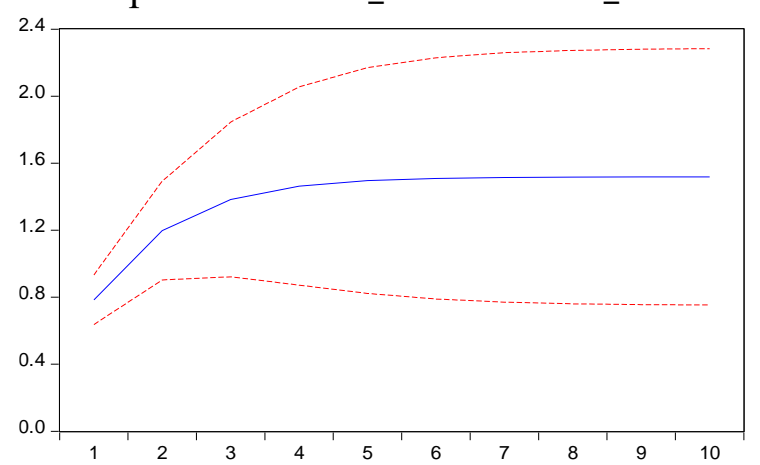




\section{United Kingdom}
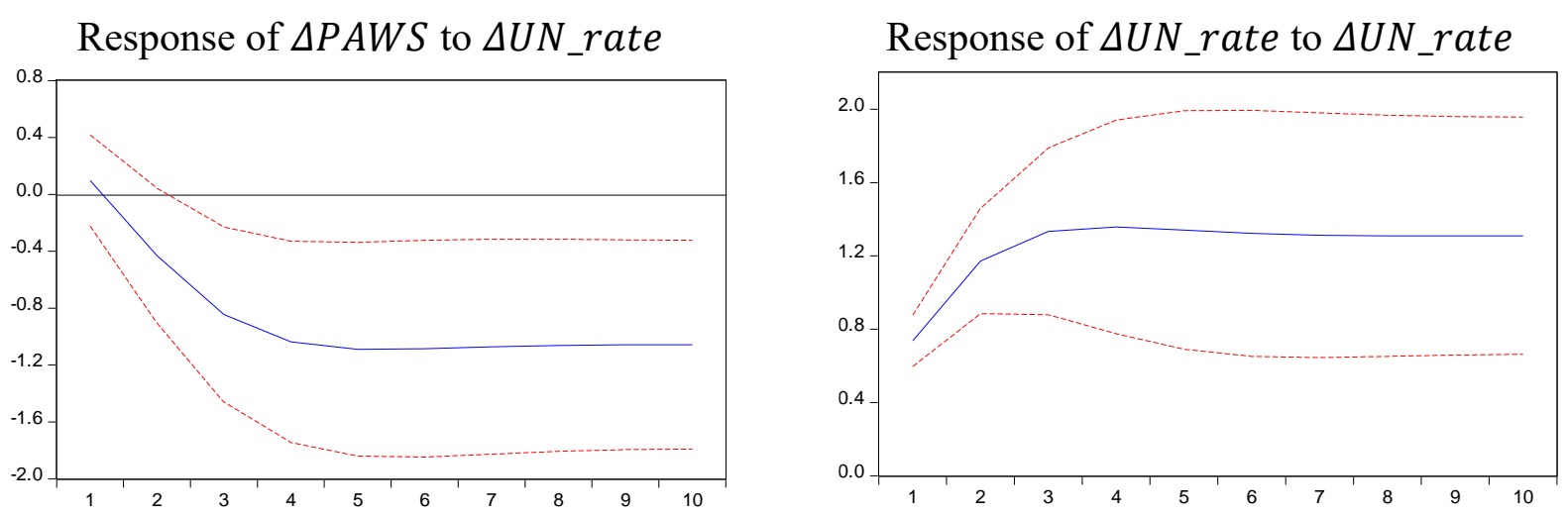

United States

Response of $\triangle P A W S$ to $\triangle U N \_$rate

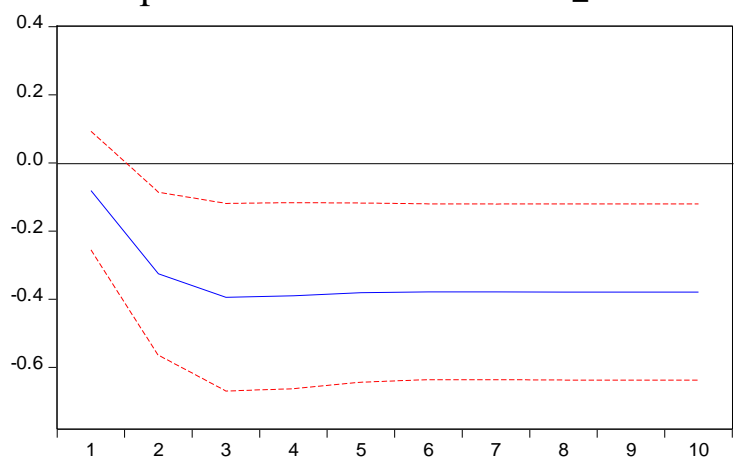

Response of $\Delta U N \_r a t e$ to $\Delta U N \_r a t e$

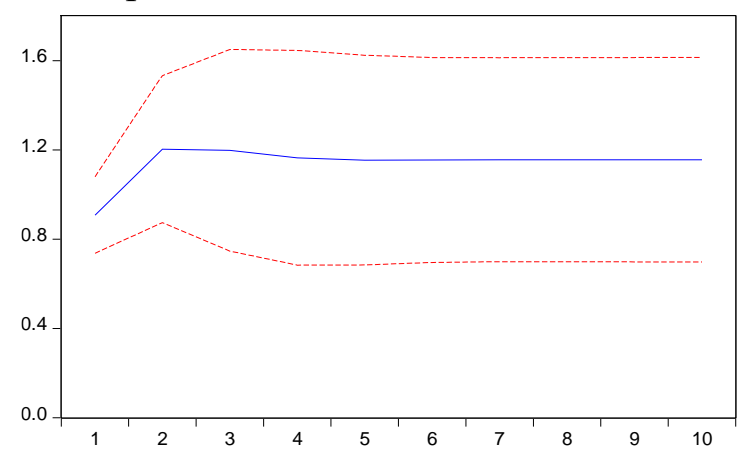

All panels

Response of $\triangle P A W S$ to $\triangle U N \_$rate

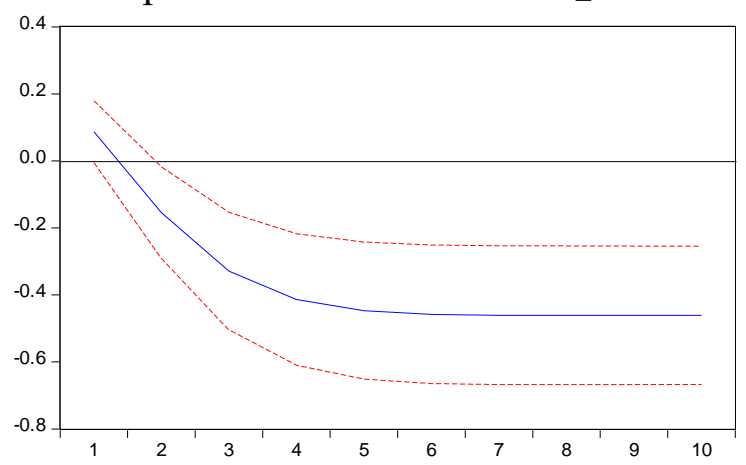

Response of $\Delta U N \_r a t e$ to $\Delta U N \_r a t e$

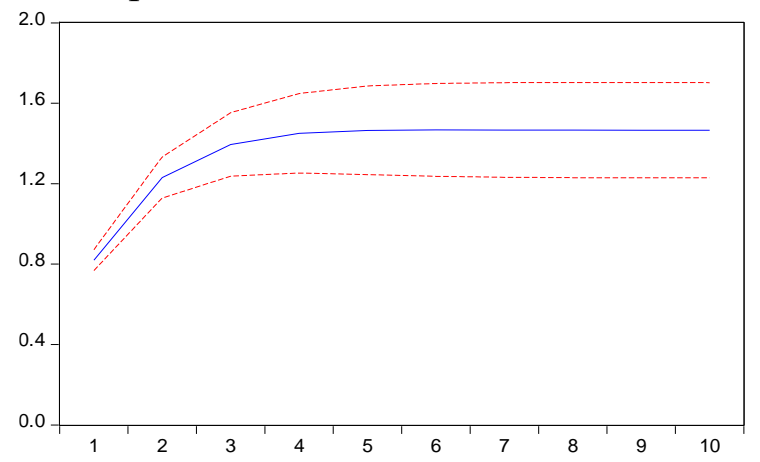

The figures in the left column depict the IRFs of the private sector adjusted wage share ( $\triangle P A W S$ ) to shock on unemployment rate $\left(\Delta U N_{-}\right.$rate), while those in the right column show the dynamic behavior of the unemployment rate after its initial shock. Cumulated responses to structural shocks are reported with two-standard error bound (95\% confidence interval, dashed lines). 


\section{Figure 3.2}

Cumulated response of the private sector adjusted wage share to shocks in the unemployment rate and in the unemployment intensity (shorter timespan)

Figure 3.2a. Unemployment rate

\section{United States (1968-2017)}
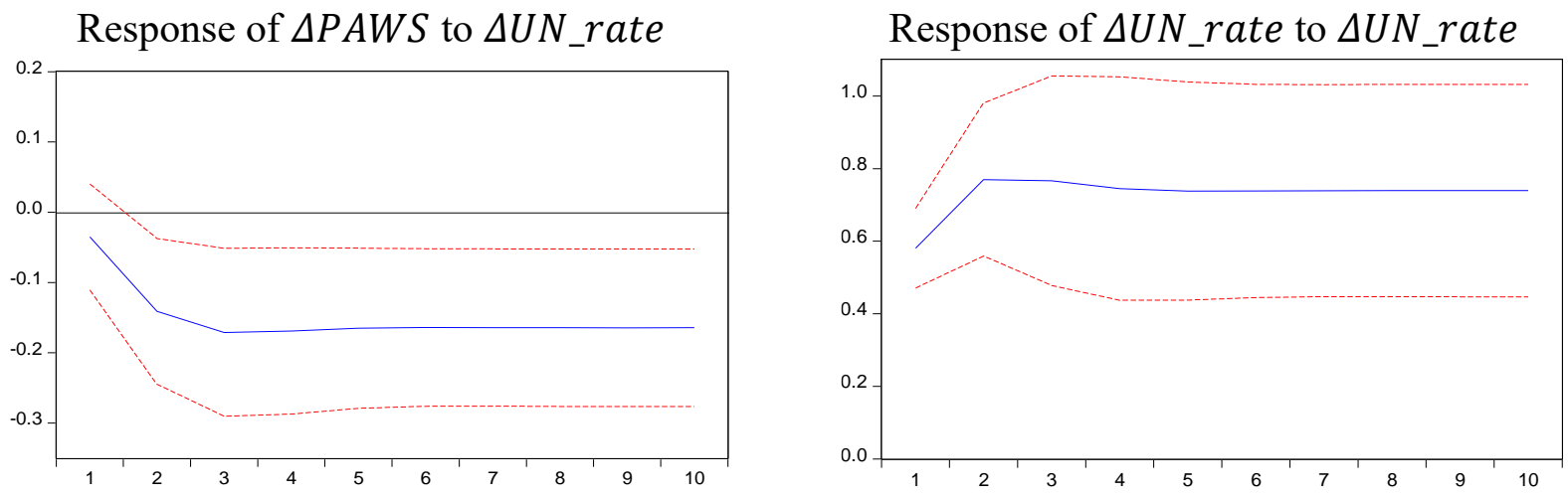

All panels (different timespans)

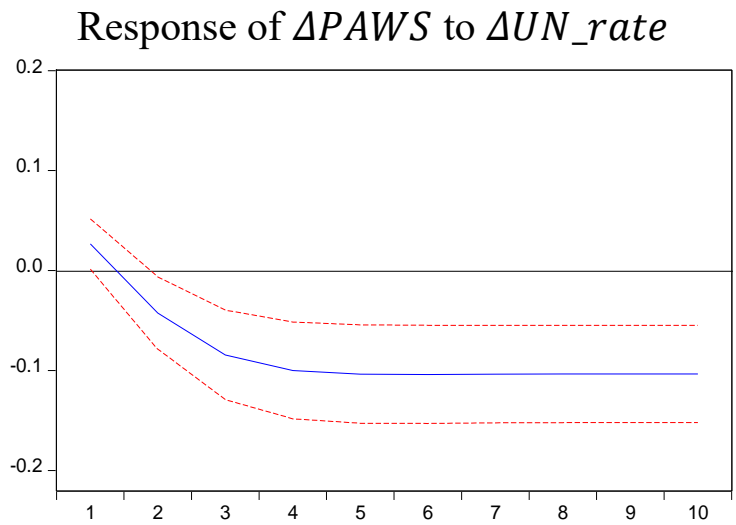

Response of $\Delta U N_{-}$rate to $\Delta U N_{-}$rate

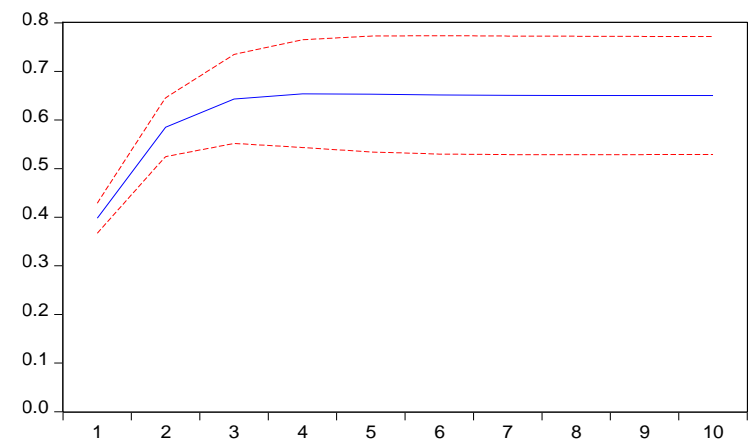

The figures in the left column depict the IRFs of the private sector adjusted wage share ( $\triangle P A W S)$ to shock on unemployment rate $\left(\triangle U N_{-}\right.$rate), while those in the right column show the dynamic behavior of the unemployment rate after its initial shock. Cumulated responses to structural shocks are reported with two-standard error bound (95\% confidence interval, dashed lines). 
United States (1968-2017)
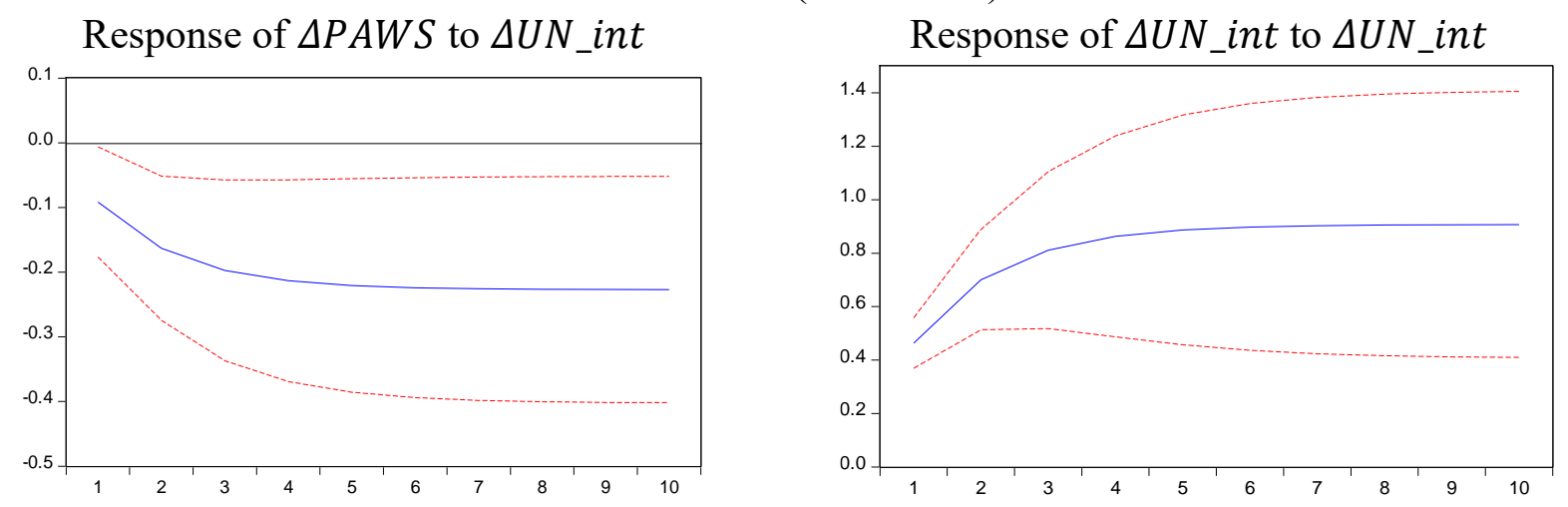

All panels (different timespans)
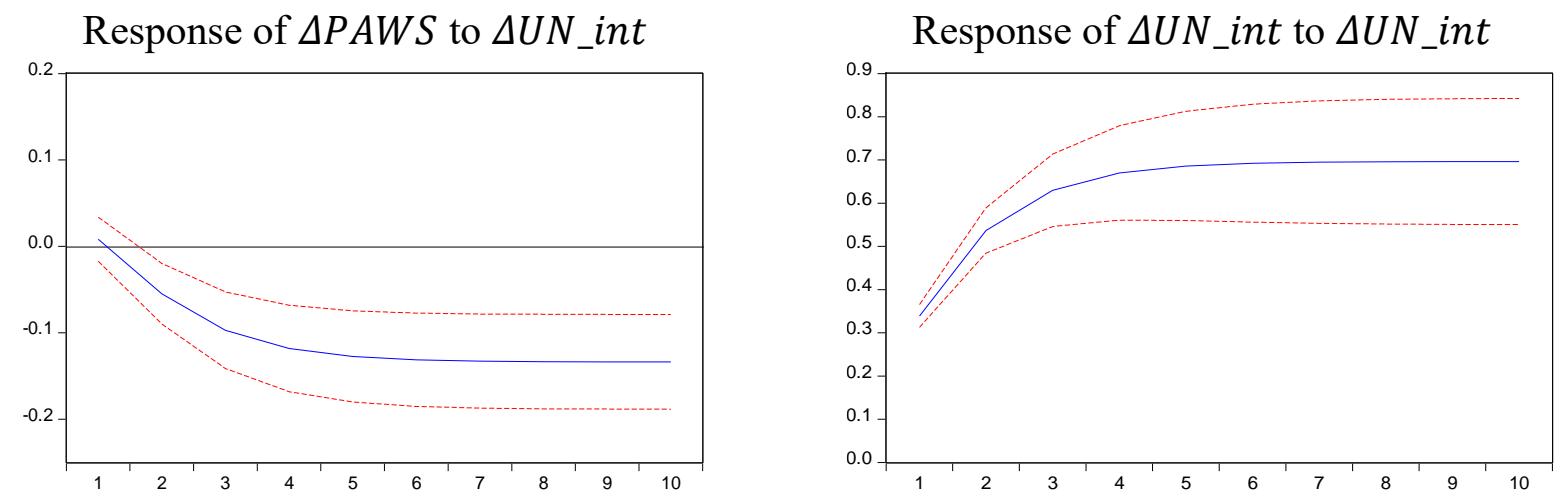

The figures in the left column depict the IRFs of the private sector adjusted wage share ( $\triangle P A W S)$ to a shock on unemployment intensity ( $\Delta U N_{-}$int), while those in the right column show the dynamic behavior of the unemployment intensity after its initial shock. Cumulated responses to structural shocks are reported with two-standard error bound (95\% confidence interval, dashed lines).

We propose also a juxtaposition between the unemployment rate and the unemployment intensity for the United States (the only country with a sufficiently long number of observations concerning the unemployment duration, that is, from 1968 to 2017) and the whole sample of countries. In doing so, we normalize the series of unemployment rate and unemployment intensity by applying the same strategy followed in Section 5.2 (cf. footnote 27). These results are presented in Figure 3.2, where we confine the analysis to the shorter time-span for which unemployment intensity can be calculated. The IRFs indicate that innovations in both the $U N_{-}$rate and the $U N_{-} i n t$ have a negative impact on the PAWS of comparable size. The IRFs exhibit the same dynamic pattern discussed above, confirming a stabilization after three (US) or five (panel) years after the initial shock, independently of the measures used. The persistence of the changes in labor market slack is also confirmed.

We are also interested in quantifying the magnitude of the overall effects. To do so, in Table 4, we report the cumulative response of the change in PAWS per unit increase in the considered measure 
of unemployment. Technically, we estimate these responses by dividing the cumulative variation of $P A W S$ for the cumulative change in the measure of unemployment. Therefore, at each time horizon, the cumulative dynamic coefficients for the unemployment rate $\left(\varepsilon_{U N \_r a t e}\right)$ reported in Table 4.1 are computed as in equation (18):

$\varepsilon_{U N_{-} \text {rate }}=\frac{\sum_{j=0}^{n} \Delta P A W S_{(t+j)}}{\sum_{j=0}^{n} \Delta U N_{-} \text {rate }_{(t+j)}}$

while the cumulative dynamic coefficients with respect to the unemployment intensity $\left(\varepsilon_{U N_{-} i n t}\right)$ reported in Table 4.2 are computed as in equation (19):

$\varepsilon_{U N_{-} i n t}=\frac{\sum_{j=0}^{n} \Delta P A W S_{(t+j)}}{\sum_{j=0}^{n} \Delta U N_{-} i n t_{(t+j)}}$

\section{Table 4. SVAR analysis}

Table 4.1. Cumulative dynamic coefficient of the change in the private sector adjusted wage share to changes in unemployment rate (1960-2017)

\begin{tabular}{lcccccc}
\hline$\Delta P A W S$ & Shock & year 1 & year 2 & year 5 & year 10 & average \\
\hline Canada & $\Delta U N \_r a t e$ & $\mathbf{0 . 4 7 3}$ & 0.158 & 0.043 & 0.046 & 0.099 \\
France & $\Delta U N \_r a t e$ & 0.494 & 0.205 & -0.040 & -0.061 & 0.042 \\
Germany & $\Delta U N \_r a t e$ & 0.343 & -0.049 & $\mathbf{- 0 . 3 3 2}$ & $\mathbf{- 0 . 3 2 2}$ & -0.220 \\
Italy & $\Delta U N \_r a t e$ & -0.057 & $\mathbf{- 0 . 4 7 7}$ & $\mathbf{- 0 . 7 0 0}$ & $\mathbf{- 0 . 7 0 1}$ & -0.606 \\
Japan & $\Delta U N \_r a t e$ & 0.404 & -0.189 & -0.629 & -0.610 & -0.457 \\
Spain & $\Delta U N \_r a t e$ & -0.005 & $-0-087$ & -0.201 & -0.224 & -0.172 \\
Sweden & $\Delta U N \_r a t e$ & 0.137 & -0.171 & -0.363 & -0.378 & -0.291 \\
United Kingdom & $\Delta U N \_r a t e$ & 0.132 & $\mathbf{- 0 . 3 6 7}$ & $\mathbf{- 0 . 8 1 2}$ & $\mathbf{- 0 . 8 0 7}$ & -0.651 \\
United States & $\Delta U N \_r a t e$ & -0.089 & $\mathbf{- 0 . 2 7 0}$ & $\mathbf{- 0 . 3 3 0}$ & $\mathbf{- 0 . 3 2 8}$ & -0.299 \\
All panels & $\Delta U N \_r a t e$ & 0.106 & $\mathbf{- 0 . 1 2 6}$ & $\mathbf{- 0 . 3 1 2}$ & $\mathbf{- 0 . 3 1 4}$ & -0.242 \\
\hline
\end{tabular}

Significant estimates at 95\% level are indicated in bold; average is the simple mean throughout the 10-years window.

The coefficients reported in Table 4.1 indicate that on average over the 1960-2017 period, the larger magnitude of the cumulated response holds for the United Kingdom (-0.81 in a 5-year window). A similar response in the 5-year window is observed for Italy $(-0.70)$ and Japan $(-0.63)$, while it is smaller in size but statistically significant in the United States (-0.33), Sweden (-0.36), Germany $(-0.33)$ and Spain (-0.20). In a 10-year window, the impact is virtually unchanged. A virtually zero coefficient is estimated for Canada and France. When the entire set of countries is considered 
together, the significance of the relationship increases and is verified at all time horizons after the initial shock, with a depressing impact of increasing labor market slack on the PAWS that reaches -0.31 in the 5-year window, and then stabilizes.

Table 4.2. Cumulative dynamic coefficient of the change in the private sector adjusted wage share to changes in unemployment rate and unemployment intensity (comparison of coefficients)

\begin{tabular}{lcccccc}
\hline$\Delta$ PAWS & Shock & year 1 & year 2 & year 5 & year 10 & average \\
\hline \multirow{2}{*}{ United States } & $\Delta U N_{-}$rate & -0.066 & $\mathbf{- 0 . 1 8 8}$ & $\mathbf{- 0 . 2 2 7}$ & $\mathbf{- 0 . 2 2 6}$ & -0.206 \\
& $\Delta U N_{-}$int & $\mathbf{- 0 . 1 9 8}$ & $\mathbf{- 0 . 2 3 3}$ & $\mathbf{- 0 . 2 4 9}$ & $\mathbf{- 0 . 2 5 0}$ & -0.242 \\
\multirow{2}{*}{ All panels } & $\Delta U N_{-}$rate & $\mathbf{0 . 0 6 7}$ & $\mathbf{- 0 . 0 7 3}$ & $\mathbf{- 0 . 1 5 9}$ & $\mathbf{- 0 . 1 5 9}$ & -0.124 \\
& $\Delta U N_{-}$int & 0.024 & $\mathbf{- 0 . 1 0 2}$ & $\mathbf{- 0 . 1 8 6}$ & $\mathbf{- 0 . 1 9 2}$ & -0.184 \\
\hline \multicolumn{2}{l}{ Significant estimates at $95 \%$ level are indicated in bold; average is the simple mean throughout the 10-years window. }
\end{tabular}

Finally, Table 4.2 compares the coefficients stemming from the two measures of unemployment for the United States and the panel analysis. The same warning introduced in Section 5.2 should be brought up here: dealing with normalized series, our estimations do not permit interpreting the size of the coefficients in absolute terms, but only compare their relative size. The five-year cumulative response in the United States is only very marginally higher when a shock on the UN_int $(-0.25)$ occurs instead of one on the $U N_{-}$rate $(-0.23)$. This is true also when we consider the nine countries as a panel (-0.19 for the unemployment intensity and -0.16 for the unemployment rate).

To test the robustness of our findings, in Appendix F we replicate the panel-SVAR analysis to some subsets of years and countries. Similar to what was done in Section 5.2, we first consider two sub-periods separately to disentangle different policy regimes. The results of this test are reported in Figure F1: the estimated cumulative dynamic coefficient at a 10 -years horizon is about -0.55 in the first sub-period (1960-1980), while it settles at approximately -0.3 afterwards. ${ }^{34}$ While this result may appear somewhat surprising, it should be considered that the panel-average unemployment rate is approximately $3.5 \%$ in the first subperiod and $8.25 \%$ in the second one. Accordingly, our results are consistent with the possibility that the downward pressure on the wage share stemming from changes in the unemployment rate may differ depending on the level of unemployment (and possibly an already attained very low or zero growth of wages).

Second, we consider two subsets of countries which, at least in principle, belong to similar universes in terms of institutional and macroeconomic features. To do so, we leave out Japan (due to its very low unemployment rate) and Sweden (the only country belonging to the Scandinavian tradition), and we pool data for Anglo-Saxon countries on the one hand (Canada, United Kingdom

\footnotetext{
${ }^{34}$ Similar to what has been done in Table 4, these two coefficients have been calculated by applying equation (18) to the values reported in Figure F1a and F1b, respectively.
} 
and United States) where the labor market is generally more flexible, and Continental European/Mediterranean countries on the other hand (France, Germany, Italy and Spain), where labor market institutions in favor of workers are commonly stronger. The results of this exercise of clustering are reported in Figure F2. This evidence indicates relevant differences between macromodels: in fact, the average 10-year coefficient is -0.49 for Anglo-Saxon countries, while -0.24 for the selected European economies, ${ }^{35}$ confirming the intuition that in addition to labor market slack institutional and macro-economic factors may also matter..

\section{Summary and conclusions}

The empirical explorations carried out in this paper take some inspiration from Shaikh's work, and, following it, we test for the existence of a lasting influence on income distribution of persistent changes in both the unemployment rate and an index of unemployment intensity that considers unemployment duration as well. Despite the fact that most of the changes in the wage share are in the negative quadrant, our explorations show that a 'structural' Phillips-type relationship between unemployment rate or unemployment intensity and the pace of change of the wage share in the private sector is remarkable for the US, Italy and Germany; more moderate in France and Japan and exists for sub-periods in the United Kingdom and Spain; while it cannot be detected in Canada and Sweden. We then explore whether a long-run relationship between the two unemployment measures and the wage share taken in levels or prime differences can be detected using other econometric tools. To do so, we make use of three different empirical strategies, each one capable of identifying the long-term correlation from a different angle. Overall, our findings confirm the depressing impact of increasing labor market slack on the wage share for almost all countries (i.e., except Canada and mixed results concerning France), albeit with varying statistical significance and economic magnitude. Accordingly, our empirical explorations suggest that the classical view that lasting changes in labor market conditions tend to have persistent effects on income distribution is confirmed, although with the rather predictable aforementioned exceptions and varieties - given the role of other influences (institutions, politics) on the bargaining position of the workers. This appears to have some interesting theoretical implications for the analysis of income distribution, namely, that bargaining power - and hence the actions undertaken by all the parties involved - does matter. This appears to be in contrast with some non-mainstream literature and models assuming that firms can fix their mark-up according to their own strategic aims or product-market conditions regardless of workers claims (with the latter affecting inflation, but unable to alter income distribution); it also conflicts with the notion that interest rate fixing on the part of central banks is the sole or main determinant of profit rates.

\footnotetext{
${ }^{35}$ Coefficients are calculated on the basis of Figure F2a and F2b (cf. footnote 34).
} 
Our empirical results may also provide some indications about the shape of the relationship between unemployment and the wage share, discussed in Section 2. On the one hand, the statistical analysis of filtered data along the lines of Shaikh's example indicates that the pace of change of the wage share often reflects the size of unemployment or unemployment intensity, at least within a certain range of the unemployment level, while the relationship tends to weaken for persistently very high levels of unemployment (when real wages growth is close to zero, the rate of change in the wage share depends on the rate of growth in productivity, a factor relatively independent of the unemployment size). On the other hand, the following results emerge from our econometric exploration: i) ARDL time series analyses suggest that changes in unemployment tend to determine long-period changes in the wage share, with coefficients over the period ranging between -0.2 and -0.8 across countries; ii) the panel-based exploration suggests an average long-run relation between unemployment and the wage share taken in levels ranging between -0.7 and -1.3 ; iii) the impulse response functions indicate a range of the impact of a one percentage point increase in the unemployment rate, after five years, between -0.3 and -0.8 , with a subsequent stabilization of the impact, thus suggesting that after a number of years, the wage share stabilizes at a lower level. We use the IRFs also to test differences according to institutional models by grouping Anglo-Saxon countries on the one hand and European on the other: the results confirm the expected higher impact of unemployment on the wage share in the former group, although there is also wide within-group heterogeneity versus similarities across institutional models.

Concerning the comparative impact of the unemployment rate and the index of unemployment intensity, the latter appears to perform remarkably better in 'explaining' the pace of changes in the wage shares only in the United States and Italy, and exhibits very similar coefficients between the two countries, which runs counter to the usual view that the two economies differ widely in terms of wage flexibility. ${ }^{36}$ In all other cases, the two measures of unemployment have similar coefficients.

The United States, Italy, the United Kingdom and, to a more limited extent, Germany also turn out to be the countries where the estimated relationships between unemployment and the wage share are economically and statistically the most significant. This again is an interesting result, which contrasts with the often-claimed greater rigidity of the Italian (and German) labor market and wagesetting process with respect to the Anglo-Saxon model, often regarded, in the case of Italy, as a major cause of high unemployment.

\footnotetext{
${ }^{36}$ Very speculative considerations might be advanced in this regard. The first is that both countries differ from other European mature economies for not having much 'active labor market policies': these most often involve training activities that (somew hat fictitiously) interrupt the measured unemployment spells of individuals; it may thus be the case that the duration measure is altered in other countries by these activities and does not fully capture the degree of labor market slack. The second one, also very tentative, is that perhaps in both countries there are sections of the labor force existing in very difficult labor markets where unemployment duration can become very high (the Southern regions, in the case of Italy).
} 
On the whole, while they are significant both from the economical and statistical point of view, the estimated impacts of unemployment on the wage share do not appear to be of a size capable of explaining the entire extension of the actually observed changes in income shares. This on the one hand tends to confirm an independent role for other institutional and structural factors already discussed in the literature (see Section 1) and, on the other hand, suggests further explorations concerning the possibility that other dimensions of labor market conditions may have an impact (for example, participation rates and the size of the underemployed). In this regard, attention should also be paid to the changing features of underemployment: for instance, before the 1980s the slack in the labor market was mainly associated with low female participation, while post-1980 this slack has often taken the form of part-time, under-employed and discouraged workers, in a context of weakening labor protection.

Another interesting result is that in our analyses we have not detected any indications that there is an endogenous spontaneous economic mechanism tending to cause a reversion of the economy toward a 'normal' unemployment rate, to use Shaikh's terminology. We found that the unemployment rate and the unemployment intensity are not stationary nor trend-stationary (which would be consistent with a moving 'attractor') and in addition that their average values have increased considerably after the 1980 s, while according to the theory the 'normal unemployment' should have become lower, owing to the weakening of pro-labor institutions. Hence, although possibly not conclusive, the evidence is not supportive of the notion.

According to Shaikh, the long-term tendency towards the 'normal unemployment rate' would be based on a strong connection between profitability and accumulation. Our results contribute to casting some doubts concerning the existence of such a strong and systematic connection. This does not mean that persistently low or high unemployment rates cannot then set in motion reactions in the economic, social, and political spheres that will affect labor market conditions and income distribution. However, the routes may be more complex than suggested by the profit-investment nexus, and may involve strategic and political actions, with no clear-cut and foreseeable consequences concerning the final outcomes and the time-spans involved.

This is particularly the case if one considers that unemployment would largely depend on aggregate demand management, involving fiscal and monetary policy. These may have to respond to a variety of objectives besides the conflict over income distribution, however important the latter may be. For example, military expenditure and public funding of research are connected to geo-political strategies; monetary policy takes care of financial and international conditions (for example, sustainable pension funds or public debt, exchange rates). Based also on the post-war experience in mature economies, one might argue that persistently low unemployment rates, increasing wage shares 
and intense distributive conflict induced firm-level reactions seeking to reduce workers' militancy by means of reorganization of the labor process and automation - which, however, were made possible by the availability of production techniques permitting such changes at no profit losses. In parallel, there has been a reorganization of political pressure and action toward changes in macroeconomic policies and labor regulations that have increased unemployment and altered the institutional set-up.

On the other hand, in Europe, a persistently high unemployment rate, though causing impoverishment, social discontent and, perhaps, particularly in the post-2008 period, political changes associated with those issues, is not necessarily leading to changes in aggregate demand by means of macroeconomic policies or even by other channels, such as investment or net exports, which can bring about higher employment levels. In Europe, unemployment rates rose considerably in the 1980s and remained very high for quite a long period. Even when they then decreased, in most countries they have never again reached the low rates of the 1960s and early 1970s.

There are of course other reasons that can limit the range of variation of the unemployment rate in the strict sense (i.e., defined as unemployed actively seeking jobs), besides those that depend on the demand side, which are recognized in Shaikh's book, but most often overlooked by mainstream economists. A persistent lack of employment opportunities may induce adjustments on the supply side, particularly in the form of reductions in participation rates and migration outflows, or the increase in forms of underemployment such as involuntary part-time or low-income self-employment. Similarly, economic growth and the consequent sustained labor demand can stimulate increased participation and migration inflows, as well as a reduction in underemployment. Thus, even a relative stability of unemployment rates cannot be taken as evidence of the existence of adjustment mechanisms of actual employment to labor supply rather than the other way around. 


\section{References}

Acemoglu, D. (1998). Why do new technologies complement skills? Directed technical change and wage inequality. The Quarterly Journal of Economics, 113(4), 1055-1089.

Acemoglu, D. (2003). Labor-and capital-augmenting technical change. Journal of the European Economic Association, 1(1), 1-37.

Acemoglu, D., \& Restrepo, P. (2018). The race between man and machine: Implications of technology for growth, factor shares, and employment. American Economic Review, 108(6), 1488-1542.

Autor, D., Dorn, D., Katz, L. F., Patterson, C., \& Van Reenen, J. (2017). Concentrating on the Fall of the Labor Share. American Economic Review, 107(5), 180-85.

Ball, L. M. (1999). Aggregate demand and long-run unemployment. Brookings Papers on Economic Activity, vol. 1999, no. 2, 189-251.

Baltagi, B. H., \& Pesaran, M. H. (2007). Heterogeneity and cross section dependence in panel data models: theory and applications introduction. Journal of Applied Econometrics, 22(2), 229-232.

Barkai, S. (2019). Declining Labor and Capital Shares. Journal of Finance, Forthcoming. Available at SSRN: https://ssrn.com/abstract=3489965.

Bassanini, A., \& Manfredi, T. (2014). Capital's Grabbing Hand? A Cross- industry Analysis of the Decline of the Labor Share in OECD Countries. Eurasian Business Review, 4, 3-30.

Basu, S. (1996). Procyclical productivity: increasing returns or cyclical utilization?. The Quarterly Journal of Economics, 111(3), 719-751.

Basu, D., \& Foley, D. K. (2013). Dynamics of output and employment in the US economy. Cambridge Journal of Economics, 37(5), 1077-1106.

Bengtsson, E. (2014). Do unions redistribute income from capital to labour? Union density and labour's share since 1960. Industrial Relations Journal, 45(5), 389-408.

Bentolila, S., \& Saint-Paul, G. (2003). Explaining Movements in the Labor Share. The B.E. Journal of Macroeconomics, 3(1), 1-33.

Beqiraj, E., Fanti, L., \& Zamparelli, L. (2019). Sectoral composition of output and the wage share: The role of the service sector. Structural Change and Economic Dynamics, 51, 1-10.

Blecker, R. A. (2016). The US economy since the crisis: slow recovery and Secular Stagnation. European Journal of Economics and Economic Policies: Intervention, 13(2), 203-214.

Brancaccio, E., Garbellini, N., \& Giammetti, R. (2018). Structural labour market reforms, GDP growth and the functional distribution of income. Structural Change and Economic Dynamics, 44(C), 34 45 .

Cesaratto, S. (2015). Neo-Kaleckian and Sraffian controversies on the theory of accumulation. Review of Political Economy, 27(2), 154-182.

Cynamon, B. Z., \& Fazzari, S. M. (2016). Inequality, the Great Recession and slow recovery. Cambridge Journal of Economics, 40(2), 373-399.

Deakin, S., Malmberg, J., \& Sarkar, P. (2014). How do labour laws affect unemployment and the labour share of national income? The experience of six OECD countries, 1970-2010. International Labour Review, 153(1), 1-27.

Deleidi, M. (2018). Post Keynesian endogenous money theory: A theoretical and empirical investigation of the credit demand schedule. Journal of Post Keynesian Economics, 41(2), 185-209. 
Deleidi, M., Paternesi Meloni, W. \& Stirati, A. (2019). Tertiarization, productivity and aggregate demand: evidence-based policies for European countries. Journal of Evolutionary Economics, online first article, DOI: 10.1007/s00191-019-00647-6.

Dünhaupt, P. (2017). Determinants of labour's income share in the era of financialisation. Cambridge Journal of Economics, 41(1), 283-306.

Elsby, M. W. L., Hobijn, B., \& Şahin, A. (2013). The Decline of US Labor Share. Paper prepared for the Brookings Panel on Economic Activity, September 2013.

Franzini, M., \& Pianta, M. (2015). Explaining inequality. Routledge, Taylor and Francis Group. London and New York.

Girardi, D., \& Pariboni, R. (2020). Autonomous demand and the investment share. Review of Keynesian Economics, 8(3), 428-453.

Girardi, D., Paternesi Meloni, W., \& Stirati, A. (2020). Reverse hysteresis? Persistent effects of autonomous demand expansions. Cambridge Journal of Economics, 44(4), 835-869.

Gollin, D. (2002). Getting income shares right. Journal of Political Economy, 110(2), 458-474.

Guscina, A. (2006). Effects of globalization on labor's share in national income. International Monetary Fund, Working Paper No. 06/294.

Hamilton, J. D. (2018). Why You Should Never Use the Hodrick-Prescott Filter. Review of Economics and Statistics, 100(5), 831-843.

Hein, E. (2014). Distribution and growth after Keynes: A Post-Keynesian guide. Edward Elgar Publishing.

Hein, E. (2015). Finance-dominated capitalism and re-distribution of income: a Kaleckian perspective. Cambridge Journal of Economics, 39(3), 907-934.

Hein, E. (2017). Financialisation and tendencies towards stagnation: The role of macroeconomic regime changes in the course of and after the financial and economic crisis 2007-9 (No. 90/2017). Working Paper, Institute for International Political Economy Berlin.

Hein, E., \& Prante, F. (2018). Functional distribution and wage inequality in recent Kaleckian growth models (No. 110/2018). Working Paper, Institute for International Political Economy Berlin.

Hein, E., \& Vogel, L. (2008). Distribution and growth reconsidered: empirical results for six OECD countries. Cambridge Journal of Economics, 32(3), 479-511.

Hein, E., Paternesi Meloni, W., \& Tridico, P. (2020). Welfare models and demand-led growth regimes before and after the financial and economic crisis. Review of International Political Economy, online first article, DOI: 10.1080/09692290.2020.1744178.

Hicks, J. R. (1964). The Theory of Wages. London, MacMillan and Company.

Hodrick, R. J., \& Prescott, E. C. (1997). Postwar U.S. Business Cycles: An Empirical Investigation. Journal of Money, Credit, and Banking, 29(1), 1-16.

Hogrefe, J., \& Kappler, M. (2013). The labour share of income: heterogeneous causes for parallel movements?. The Journal of Economic Inequality, 11(3), 303-319.

Hutchinson, J., \& Persyn, D. (2012). Globalisation, concentration and footloose firms: in search of the main cause of the declining labour share. Review of World Economics, 148(1), 17-43.

ILO (2019). The Global Labour Income Share and Distribution. Methodological description, ILO Department of Statistics, Geneva, July 2019.

IMF (2012). World Economic Outlook: Growth Resuming, Dangers Remain. Washington, April. 
IMF (2017). Understanding the downward trend in labor income shares. In: World Economic Outlook: Gaining Momentum?

Jayadev, A. (2007). Capital account openness and the labour share of income. Cambridge Journal of Economics, 31(3), 423-443.

Karabarbounis, L., \& Neiman, B. (2014). The global decline of the labor share. The Quarterly Journal of Economics, 129(1), 61-103.

Khotari, S. P., Lewellen, J., \& Warner, J. B. (2014). The Behaviour of Aggregate Corporate Investment. MIT Sloan School, Research Paper No. 5112-14.

Koh, D., Santaeulalia-Llopis, R., \& Zheng, Y. (2016). Labor share decline and intellectual property products capital. Available at SSRN: https://ssrn.com/abstract $=2546974$.

Kristal, T. (2010). Good times, bad times: postwar labor's share of national income in capitalist democracies. American Sociological Review, 75(5), 729-63.

Krueger, A. B. (1999). Measuring labor's share. American Economic Review, 89(2), 45-51.

Lavoie, M. (2016). Convergence towards the Normal rate of capacity utilization in neo-Kaleckian models: the role of non-capacity creating autonomous expenditures. Metroeconomica, 67(1), 172201.

Lazonick, W. (2014). Profits without prosperity. Harvard Business Review, 92(9), 46-55.

Lazonick, W. and O'Sullivan, M. (2000). Maximizing shareholder value: a new ideology for corporate governance. Economy and Society, 29(1), 13-35.

Llaudes, R. (2005). The Phillips Curve and Long-term Unemployment. European Central Bank Working Paper No. 441 (February).

Martinez, J. (2018). Automation, growth and factor shares. Society for Economic Dynamics, Meeting Papers, Vol. 736.

Millemaci, E., \& Ofria, F. (2014). Kaldor-Verdoorn's law and increasing returns to scale. Journal of Economic Studies, 41(1), 140-62.

Mohr, M. F. (2006). The Missing Cycle in the HP Filter and the Measurement of Cyclically-Adjusted Budget Balances (March 30, 2006). Available at SSRN: https://ssrn.com/abstract=2005022.

Naastepad, C. W. M., \& Storm, S. (2006). OECD demand regimes (1960-2000). Journal of Post Keynesian Economics, 29(2), 211-246.

Nickell, S. (1981). Biases in dynamic models with fixed effects. Econometrica: Journal of the Econometric Society, 1417-1426.

Obst, T., Onaran, Ö., \& Nikolaidi, M. (2017). The effect of income distribution and fiscal policy on growth, investment, and budget balance: the case of Europe. FMM Working Paper No. 10.

OECD (2012). Labour Losing to Capital: What Explains the Declining Labour Share? In: OECD Employment Outlook 2012, 109-161.

OECD (2018), Decoupling of wages from productivity: What implications for public policies?. In: OECD Economic Outlook, November.

Okun, A. M. (1962). Potential GNP: Its Measurement and Significance. In: Proceedings of the Business and Economics Statistics Section. American Statistical Association (vol. 89).

Onaran, O. (2011). Globalisation, macroeconomic performance and distribution. In: Hein, E., \& Stockhammer, E. (eds.). A Modern Guide To Keynesian Macroeconomics and Economic Policies. Cheltenham: Edward Elgar, pp. 240-266. 
Özdemir, O. (2019). Financialization and the Labor Share of Income. Review of Economic Perspectives, 19(4), 265-306.

Palley, T. I. (2016). Inequality, the financial crisis and stagnation: competing stories and why they matter. Real World Economics Review, 74, 1-18.

Pariboni, R., \& Tridico, P. (2019a). Structural change, institutions and the dynamics of labor productivity in Europe. Journal of Evolutionary Economics, online first article, DOI: 10.1007/s00191-019-00641y.

Pariboni, R., \& Tridico, P. (2019b). Labour share decline, financialisation and structural change. Cambridge Journal of Economics, 43(4), 1073-1102.

Pariboni, R., Paternesi Meloni, W., \& Tridico, P. (2020). When Melius Abundare Is No Longer True: Excessive Financialization and Inequality as Drivers of Stagnation. Review of Political Economy, online first article, DOI: 10.1080/09538259.2020.1769282.

Paternesi Meloni, W., \& Stirati, A. (2018). A short story of the Phillips curve: from Phillips to Friedman...and back?. Review of Keynesian Economics, 6(4), 493-516.

Pesaran, M. H., \& Shin, Y. (1998). An autoregressive distributed-lag modelling approach to cointegration analysis. Econometric Society Monographs, 31, 371-413.

Pesaran, M. H., \& Smith, R. (1995). Estimating long-run relationships from dynamic heterogeneous panels. Journal of Econometrics, 68(1), 79-113.

Pesaran, M. H., Shin, Y., \& Smith, R. P. (1999). Pooled mean group estimation of dynamic heterogeneous panels. Journal of the American Statistical Association, 94(446), 621-634.

Pivetti, M. (1991). An essay on money and distribution. London, Macmillan.

Rodrik, D. (1997). Has Globalization Gone Too Far?. Washington, DC: Institute of International Economics.

Rognlie, M. (2016). Deciphering the fall and rise in the net capital share: accumulation or scarcity?. Brookings papers on economic activity, 2015(1), 1-69.

Romer, D. (2006). Advanced Macroeconomics (third edition). New York: McGraw Hill.

Rusticelli, E. (2014). Rescuing the Phillips curve: making use of long-term unemployment in the measurement of the NAIRU. OECD Journal Economic Studies, vol. 2014, no. 1.

Schoder, C. (2014). Effective Demand, Exogenous Normal Utilization and Endogenous Capacity in the Long Run: Evidence from a Cointegrated Vector Autoregression Analysis for the USA. Metroeconomica, 65(2), 298-320.

Shaikh, A. (2016). Capitalism: Competition, conflict, crises. Oxford University Press.

Sharpe, S. A., \& Suarez, G. (2014). The Insensitivity of Investment to Interest Rates: Evidence from a Survey of CFOs. FEDS Working Paper No. 2014-2. Available at SSRN: https://ssrn.com/abstract=2976891.

Stansbury, A., \& Summers, L. H. (2018). Productivity and Pay: Is the Link Broken? Peterson Institute for International Economics, Working Paper No. 18-5. Available at SSRN: https://ssrn.com/abstract=3192609.

Steedman, I. (1992). Questions for Kaleckians. Review of Political Economy, 4(2), 125-151.

Stirati, A. (1992). Unemployment, institutions and the living standard in the classical theory of wages. Contributions to Political Economy, 11(1), 41-66.

Stirati, A. (2001). Inflation, unemployment and hysteresis: an alternative view. Review of Political Economy, 13(4), 427-451. 
Stirati, A. (2016). Real wages in the business cycle and the theory of income distribution: an unresolved conflict between theory and facts in mainstream macroeconomics. Cambridge Journal of Economics, 40(2), 639-661.

Stockhammer, E. (2008). Is the NAIRU theory a monetarist, new Keynesian, post Keynesian or a Marxist theory?. Metroeconomica, 59(3), 479-510.

Stockhammer, E. (2009). Determinants of functional income distribution in OECD countries. IMK Studies 05-2009.

Stockhammer, E. (2013). Wage-led Growth: An equitable strategy for economic recovery. Springer.

Stockhammer, E. (2017). Determinants of the wage share: a panel analysis of advanced and developing economies. British Journal of Industrial Relations, 55(1), 3-33.

Storm, S. (2017). The new normal: Demand, secular stagnation, and the vanishing middle class. International Journal of Political Economy, 46(4), 169-210.

Storm, S., \& Naastepad, C. M. (2012). Macroeconomics beyond the NAIRU. Harvard University Press.

Tori, D., \& Onaran, O. (2017). The effects of financialisation and financial development on investment: evidence from firm-level data in Europe. Greenwich Papers in Political Economy, N. 44.

Tridico, P., \& Paternesi Meloni, W. (2018). Economic growth, welfare models and inequality in the context of globalisation. The Economic and Labour Relations Review, 29(1), 118-139.

van Treeck, T. (2009). The political economy debate on 'financialization' - a macroeconomic perspective. Review of International Political Economy, 16(5), 907-944.

van Treeck, T. (2015). Inequality, the crisis, and stagnation. European Journal of Economics and Economic Policies: Intervention, 12(2), 158-169.

Yellen, J. L. (2017). Inflation, uncertainty, and monetary policy. Business Economics, 52(4), 194-207. 
APPENDICES

\section{Appendix A. Data and sources}

\begin{tabular}{|c|c|}
\hline Variable & Definition and source \\
\hline $\begin{array}{l}\text { Adjusted wage share } \\
(A W S)\end{array}$ & $\begin{array}{l}\text { Adjusted wage share (\% of GDP). } \\
\text { Source: Ameco database. } \\
\text { Note. Series have been integrated with the ILO database (labour } \\
\text { income share). }\end{array}$ \\
\hline $\begin{array}{l}\text { Government consumption } \\
(C G)\end{array}$ & $\begin{array}{l}\text { Government consumption as \% of GDP. } \\
\text { Source: Penn World Tables. } \\
\text { Note. Series have been integrated with the OECD. Stat COFOG } \\
\text { database (final consumption government expenditure as \% of GDP). }\end{array}$ \\
\hline $\begin{array}{l}\text { Unemployment rate } \\
\left(U N \_ \text {rate }\right)\end{array}$ & $\begin{array}{l}\text { Unemployment rate as } \% \text { of active labor force. } \\
\text { Source: Ameco database. } \\
\text { Note. Series have been integrated with the OECD.Stat database } \\
\text { (Economic Outlook No. } 103 \text { - May 2018). }\end{array}$ \\
\hline Unemployment duration & $\begin{array}{l}\text { Average duration of unemployment (months), all persons } \\
\text { unemployed from } 0 \text { to } 18 \text { months. } \\
\text { Source: OECD.Stat, Labour force statistics, Unemployment by } \\
\text { duration. } \\
\text { Note. Available timespans are the following: } \\
\text { - Canada 1976-2017; } \\
\text { - } \quad \text { France 1975-2017; } \\
\text { - } \quad \text { Germany 1983-2017; } \\
\text { - } \quad \text { Italy 1983-2017; } \\
\text { - Japan 1977-2017; } \\
\text { - } \quad \text { Spain 1986-2017; } \\
\text { - } \quad \text { Sweden 1971-2017; } \\
\text { - } \quad \text { United Kingdom 1983-2017; } \\
\text { - } \quad \text { United States } 1968-2017 .\end{array}$ \\
\hline
\end{tabular}




\section{Appendix B. Descriptive statistics}

\begin{tabular}{|c|c|c|c|c|c|c|c|c|c|}
\hline & Canada & France & Germany & Italy & Japan & Spain & Sweden & $\begin{array}{c}\text { United } \\
\text { Kingdom }\end{array}$ & $\begin{array}{l}\text { United } \\
\text { States }\end{array}$ \\
\hline Adjusted wage share in the total economy (AWS) & $\mathrm{Obs}=58$ & $\mathrm{Obs}=58$ & Obs $=58$ & $\mathrm{Obs}=58$ & $\mathrm{Obs}=58$ & $\mathrm{Obs}=58$ & $\mathrm{Obs}=58$ & Obs $=58$ & Obs $=58$ \\
\hline 2 & $\begin{array}{c}58.22 \\
2.31 \\
54.17 \\
62.78 \\
\end{array}$ & $\begin{array}{c}60.35 \\
3.54 \\
55.41 \\
66.21 \\
\end{array}$ & $\begin{array}{c}59.45 \\
2.68 \\
53.65 \\
64.38 \\
\end{array}$ & $\begin{array}{c}58.21 \\
4.97 \\
51.05 \\
66.12 \\
\end{array}$ & $\begin{array}{c}65.25 \\
3.37 \\
56.33 \\
75.48 \\
\end{array}$ & $\begin{array}{c}60.99 \\
3.98 \\
53.92 \\
67.53 \\
\end{array}$ & $\begin{array}{l}51.03 \\
2.72 \\
46.45 \\
57.06 \\
\end{array}$ & $\begin{array}{c}58.68 \\
3.49 \\
52.11 \\
66.95 \\
\end{array}$ & $\begin{array}{c}60.51 \\
1.90 \\
56.36 \\
63.69 \\
\end{array}$ \\
\hline Government consumption, \% of GDP $(C G)$ & Obs $=55$ & $\mathrm{Obs}=58$ & Obs $=58$ & $\mathrm{Obs}=58$ & Obs $=55$ & Obs $=58$ & $\mathrm{Obs}=58$ & Obs $=57$ & Obs $=58$ \\
\hline $\begin{array}{l}\operatorname{mean} \\
\text { s.d. } \\
\min \\
\max \end{array}$ & $\begin{array}{c}14.78 \\
2.11 \\
10.36 \\
18.39 \\
\end{array}$ & $\begin{array}{c}17.34 \\
2.57 \\
12.75 \\
22.81\end{array}$ & $\begin{array}{c}14.97 \\
1.58 \\
11.92 \\
18.29 \\
\end{array}$ & $\begin{array}{c}15.11 \\
1.17 \\
12.82 \\
17.83 \\
\end{array}$ & $\begin{array}{c}15.60 \\
2.55 \\
12.02 \\
20.89 \\
\end{array}$ & $\begin{array}{c}13.69 \\
3.25 \\
8.84 \\
19.65 \\
\end{array}$ & $\begin{array}{c}21.88 \\
2.27 \\
17.68 \\
26.47 \\
\end{array}$ & $\begin{array}{c}17.79 \\
2.34 \\
13.72 \\
23.14 \\
\end{array}$ & $\begin{array}{c}11.49 \\
1.26 \\
9.10 \\
13.79 \\
\end{array}$ \\
\hline Adjusted wage share in the private sector $(P A W S)$ & Obs $=55$ & Obs $=58$ & $\mathrm{Obs}=58$ & $\mathrm{Obs}=58$ & $\mathrm{Obs}=55$ & Obs $=58$ & $\mathrm{Obs}=58$ & Obs $=57$ & Obs $=58$ \\
\hline 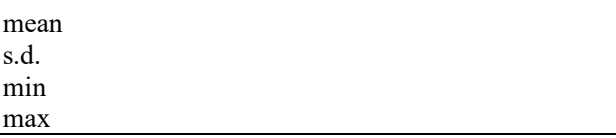 & $\begin{array}{c}51.04 \\
3.57 \\
45.22 \\
57.87 \\
\end{array}$ & $\begin{array}{c}51.69 \\
5.49 \\
44.81 \\
59.66 \\
\end{array}$ & $\begin{array}{c}52.15 \\
3.39 \\
45.57 \\
57.91 \\
\end{array}$ & $\begin{array}{c}50.63 \\
6.14 \\
41.35 \\
60.25 \\
\end{array}$ & $\begin{array}{c}59.27 \\
6.71 \\
46.61 \\
71.26 \\
\end{array}$ & $\begin{array}{c}54.45 \\
6.19 \\
43.47 \\
63.76 \\
\end{array}$ & $\begin{array}{c}37.10 \\
3.70 \\
30.97 \\
43.51 \\
\end{array}$ & $\begin{array}{c}49.71 \\
4.13 \\
44.26 \\
58.42 \\
\end{array}$ & $\begin{array}{c}55.30 \\
2.30 \\
49.32 \\
58.28 \\
\end{array}$ \\
\hline Unemployment rate (UN_rate) & Obs $=58$ & Obs $=58$ & Obs $=58$ & Obs $=58$ & Obs $=58$ & Obs $=58$ & Obs $=58$ & Obs $=58$ & Obs $=58$ \\
\hline 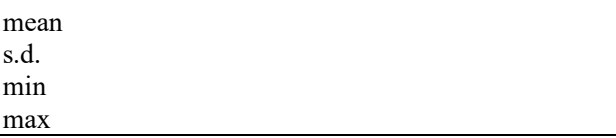 & $\begin{array}{c}7.47 \\
1.99 \\
3.3 \\
12.0 \\
\end{array}$ & $\begin{array}{c}6.62 \\
3.32 \\
1.2 \\
10.7 \\
\end{array}$ & $\begin{array}{c}5.05 \\
3.23 \\
0.4 \\
11.2 \\
\end{array}$ & $\begin{array}{c}7.92 \\
2.37 \\
3.7 \\
12.7 \\
\end{array}$ & $\begin{array}{c}2.80 \\
1.29 \\
1.1 \\
5.4 \\
\end{array}$ & $\begin{array}{c}12.05 \\
7.39 \\
1.5 \\
26.1 \\
\end{array}$ & $\begin{array}{c}4.97 \\
2.91 \\
1.3 \\
11.0 \\
\end{array}$ & $\begin{array}{c}5.71 \\
2.99 \\
1.1 \\
11.2 \\
\end{array}$ & $\begin{array}{c}6.04 \\
1.56 \\
3.5 \\
9.7 \\
\end{array}$ \\
\hline Unemployment duration (in months) & Obs $=42$ & Obs $=43$ & Obs $=35$ & Obs $=35$ & Obs $=41$ & Obs $=32$ & Obs $=45$ & Obs $=35$ & Obs $=50$ \\
\hline $\begin{array}{l}\text { mean } \\
\text { s.d. } \\
\text { min } \\
\max \\
\end{array}$ & $\begin{array}{l}4.41 \\
0.73 \\
3.18 \\
5.98 \\
\end{array}$ & $\begin{array}{c}9.44 \\
0.81 \\
6.40 \\
10.62 \\
\end{array}$ & $\begin{array}{c}10.90 \\
0.72 \\
9.02 \\
12.11 \\
\end{array}$ & $\begin{array}{c}12.65 \\
1.24 \\
10.43 \\
14.45 \\
\end{array}$ & $\begin{array}{l}7.26 \\
1.49 \\
4.97 \\
9.81 \\
\end{array}$ & $\begin{array}{c}10.47 \\
1.93 \\
6.25 \\
13.08 \\
\end{array}$ & $\begin{array}{l}5.27 \\
1.57 \\
2.73 \\
8.73 \\
\end{array}$ & $\begin{array}{c}8.78 \\
1.52 \\
6.51 \\
11.43 \\
\end{array}$ & $\begin{array}{l}3.96 \\
1.45 \\
1.84 \\
7.96 \\
\end{array}$ \\
\hline Unemployment duration index (indur) & Obs $=42$ & Obs $=43$ & Obs $=35$ & Obs $=35$ & Obs $=41$ & Obs $=32$ & Obs $=45$ & Obs $=35$ & Obs $=50$ \\
\hline $\begin{array}{l}\text { mean } \\
\text { s.d. } \\
\text { min } \\
\text { max }\end{array}$ & $\begin{array}{c}1.38 \\
0.23 \\
1 \\
1.88 \\
\end{array}$ & $\begin{array}{c}1.47 \\
0.13 \\
1 \\
1.66 \\
\end{array}$ & $\begin{array}{c}1.21 \\
0.08 \\
1 \\
1.34 \\
\end{array}$ & $\begin{array}{c}1.21 \\
0.12 \\
1 \\
1.38 \\
\end{array}$ & $\begin{array}{c}1.46 \\
0.30 \\
1 \\
1.97 \\
\end{array}$ & $\begin{array}{c}1.67 \\
0.31 \\
1 \\
2.09 \\
\end{array}$ & $\begin{array}{c}1.92 \\
0.57 \\
1 \\
3.19 \\
\end{array}$ & $\begin{array}{c}1.35 \\
0.23 \\
1 \\
1.75 \\
\end{array}$ & $\begin{array}{c}2.14 \\
0.78 \\
1 \\
4.31 \\
\end{array}$ \\
\hline Unemployment intensity (UN_int) & Obs $=42$ & Obs $=43$ & Obs $=35$ & Obs $=35$ & $\mathrm{Obs}=41$ & Obs $=32$ & $\mathrm{Obs}=45$ & Obs $=35$ & Obs $=50$ \\
\hline $\begin{array}{l}\text { mean } \\
\text { s.d. } \\
\text { min } \\
\text { max }\end{array}$ & $\begin{array}{c}11.72 \\
4.05 \\
6.36 \\
21.16 \\
\end{array}$ & $\begin{array}{c}12.41 \\
3.57 \\
3.30 \\
17.10 \\
\end{array}$ & $\begin{array}{c}8.87 \\
2.67 \\
4.18 \\
14.56 \\
\end{array}$ & $\begin{array}{c}11.49 \\
2.56 \\
6.23 \\
15.56 \\
\end{array}$ & $\begin{array}{l}5.19 \\
2.45 \\
2.06 \\
9.56 \\
\end{array}$ & $\begin{array}{c}29.22 \\
11.51 \\
8.44 \\
47.67 \\
\end{array}$ & $\begin{array}{c}12.11 \\
8.97 \\
2.19 \\
35.12 \\
\end{array}$ & $\begin{array}{c}10.30 \\
4.66 \\
4.70 \\
19.66 \\
\end{array}$ & $\begin{array}{c}13.91 \\
8.08 \\
3.50 \\
40.31 \\
\end{array}$ \\
\hline
\end{tabular}




\section{Appendix C. Stationarity test}

Table C1. ADF test on levels (with constant term)

\begin{tabular}{lcccccc} 
& \multicolumn{2}{c}{$\begin{array}{c}\text { Private sector } \\
\text { adjusted wage share }\end{array}$} & $\begin{array}{c}\text { Unemployment } \\
\text { rate }\end{array}$ & \multicolumn{2}{c}{$\begin{array}{c}\text { Unemployment } \\
\text { intensity }\end{array}$} \\
\cline { 2 - 7 } & $\mathbf{Z ( t )}$ & lags & $\mathbf{Z ( t )}$ & lags & $\mathbf{Z ( t )}$ & lags \\
\hline Canada & -1.441 & 1 & -2.180 & 2 & -2.293 & 2 \\
France & -0.826 & 2 & -1.490 & 2 & $-2.768^{*}$ & 2 \\
Germany & -0.151 & 3 & -1.584 & 3 & -1.384 & 3 \\
Italy & -0.221 & 1 & -1.689 & 2 & $-2.639^{*}$ & 2 \\
Japan & -0.488 & 2 & -1.483 & 2 & -0.1469 & 2 \\
Spain & -0.345 & 2 & -1.989 & 2 & -2.244 & 2 \\
Sweden & -1.472 & 1 & -1.730 & 4 & -1.876 & 2 \\
United Kingdom & -2.243 & 3 & -1.777 & 3 & -1.988 & 3 \\
United States & -0.073 & 1 & $-2.974^{* *}$ & 2 & $-2.645^{*}$ & 3 \\
\hline All panels & -1.768 & 1 & -1.137 & 2 & -1.171 & 2 \\
\hline
\end{tabular}

Table C2. ADF test on levels (with constant term and deterministic trend)

\begin{tabular}{lcccccc} 
& \multicolumn{2}{c}{$\begin{array}{c}\text { Private sector } \\
\text { adjusted wage share }\end{array}$} & \multicolumn{2}{c}{$\begin{array}{c}\text { Unemployment } \\
\text { rate }\end{array}$} & \multicolumn{3}{c}{$\begin{array}{c}\text { Unemployment } \\
\text { intensity }\end{array}$} \\
\cline { 2 - 7 } & $\mathbf{Z ( t )}$ & lags & $\mathbf{Z ( t )}$ & lags & $\mathbf{Z ( t )}$ & lags \\
\hline Canada & $-3.486^{* *}$ & 1 & -2.020 & 2 & -2.801 & 2 \\
France & -1.785 & 2 & -1.295 & 2 & -2.760 & 2 \\
Germany & -1.809 & 3 & -0.476 & 3 & -1.212 & 3 \\
Italy & -2.561 & 1 & -2.427 & 2 & -2.662 & 2 \\
Japan & -1.829 & 2 & -1.315 & 2 & -1.218 & 2 \\
Spain & $-3.618^{* *}$ & 2 & -2.342 & 2 & -2.263 & 2 \\
Sweden & $-3.300^{*}$ & 1 & -2.890 & 4 & -1.799 & 2 \\
United Kingdom & -1.861 & 3 & -1.362 & 3 & -2.143 & 3 \\
United States & -1.102 & 1 & -2.879 & 2 & -3.044 & 3 \\
\hline All panels & -0.984 & 1 & -0.902 & 2 & -0.384 & 2 \\
\hline
\end{tabular}


Table C3. ADF test on first differences (with constant term)

\begin{tabular}{|c|c|c|c|c|c|c|}
\hline \multirow[t]{2}{*}{ Country } & \multicolumn{2}{|c|}{$\begin{array}{c}\text { Private sector } \\
\text { adjusted wage share } \\
\text { (first differences) }\end{array}$} & \multicolumn{2}{|c|}{$\begin{array}{l}\text { Unemployment } \\
\text { rate } \\
\text { (first differences) }\end{array}$} & \multicolumn{2}{|c|}{$\begin{array}{l}\text { Unemployment } \\
\text { intensity } \\
\text { (first differences) }\end{array}$} \\
\hline & $\mathbf{Z}(\mathbf{t})$ & lags & $\mathbf{Z}(\mathbf{t})$ & lags & $\mathbf{Z}(\mathbf{t})$ & lags \\
\hline Canada & $-5.263 * * *$ & 0 & $-4.649 * * *$ & 3 & $-4.028 * * *$ & 2 \\
\hline France & $-4.496 * * *$ & 1 & $-4.496 * * *$ & 1 & $-3.835 * * *$ & 1 \\
\hline Germany & $-3.777 * * *$ & 2 & $-3.777 * * *$ & 2 & $-2.739 *$ & 1 \\
\hline Italy & $-4.628 * * *$ & 0 & $-4.609 * * *$ & 1 & $-3.098 * *$ & 1 \\
\hline Japan & $-4.458 * * *$ & 1 & $-4.458 * * *$ & 1 & $-3.161 * *$ & 3 \\
\hline Spain & $-3.781 * * *$ & 1 & $-3.126^{* *}$ & 4 & $-2.829^{*}$ & 3 \\
\hline Sweden & $-5.320 * * *$ & 1 & $-3.436^{* * *}$ & 2 & $-3.879 * * *$ & 1 \\
\hline United Kingdom & $-3.940 * * *$ & 2 & $-3.940 * * *$ & 2 & $-4.167 * * *$ & 1 \\
\hline United States & $-5.550 * * *$ & 0 & $-4.792 * * *$ & 2 & $-4.042 * * *$ & 2 \\
\hline All panels & $-9.548 * * *$ & 2 & $-11.454 * * *$ & 2 & $-5.816^{* * *}$ & 2 \\
\hline
\end{tabular}

We performed the standard ADF test by calculating the statistic $Z(t)$ relative to each series. The null hypothesis is 'the variable contains a unit root'. The number of lags to be considered has been selected by minimizing the Akaike criterion. In Table C1 and Table C3 we include the constant term, while in Table C2 a deterministic time trend is also considered. For panel-stationarity, we make use of a Fisher-type unit-root test for panel (based on ADF tests), and the Z-statistics refers to an inverse normal distribution. For each series, the table reports the $Z(t)$, while the MacKinnon approximate $p$ value is indicated as $*$ if $<0.1, * *$ if $<0.05$, and $* * *$ if $<0.01$. 


\section{Appendix D. Stability diagnostic and structural breaks}

Table D1. Multiple breakpoint test

\begin{tabular}{lccccc}
\hline Country & breaks & UN_rate & F-stat & PAWS & F-stat \\
\hline Canada & 1 & 1975 & $\mathbf{4 3 . 0 9}$ & 1983 & $\mathbf{1 3 2 . 4 8}$ \\
& 2 & 1999 & $\mathbf{3 0 . 5 6}$ & 2001 & $\mathbf{4 9 . 4 0}$ \\
France & 1 & 1981 & $\mathbf{4 1 6 . 8 3}$ & 1987 & $\mathbf{5 4 7 . 2 2}$ \\
& 2 & 1973 & $\mathbf{1 5 . 3 7}$ & 1997 & $\mathbf{4 2 . 1 0}$ \\
Germany & 1 & 1982 & $\mathbf{1 6 2 . 5}$ & 2002 & $\mathbf{1 7 4 . 7 1}$ \\
& 2 & 2010 & $\mathbf{2 3 . 1 9}$ & 1983 & $\mathbf{2 4 . 4 5}$ \\
Italy & 1 & 1982 & $\mathbf{9 2 . 2 9}$ & 1994 & $\mathbf{2 8 4 . 7 4}$ \\
& 2 & 2010 & 13.08 & 1985 & $\mathbf{7 8 . 1 4}$ \\
Japan & 1 & 1995 & $\mathbf{1 6 7 . 5 6}$ & 2000 & $\mathbf{1 2 0 . 9 8}$ \\
& 2 & 1975 & $\mathbf{3 4 . 4 7}$ & 1986 & $\mathbf{2 4 . 4 8}$ \\
Spain & 1 & 1980 & $\mathbf{1 4 6 . 4 6}$ & 1985 & $\mathbf{1 7 3 . 0 8}$ \\
& 2 & 2010 & $\mathbf{2 8 . 2 9}$ & 2002 & $\mathbf{7 2 . 4 4}$ \\
Sweden & 1 & 1992 & $\mathbf{2 8 3 . 7}$ & 1982 & $\mathbf{2 4 2 . 3 4}$ \\
\multirow{2}{*}{ United Kingdom } & 2 & 2000 & $\mathbf{3 4 . 1 6}$ & - & - \\
\multirow{2}{*}{ United States } & 1 & 1981 & $\mathbf{8 8 . 0 2}$ & 1977 & $\mathbf{2 0 0 . 1 1}$ \\
& 2 & 1997 & $\mathbf{2 4 . 4 7}$ & 1968 & $\mathbf{1 8 . 2 5}$ \\
& 1 & 1975 & 10.9 & 2005 & $\mathbf{2 2 7 . 2 8}$ \\
\hline
\end{tabular}

The table reports the values of the F-statistics stemming from a multiple breakpoint test (Bai-Perron tests of $L+1$ vs. $L$ sequentially determined breaks), under the null hypothesis of no break. Values in bold are significant at the $99 \%$ level, while values in italics are significant at the 95\% level. Critical values are as follows: 0 vs. 1 breaks, 12.29 (0.01) and 8.58 (0.05); 1 vs. 2 breaks, 13.89 (0.01) and 10.13 (0.05). The breaking variable is the constant term uniquely. Break test options: Trimming 0.15; Max n. breaks: 2.

Table D2. Chow breakpoint test

\begin{tabular}{lcc}
\hline Country & UN_rate & $P A W S$ \\
\hline Canada & $\mathbf{3 1 . 0 0}$ & $\mathbf{1 0 3 . 5 0}$ \\
France & $\mathbf{3 6 7 . 2 9}$ & $\mathbf{7 9 . 7 5}$ \\
Germany & $\mathbf{1 3 5 . 0 9}$ & $\mathbf{2 8 . 9 9}$ \\
Italy & $\mathbf{8 9 . 6 0}$ & $\mathbf{7 1 . 3 9}$ \\
Japan & $\mathbf{6 8 . 0 5}$ & $\mathbf{2 2 . 0 3}$ \\
Spain & $\mathbf{1 4 6 . 4 6}$ & $\mathbf{7 5 . 6 4}$ \\
Sweden & $\mathbf{5 2 . 2 8}$ & $\mathbf{1 9 0 . 6 8}$ \\
United Kingdom & $\mathbf{8 4 . 7 3}$ & $\mathbf{1 2 0 . 3 1}$ \\
United States & 3.89 & 12.04 \\
\hline
\end{tabular}

The table reports the values of the F-statistics associated to a Chow breakpoint test in 1980 (under the null hypothesis of no break). Values in bold are significant at the 99\% level, while values in italics are significant at the 95\% level (critical values are reported in Table E1).

Table D3. Panel ARDL $(1 ; 1)$ regression with unemployment rate. Dependent variable: $\triangle P A W S$. 
a) Timespan: 1960-1980

\begin{tabular}{lccc}
\hline & Pooled mean group (PMG) & Mean group (MG) & $\begin{array}{c}\text { Dynamic fixed effect } \\
\text { (DFE) }\end{array}$ \\
\hline Long run & & & \\
UN_rate & $0.894^{* * *}$ & -0.256 & -0.447 \\
$\alpha$ & $-0.384)$ & $(0.551)$ & $(0.524)$ \\
& $(0.087)$ & $-0.289^{* * *}$ & $-0.171^{* * *}$ \\
Short run & & $(0.089)$ & $(0.042)$ \\
UUN_rate & 0.723 & 0.701 & 0.145 \\
& $(0.623)$ & $(0.652)$ & $(0.170)$ \\
$\Delta U N_{-}$rate & -0.202 & -0.231 & $-0.483^{* * *}$ \\
SPAWS & $(0.314)$ & $(0.309)$ & $(0.167)$ \\
& 0.057 & 0.119 & $0.228^{* * *}$ \\
$c$ & $(0.072)$ & $(0.072)$ & $(0.076)$ \\
& $9.572^{* * *}$ & $6.088^{* * *}$ & $9.818^{* * *}$ \\
Obs. & $(4.057)$ & $(4.39)$ & $(2.346)$ \\
\hline
\end{tabular}

b) Timespan: 1981-2017

\begin{tabular}{lccc}
\hline & Pooled mean group (PMG) & Mean group (MG) & $\begin{array}{c}\text { Dynamic fixed effect } \\
\text { (DFE) }\end{array}$ \\
\hline Long run & $-0.571^{* * *}$ & -0.331 & $-0.785^{*}$ \\
UN_rate & $(0.138)$ & $(1.222)$ & $(0.439)$ \\
$\alpha$ & $-0.115^{* *}$ & $-0.161^{* *}$ & $-0.056^{* * *}$ \\
& $(0.056)$ & $(0.062)$ & $(0.014)$ \\
\hline Short run & & & \\
$\Delta U N_{-}$rate & $0.258^{* * *}$ & $0.337^{* * *}$ & $0.134^{* *}$ \\
$\Delta U N_{-}$rate & $(0.083)$ & $(0.123)$ & $(0.055)$ \\
& $-0.349_{-1}^{* * *}$ & $-0.225^{* * *}$ & $-0.246^{* * *}$ \\
SPAWS & $(0.099)$ & $(0.091)$ & $(0.060)$ \\
& $0.128_{-1}^{* * *}$ & $0.098^{*}$ & $0.119^{*}$ \\
$c$ & $(0.048)$ & $(0.058)$ & $(0.052)$ \\
& $5.274^{*}$ & $7.870^{* * *}$ & $2.855^{* * *}$ \\
Obs. & $(2.687)$ & $(2.786)$ & $(0.784)$ \\
\hline
\end{tabular}

$U N \_r a t e=$ long-run coefficient (between variables in levels); $\triangle P A W S$ = adjusted wage share in the private sector of the economy (first difference); $\Delta U N_{-}$rate = unemployment rate (first difference).

Standard error in parentheses; $*{ }^{* *}$, and $* * *$ denote levels $0.1,0.05$, and 0.01 of significance. 
Appendix E. Hausman statistic for the comparison between panel estimators

\begin{tabular}{lcccc}
\hline \multirow{3}{*}{ Estimators } & Diagnostic & Table 3.1 & \multicolumn{2}{c}{ Table 3.2 } \\
\cline { 2 - 5 } & & UN_rate & UN_rate & UN_intensity \\
\hline \multirow{3}{*}{ MG - PMG } & difference & $-0.264(0.289)$ & $0.660^{* *}(0.282)$ & $-0.157(0.787)$ \\
\cline { 2 - 5 } & $\chi^{2}$ & -0.85 & -5.47 & -0.04 \\
\cline { 2 - 5 } & Prob $>\chi^{2}$ & 0.361 & 0.019 & 0.842 \\
\hline \multirow{3}{*}{ MG - DFE } & difference & $-0.619^{*}(0.338)$ & $-0.600(2.207)$ & $-0.276(5.849)$ \\
\cline { 2 - 5 } & $\chi^{2}$ & 3.35 & 0.07 & 0.00 \\
\hline \multirow{3}{*}{ DFE - PMG } & Prob $>\chi^{2}$ & 0.067 & 0.785 & 0.962 \\
\cline { 2 - 5 } & difference & $0.355^{* *}(0.150)$ & $0.059(0.496)$ & $-0.119(0.470)$ \\
\cline { 2 - 5 } & $\chi^{2}$ & 5.57 & 0.01 & 0.06 \\
\hline
\end{tabular}

Note: the null hypothesis of the test is 'the difference in coefficients is not systematic'. 


\section{Appendix F. Panel-SVAR analysis on alternative subsets of countries}

Figure F1. IRFs from panel-SVAR analysis (different sub-periods)

a) Cumulated response of the private sector adjusted wage share to unemployment rate shocks (timespan: 1960-1980)

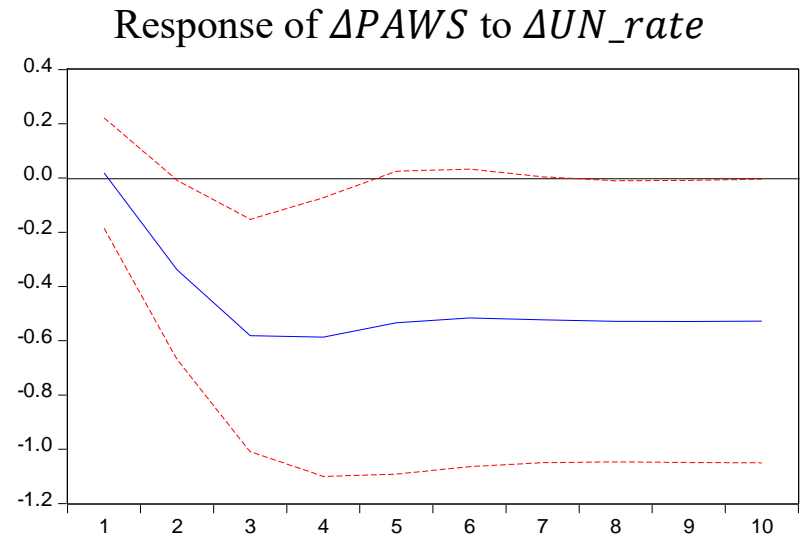

Response of $\Delta U N \_r a t e$ to $\Delta U N \_r a t e$

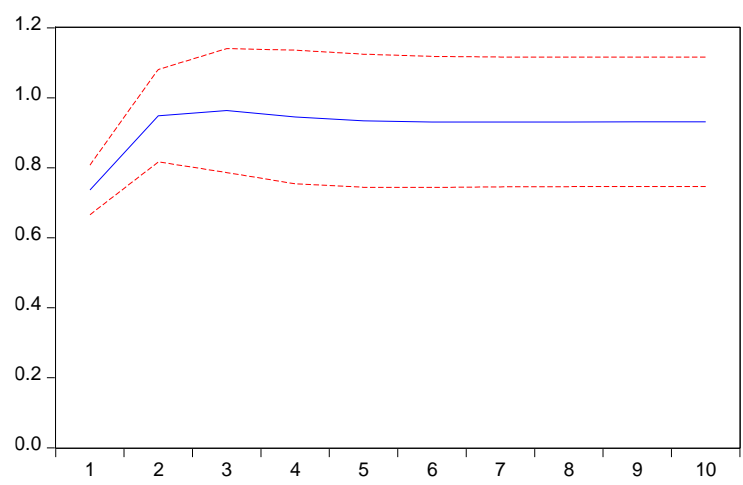

b) Cumulated response of the private sector adjusted wage share to unemployment rate shocks (timespan: 1981-2017)

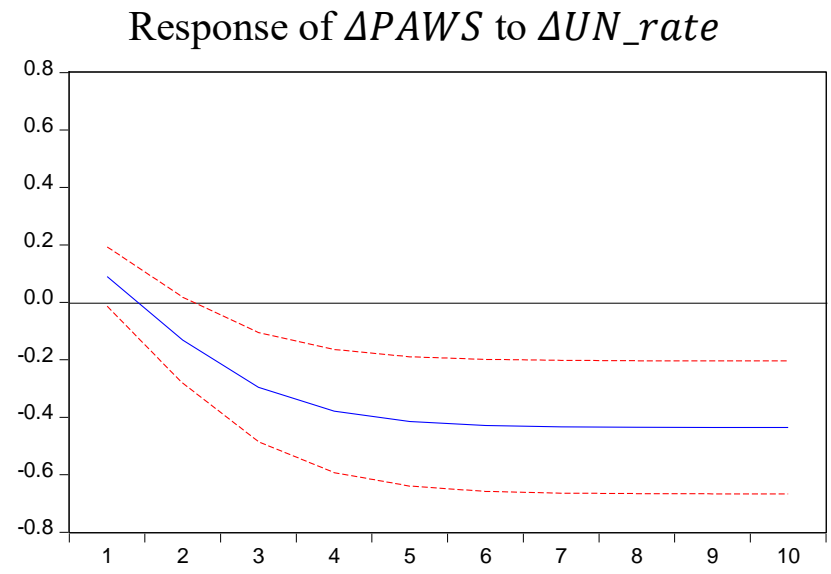

Response of $\Delta U N_{-}$rate to $\Delta U N_{-}$rate

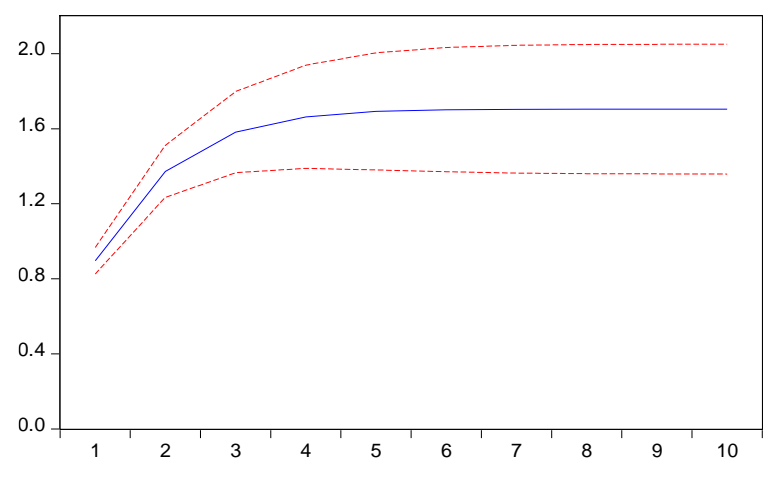

The figures in the left column depict the IRFs of the private sector adjusted wage share (DPAWS) to shock on unemployment rate ( $\triangle U N_{-}$rate), while those in the right column show the dynamic behavior of the unemployment rate after its initial shock. Cumulated responses to structural shocks are reported with two-standard error bound (95\% confidence interval, dashed lines). 
Figure F2. IRFs from panel-SVAR analysis (different clusters of countries)

a) Cumulated response of the private sector adjusted wage share to unemployment rate shocks in Anglo-Saxon countries (timespan: 1960-2017)

Response of $\triangle P A W S$ to $\triangle U N \_r a t e$

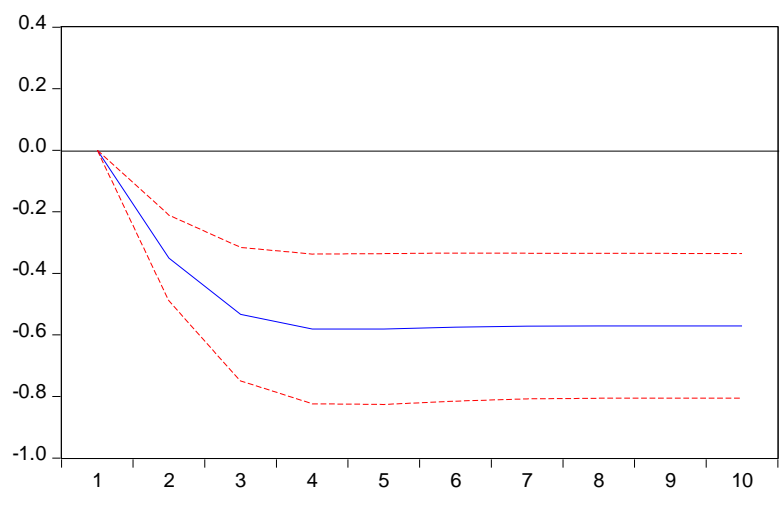

Response of $\Delta U N_{-} r a t e$ to $\Delta U N_{\_} r a t e$

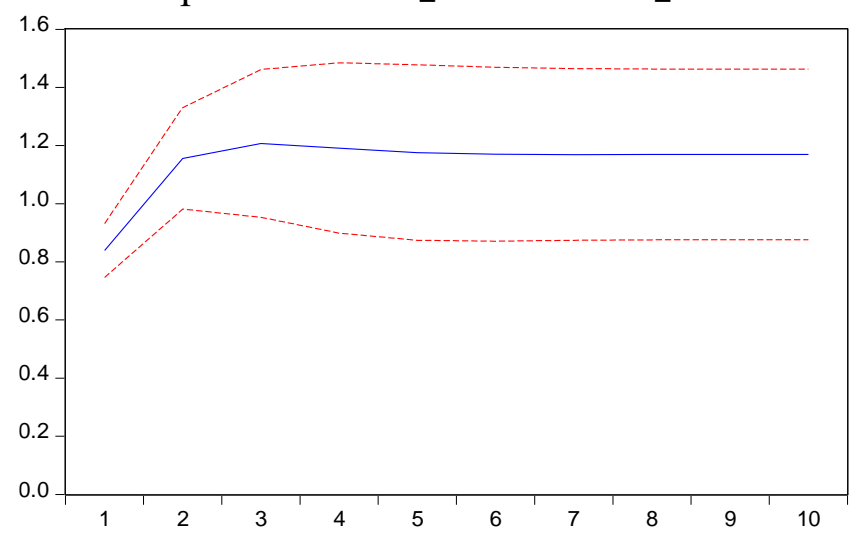

b) Cumulated response of the private sector adjusted wage share to unemployment rate shocks in Continental European and Mediterranean countries (timespan: 1960-2017)

Response of $\triangle P A W S$ to $\triangle U N \_r a t e$

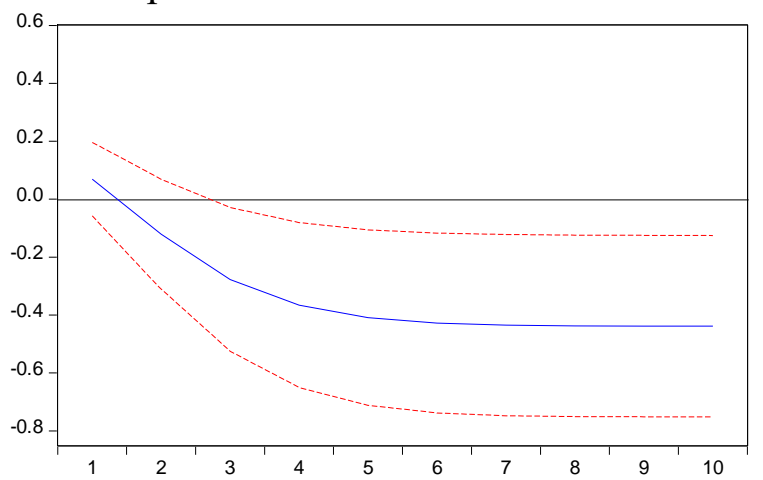

Response of $\Delta U N \_r a t e$ to $\Delta U N \_r a t e$

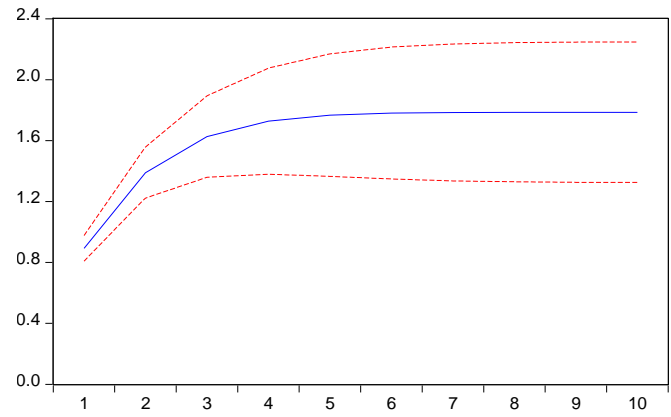

The figures in the left column depict the IRFs of the private sector adjusted wage share ( $\triangle P A W S$ ) to shock on unemployment rate $\left(\triangle U N_{-}\right.$rate), while those in the right column show the dynamic behavior of the unemployment rate after its initial shock. Cumulated responses to structural shocks are reported with two-standard error bound (95\% confidence interval, dashed lines). 